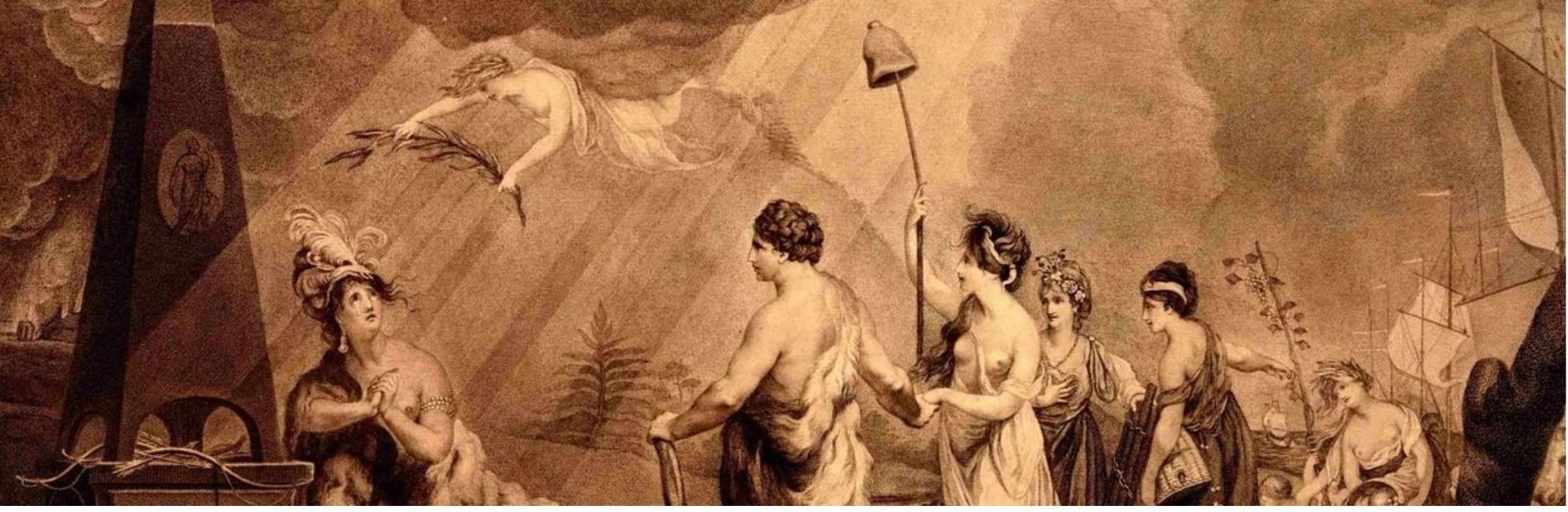

From the Visual Defence of Rights to the Visual Representation of a Fundamental Value

$\begin{aligned} \text { Authors: } & \text { Frank Zeiler } \\ \text { Submitted: } & \text { 23. May } 2018 \\ \text { Published: } & \text { 11. June } 2018 \\ \text { Volume: } & 5 \\ \text { Issue: } & 5 \\ \text { Affiliation: } & \text { Albert-Ludwigs-Universität Freiburg } \\ \text { Languages: } & \text { German } \\ \text { Keywords: } & \text { iconography, liberty, Libertas, cap of liberty, United States of } \\ & \text { America } \\ \text { DOI: } & \text { 10.17160/josha.5.5.433 }\end{aligned}$

Journal of Science,

Humanities and Arts 


\title{
From the Visual Defence of Rights to the Visual Representation of a Fundamental Value
}

Changes and Continuities in the Iconography of Liberty in the Early USA

Frank Zeiler, Albert-Ludwigs-Universität Freiburg ${ }^{*}$

\begin{abstract}
In the 1760s, most inhabitants of the North American colonies which were to become the United States considered liberty as an inherited right that had to be defended within the framework of the British constitution against unwarranted intrusions by the government in London. To visualize this struggle in political prints, they made use of motifs like the Roman goddess Libertas and the cap of liberty, both of which they knew from corresponding English prints. Following the Declaration of Independence, these motifs were increasingly turned into attributes of a new political order built on liberty. This transformation led to a mélange of changes and continuities in the iconography of liberty which this article seeks to demonstrate by examining examples of relevant images from the first decades of independence.
\end{abstract}

Keywords: iconography, liberty, Libertas, cap of liberty, United States of America

\footnotetext{
${ }^{*}$ Belfortstr. 20, 79085 Freiburg im Breisgau. E-Mail: frank.zeiler@jura.uni-freiburg.de.
} 


\title{
Von der visuellen Rechtsverteidigung zur visuellen Repräsentation eines Grundwertes
}

\author{
Wandlungen und Kontinuitäten in der Ikonographie der Freiheit in der Frühzeit \\ der USA
}

\section{Einleitung}

Freiheit ist ein Gründungswert der Vereinigten Staaten von Amerika. ${ }^{1}$ Vielbeschworen in der Zeit vor der Unabhängigkeitserklärung war »Freiheit« in den 1760er Jahren für opponierende Kolonisten zunächst ein aus Großbritannien ererbtes Recht, das es im Rahmen der britischen Verfassung gegen Eingriffe zu verteidigen galt. ${ }^{2} \mathrm{Zu}$ diesem Zweck rezipierten sie für ihre Bildpublizistik eine Motivik, mit der in England seit dem 17. Jahrhundert in Druckgraphiken die Freiheit repräsentiert wurde. ${ }^{3}$ Dazu bedienten sie sich in enger Anlehnung an englische Vorlagen ${ }^{4}$ sowohl des aus der Antike stammenden Sinnbildes der Libertas und deren Attributs, der Freiheitsmütze, als auch des spezifisch englischen Symbols der Magna Charta. ${ }^{5}$ Für

Zitierte digitale Sammlungen: Bibliothèque nationale de France (BnF): http://gallica.bnf.fr; British Museum (BM): http://www.britishmuseum.org/research/collection_onlinesearch.aspx; Library of Congress (LC): http:// www.loc.gov/pictures/; Museum Rotterdam (MR): http://museumrotterdam.nl/collectie; Rijksmuseum Amsterdam (RMA): http://www.rijksmuseum.nl/nl/zoeken.

${ }^{1}$ Vgl. zur Freiheit als der »alles umfassende[n] Zielvorstellung« der neuen politischen Ordnung Willi Paul Adams, Republikanische Verfassung und bürgerliche Freiheit. Die Verfassungen und politischen Ideen der amerikanischen Revolution, Darmstadt u. a. 1973, S. 142 ff.; zur Bedeutung der Freiheit in den Beratungen der USVerfassung siehe Glen E. Thurow, »The Form Most Eligible«: Liberty in the Constitutional Convention, in: Publius, Bd. 20 (1990), S. 15 ff.; zur Fundamentalität der Freiheitsidee für die nationale Identität der USA im Verlauf ihrer Geschichte vgl. Eric Foner, The Story of American Freedom, New York (N.Y.) 1999, S. xiii.

${ }^{2}$ Siehe etwa Michael Zuckert, Rights, in: Jack P. Greene/J. R. Pole (Hrsg.), A Companion to the American Revolution, Malden (Mass.)/Oxford 2000, S. 694.

${ }^{3}$ Vgl. hierzu Frank Zeiler, Visuelle Rechtsverteidigung im Nordamerikakonflikt. Ein Beitrag zur Rezeption der englischen Freiheits- und Verfassungssymbolik in nordamerikanischen Druckgraphiken der Jahre 1765-1783, in: Signa Ivris, Bd. 13 (2014), S. 315 ff. (auch verfügbar unter: http://www.freidok.uni-freiburg.de/ data/11157).

${ }^{4}$ Bei einigen der kolonialen Graphiken handelt es sich um lediglich in kleinen Details veränderte Kopien von englischen Drucken, die meisten anderen Bilder sind mehr oder weniger stark von englischen Vorlagen beeinflusst (vgl. Zeiler, Visuelle Rechtsverteidigung [Fn. 3], auch zu den nicht eben zahlreichen Ausnahmen; die ebd., S. 323, versehentlich als originär amerikanische Schöpfung bezeichnete Gestaltung der Titelvignette zu den Protokollen des Nationalkongresses ist unrichtig; das dort verwendete Motiv findet sich einschließlich der Umschrift bereits auf einem niederländischen Rekenpenning aus dem Jahr 1590 [MR, INr. 51813]).

${ }^{5}$ Zur Entstehung und Entwicklung der englischen Freiheitssymbolik: Frank Zeiler, Die visuelle Repräsentation der Freiheit in englischen Druckgraphiken (in Vorbereitung). 
dessen Verwendung als Repräsentation der britischen Verfassung und der von ihr gewährten Freiheiten entfiel nach der Unabhängigkeitserklärung die Grundlage, ${ }^{6}$ die beiden anderen Motive wurden jedoch weiterhin genutzt. Allerdings wurden sie im Zuge der Konstituierung eigenständiger Staaten und der Union zunehmend nicht mehr zur bildlichen Darstellung der Bewahrung überkommener Freiheitsrechte innerhalb der bisherigen politischen Ordnung herangezogen, sondern dienten als Signum für eine neue politische Ordnung, die als auf dem Fundament der Freiheit aufgebaut betrachtet wurde. Dies führte durch den der staatlichen Selbstdarstellung dienenden Gebrauch von Emblemen der Freiheit auf Siegeln und Geld oder in symbolträchtigen Bauwerken wie dem Kapitol in Washington - dem »nationalen Hauptsymbol der Freiheit und Demokratie ${ }^{7}$ - zu einer im angelsächsischen Raum in dieser Form bis dahin nicht existierenden Art der Nutzung von Sinnbildern der Freiheit, und auch in ikonographischer Hinsicht wurde in mancherlei Hinsicht Neuland betreten. Andererseits bestanden bereits im einstmaligen Mutterland bekannte Verwendungsweisen von Freiheitssymbolen fort, und auch Elemente der dort geläufigen Darstellungsweisen waren weiterhin präsent. Demnach gab es in der Frühzeit der Vereinigten Staaten bei der Nutzung von Emblemen der Freiheit eine Gemengelage von Kontinuitäten und Wandlungen, die im Folgenden anhand einiger Bereiche der US-amerikanischen Staatsrepräsentation und Bildpublizistik näher beleuchtet wird.

\section{Sinnbilder der Freiheit als Kennzeichen der neuen politischen Ordnung}

Die Vorstellung der Etablierung einer neuen politischen Ordnung, die auf der Freiheit aufgebaut ist, verband sich in Amerika zur Zeit des Unabhängigkeitskrieges mitunter mit der Auffassung, dass die ehemaligen Kolonien zum einzigen Zufluchtsort für die nunmehr auch aus Großbritannien als einem ihrer letzten Refugien vertriebene Freiheit geworden sei. Diese verbal etwa von dem Kongressabgeordneten und Unterzeichner der Unabhängigkeitserklärung William Hooper mit den Worten $»$ Liberty shuddering at thy [i. e. Britannias] fate is seeking an asylum westward « zum Ausdruck gebrachte ${ }^{8}$ und in dem Theaterstück »The Fall of British

\footnotetext{
${ }^{6}$ Wiewohl die Magna Charta im Denken der Amerikaner noch weiterhin eine Rolle spielte und Einfluss auf das US-amerikanische Verfassungsrecht hatte (vgl. hierzu A. E. Dick Howard, The Road from Runnymede. Magna Charta and Constitutionalism in America, Charlottesville 1968, S. 203 ff.).

${ }^{7}$ So Barbara A. Wolanin, The Artist of the Capitol, in: Donald R. Kennon (Hrsg.), The United States Capitol. Designing and Decorating a National Icon, Athens (Oh.) 2000, S. 171.

${ }^{8}$ Brief an James Iredell vom 6.1.1776, abgedruckt in: Griffith John McRee, Life and Correspondence of James Iredell, Bd. 1, New York (N.Y.) 1857, S. 268 f.; für weitere Beispiele siehe Adams, Republikanische Verfassung (Fn. 1), S. $142 \mathrm{f}$.
} 
Tyranny or, American Liberty Triumphant« ebenfalls durchscheinende Haltung ${ }^{9}$ tritt visuell in der Radierung »America Triumphant and Britannia in Distress« (Abb. 1) zutage. In dieser 1782 geschaffenen mutmaßlich letzten amerikanischen Graphik mit einem Sinnbild der Freiheit aus der Zeit des Konflikts mit dem früheren Mutterland zeigt auf der linken Seite Britannia, die neben ihrem nicht wie sonst üblich stolz in der Hand gehaltenen, sondern am Boden liegenden Speer sitzt und in einer niedergeschlagenen Pose über den Verlust des Handels mit den Kolonien weint. Ihr gegenüber befindet sich eine strahlende Verkörperung Amerikas, die nicht nur, anders als ihr Pendent, mit einer Freiheitsmütze versehen ist und so in Analogie zu englischen Britannia-Bildnissen dieser Zeit als Nationalpersonifikation eines freien Landes ausgewiesen ist, ${ }^{10}$ sondern sich darüber hinaus als eine fast identische Kopie der BritanniaLibertas-Darstellung entpuppt, mit der im Jahr 1775 in dem von Giovanni Battista Cipriani entworfenen und von Francesco Bartolozzi gefertigten Druck »Liberty or Britannia« (Abb. 2) die britische Freiheit verherrlicht wurde. ${ }^{11}$

Ob die Botschaft vom Exodus der Freiheit in dieser satirischen Graphik tatsächlich gewollt vermittelt werden sollte (und von den Zeitgenossen verstanden werden konnte), muss dahingestellt bleiben; unmissverständlich propagiert werden sollte sie jedenfalls in dem (letztlich in anderer Form verwirklichten) Siegel des Staates Delaware. Hier wurde 1776 beschlossen, »that a committee [...] be appointed to procure [...] a silver Seal [...] there be engraved, >Britania< upon the Right side thereof, and upon the left side opposite to her, >Liberty< in the usual shape, with a label proceeding from >Britania< to >Liberty< in these words, >Go to America $[\ldots] \ll .{ }^{12}$ Gleichermaßen bewusst ins Bild gesetzt wurde der Gedanke des Unterganges der Freiheit in Großbritannien und ihrem Fortleben in Amerika bei der Gestaltung des dritten Entwurfs für die Vorderseite des Großen Siegels der Union ${ }^{13}$ - in diesem Fall allerdings nicht mithilfe eines damals weithin bekannten Sinnbildes der Freiheit und damit im Grunde auch

\footnotetext{
${ }^{9}$ Das Schwinden der Freiheit in Großbritannien wird thematisiert in Phrasen wie »expiring liberty in Britain « (S. 17), »of Britain [...] liberty has taken its farewell« oder »the voice of poor liberty can no longer be heard in Britain or Hibernia« (beide S. 20); mit ihnen verbunden sind Aussagen wie »Liberty flourishes in the wilds of America« (S. 17) oder »away with the goddess [i. e. die Freiheit] to the American shore« (S. 21).

${ }^{10}$ Zur Figur der Britannia-Libertas: Zeiler, Visuelle Repräsentation (Fn. 5).

${ }^{11}$ Eine ähnliche Gegenüberstellung findet sich auf dem sog. Myddleton Token von 1796, einem inoffiziellen Geldstück, das von dem in Amerika lebenden Engländer Philip Parry Price Myddelton für eine von ihm geplante Ansiedlung im Bundesstaat Kentucky entworfen und bei Matthew Boulten in Birmingham in Auftrag gegeben worden war (vgl. hierzu Richard Margolis, Matthew Boulton, Philip Parry Price Myddelton and the Proposed Token Coinage for Kentucky, in: The Colonial Newsletter, Bd. 39 [1999], S. 1991 ff. [mit Abb.]).

12 Zitiert nach Eugene Zieber, Heraldry in America, Philadelphia (Pa.) 1895, S. 123 f. Dieser Entwurf wurde abgelehnt, weil er nach Meinung des zuständigen Komitees passender für eine Medaille als für ein Staatssiegel war (ebd., S. 124).

${ }^{13}$ Siehe zur Entstehungsgeschichte des Bundessiegels umfassend Richard S. Patterson/Richardson Dougall, The Eagle and the Shield. A History of the Great Seal for the United States, Washington (D.C.) 1976, S. 6 ff.
} 
unverständlich. In diesem aus dem Jahr 1782 stammenden Entwurf (Abb. 3) war es ein zentral positionierter Phoenix, der in den Worten des Schöpfers dieses Vorschlages, des vom zuständigen dritten Komitee für die Schaffung eines Bundessiegels als Experten konsultierten William Barton, als Emblem »of the expiring Liberty of Britain, revived by her Descendants, in America ${ }^{14}$ stehen sollte. Der überkommenen Freiheitssymbolik kommt in dem Vorschlag in Gestalt einer kleinen, sich auf einem heraldischen Helm als Zeichen der Souveränität ${ }^{15}$ befindlichen Kopfbedeckung ebenfalls eine Rolle zu, jedoch eine, die nicht nur bescheiden ist, sondern wie diejenige des Phoenix ohne Erläuterung wohl nur schwerlich verstanden werden konnte. Denn das von Barton in seiner »gemäß den Gesetzen der Heraldik« gegebenen Erklärung der Bildkomposition als »Cap of Liberty« bezeichnete Kleidungsstück ${ }^{16}$ weist mit seiner fezartigen Machart eine Form auf, der man - zumindest in den damals verbreiteten englischen und amerikanischen Druckgraphiken ${ }^{17}$ - sonst nicht begegnet. ${ }^{18}$

Dies war im ersten wie im zweiten Entwurf für das Bundessiegel noch anders. In beiden Fällen kam mit der Libertas ein Motiv der traditionellen, auch in Nordamerika bekannten Freiheitssymbolik zum Einsatz, das ohne Weiteres als solches erkannt werden konnte, zumal die beiden Personifikationen nicht lediglich als ein kleines Element von vielen auftraten. Vielmehr diente die Libertas in dem von Pierre Eugène du Simitière stammenden ersten Entwurf für den Avers des Siegels (Abb. 4) als sofort ins Auge fallender Halter eines Schildes, dessen sechs Felder mit Emblemen für die hauptsächlichen Herkunftsländer der amerikanischen Siedler (England, Schottland, Irland, Frankreich, Holland und Deutschland) versehen waren. Dieser Entwurf, der 1776 von dem unter anderem aus Benjamin Franklin bestehenden ersten Komitee für die Ausarbeitung eines Siegels der Union vorgelegt worden war, wurde vom Kongress aus unbekannten Gründen nicht übernommen. ${ }^{19}$ Ein neues, im Jahr 1780 gebildetes

\footnotetext{
${ }^{14}$ Zitiert nach ebd., S. 68 .

${ }^{15}$ Vgl. Bartons Erläuterung, abgedruckt in: Patterson/Dougall, Eagle and Shield (Fn. 13), S. 61.

${ }^{16}$ Zitiert nach Patterson/Dougall, Eagle and Shield (Fn. 13), S. 67.

${ }^{17}$ Lediglich aus der Zeit der sog. Glorreichen Revolution gibt es teilweise Graphiken mit Freiheitsmützen, die einem Fez ähneln; diese sind allerdings alle niederländischen Ursprungs (Bspe.: BM, RNr. 1868,0808.3308; BM, RNr. 1868,0808.3388; BM, RNr. 1868,0808.3390).

${ }^{18}$ Die eigenartige Verbindung einer fezartigen Freiheitsmütze mit einem Helm findet sich - wohl erstmals - in den 1624 in Brüssel erschienenen, von dem Holländer Otto van Veen (latinisiert Otto Vaenius) verfassten »Emblemata sive symbola a principibus, viris ecclesiasticis, ac militaribus, aliisque usurpanda«, wo es in Emblem 53 zusammen mit einem Joch unter dem Motto »Non degenerare iugum« dargestellt ist. Bei den Bildkompositionen dieses Werkes handelt es sich nach Olga Vassilieva-Codognet, Coining Neo-Stoic Hieroglyphs: From the Brussels Mint to Emblemata sive symbola, in: Simon McKeown (Hrsg.), Otto Vaenius and his Emblem Books, Glasgow 2012, S. 212, 227, um originale Schöpfungen des Autors.

${ }^{19}$ Patterson/Dougall, Eagle and Shield (Fn. 13), S. 27, führen hierzu aus: »[...] the Journals laconically record its fate: >Ordered, To lie on the table.< Then as now in Congress, this action had the effect of killing the proposal.
} 
Komitee schlug in seinem Entwurf wiederum die Verwendung einer Freiheitspersonifikation vor, dieses Mal allerdings nicht auf der Vorder-, sondern auf der Rückseite des Siegels (Abb. 5a, b). Dafür fungierte die Libertas in diesem Fall nicht lediglich als einer von zwei Schildhaltern, sondern bildete das einzige, den gesamten Revers einnehmende Motiv.

Ungeachtet der recht großen Prominenz der Freiheit in den ersten Entwürfen für das Bundessiegel - auch der dritte Entwurf stand, trotz der nur kleinen, ob ihrer Form kaum als solche erkennbaren Freiheitsmütze durch das Motto »In Vindiciam Libertatis« in ihrem Bann - wurde das Siegel letztlich ohne eine Visualisierung dieses Gründungswertes realisiert. Dagegen war die Freiheit in den Siegeln der aus den Kolonien hervorgegangenen dreizehn Staaten der dominierende Wert: ${ }^{20}$ Von elf nach der Konstituierung eigenständiger Staatswesen neugeschaffenen Siegeln ${ }^{21}$ verfügten sieben über ein Sinnbild der Freiheit (fünf auf der Vorder-, zwei auf der Rückseite), in einem weiteren (dem von Delaware) wurde durch das Motto »Liberty and Independence« auf sie verwiesen. Bei den verwendeten Freiheitssymbolen handelte es sich im Falle von Massachusetts um die Magna Charta (Abb. 6), so dass dieses im Jahr 1775 geschaffene und bis 1780 benutzte Siegel unbeschadet der bereits bestehenden militärischen Auseinandersetzung mit dem Mutterland uneingeschränkt in der englischen Tradition stand. ${ }^{22}$ Demgegenüber wurde bei der Gestaltung des letzten Siegels der Gründungsstaaten der USA, demjenigen von Maryland aus dem Jahr 1794 (Abb. 7), erstmals grundlegend von britischen Vorlagen abgewichen, wenn dort mit einer auf einem Liktorenbündel steckenden Freiheitsmütze ein im revolutionären Frankreich entstandenes und dort beispielsweise auf Medaillen ${ }^{23}$ und Münzen (Abb. 8) verwendetes Motiv herangezogen wurde. Die übrigen Siegel waren mit Personifikationen der Freiheit versehen. Diese wurden, wie damals im angelsächsischen Raum üblich und in den beschriebenen Entwürfen zum Großen Siegel der Union ebenfalls verwirklicht, in Gestalt einer Frau wiedergegeben, die eine mit der Freiheitsmütze bekrönte Stange hält (Abb. 9a-e). Da die Platzierung des Libertas-Attributs auf einem Gegen-

\footnotetext{
Although no other record of the reaction of Congress has been found, that the majority was dissatisfied with the device is obvious « (Kursivschrift im Original).

${ }^{20}$ Siehe zur Gestaltung der einzelnen Staatssiegel Zieber, Heraldry (Fn. 12), S. 113 ff.; zur Visualisierung von Werten in den Staatssiegeln vgl. Mortimer N. S. Sellers, American Republicanism. Roman Ideology in the United States Constitution, Basingstoke/London 1994, S. 16 f.

${ }^{21}$ Rhode Island führte sein altes Siegel fort, Connecticut änderte lediglich das Motto des alten Siegels.

${ }^{22}$ Zeiler, Visuelle Rechtsverteidigung (Fn. 3), S. 322 f. Für das Siegel von Virginia wurde im Jahr 1776 von Pierre Eugène du Simitière ebenfalls die Verwendung der Magna Charta - in diesem Fall als Schriftzug auf einer »standard of Liberty« - vorgeschlagen, doch wurde sein Entwurf nicht umgesetzt (Edward S. Evans, The Seals of Virginia, in: Seventh Annual Report of the Library Board of the Virginia State Library 1909-1910, Richmond [Va.] 1911, S. 33).

${ }^{23}$ Bsp.: BM, RNr. 1947,0607.660.
} 
stand eine neuzeitliche Erfindung ist, sind diese Bildnisse - zumindest in dieser Hinsicht keine Übernahmen von in antiker Tradition stehenden Illustrationen in Emblembüchern, ${ }^{24}$ und sie wurden trotz der damals geläufigen Rückgriffe der Revolutionäre auf die Ideenwelt der römischen Antike $^{25}$ diesbezüglich auch nicht direkt nach römischen Vorlagen geschaffen. Denn in antiken Darstellungen hält die mit einem pileus versehene Freiheitspersonifikation (soweit sie als Ganzfigur gestaltet ist) ${ }^{26}$ das Attribut regelmäßig in der Hand, ${ }^{27}$ in seltenen Fällen tritt es unabhängig von ihr auf ${ }^{28}$ oder ganz ohne sie. Die bekannteste antike Ausnahme des Auftritts eines pileus ohne Libertas - sein Erscheinen auf einem von Brutus zur Legitimation der Tötung Cäsars geprägten Denar - zeigt die als Sinnbild für die Befreiung von der Diktatur gedachte Filzkappe zwischen zwei Gegenständen, bei denen es sich um nach unten gerichtete Dolche handelt, die für den Tyrannizid stehen. ${ }^{29}$ Der Verweis auf diese Münze und ihre Symbolik bildete 1546 die Grundlage für die Entstehung einer eigentümlichen Illustration mit der Kopfbedeckung auf Gegenständen. Sie findet sich in der Venediger Ausgabe des ältesten aller Emblemwerke, Andrea Alciatos erstmals 1531 publiziertem Buch »Emblematum libellus«, und gibt unter der Überschrift »Resp[ublica] liberata« zwei kurze Schwerter (ensiculi) wieder, die, anders als die Dolche des Denars, nach oben gerichtet sind und auf ihren Spitzen einen breitkrempigen Hut anstelle des pileus tragen (Abb. 10). ${ }^{30}$ In der 1549 in Lyon gedruckten spanischsprachigen (und einer im Folgejahr ebenda herausgegebenen lateinischen) Ausgabe wurde diese Bildkomposition durch ein Schwert mit einem gleichsam aufgespießten Birett ersetzt (Abb. 11). ${ }^{31}$ Dieses nicht minder eigentümliche Design könnte durch einen Be-

\footnotetext{
${ }^{24}$ Beispiele sind Cesare Ripa, Iconologia, 1. bebilderte Aufl., Rom 1603, S. 294, und Joseph Spence, Polymetis, 1. Aufl., London 1747, pl. XXII, fig. III. Bei der Schaffung des Siegels von Virginia (Abb. 9a) wurde auf die Darstellung der Libertas in diesem Werk als Modell verwiesen, falls der Graveur keine Kenntnis von der Gestaltung der Libertas haben sollte (Evans, Seals of Virginia [Fn. 22], S. 33). Zu einer Übernahme der dortigen Libertas, die antiken Vorbildern entsprechend einen pileus in der Hand hält, kam es aber trotz anderweitiger Anleihen an Spence' Buch bei der Gestaltung des Siegels nicht.

${ }^{25}$ Vgl. hierzu Sellers, American Republicanism (Fn. 20).

${ }^{26}$ Für die eher seltene Verwendung einer Büste der Libertas mit einem kleinen pileus (der sich hinter dem Kopf befindet) siehe z. B. BM, RNr. 2002,0102.3708.

${ }^{27}$ Vgl. zu den verschiedenen Kategorien römischer Libertas-Darstellungen (mit und ohne pileus) Rainer Vollkommer, Art. Libertas, in: Lexicon Iconographicum Mythologiae Classicae, Bd. VI/1, Zürich 1992, S. 278 ff.; zahlreiche Bildbeispiele finden sich in der digitalen Sammlung des Britischen Museums unter den Stichworten »libertas pileus«.

${ }^{28}$ Siehe BM, RNr. 1973,0822.275 (pileus hinter der auf einem Streitwagen fahrenden Libertas); BM, RNr. 2002 , 0102.3720 (pileus über der Libertas im Giebeldreieck eines Tempels).

${ }^{29}$ Abb.: BM, RNr. 1860,0328.124.

${ }^{30}$ Vgl. zu diesem Emblem Bartłomiej Czarski/Piotr Jaworski, Respublica liberata. The Coin of Brutus Commemorating the Ides of March in the Emblematic Interpretation of Alciatus, in: Polish Numismatic News, Bd. IX (2015), S. $258 \mathrm{ff}$.

${ }^{31}$ Los emblemas de Alciato. Traducidos en rhimas españolas, Lyon 1549, S. 202; Emblemata d. A. Alciati, Lyon 1550, S. 163. Zu einer vollständig korrekten Wiedergabe aller Elemente des Brutus-Denars in dem Emblem
} 
richt Appians angeregt worden sein, ${ }^{32}$ dem zufolge die Mörder Cäsars im Jahr 44 v. Chr. den Senat mit einem pileus auf einer Lanze als Zeichen der Freiheit verließen. ${ }^{33}$ Explizit auf diese Begebenheit zurückgeführt wird eine Illustration in dem 1551 erstmals erschienenen Emblembuch »Devises héroiques« von Claude Paradin. In ihm zeigt das mit »Captive Liberté« betitelte Bild eine Lanze mit einem Helm auf der Spitze (Abb. 12a). In der Ausgabe von 1557 ist der Helm zu einem pileus mutiert (Abb. 12b) und das Emblem mit einer Erläuterung versehen, die auf Appians Bericht verweist. Möglicherweise war dieses Bild (und vielleicht zusätzlich dasjenige aus den Alciato-Editionen von 1549/50) der Grund dafür, dass einige Zeit später die Darstellung einer aufgesteckten Kopfbedeckung als Zeichen der Freiheit in den Niederlanden in Gebrauch kam. ${ }^{34}$ Vor allem im 17./18. Jahrhundert war das nicht nur in Verbindung mit allegorischen Figuren, sondern auch unabhängig davon auftretende Motiv dort weit verbreitet, ebenso wie es im England des 18. Jahrhunderts eine umfangreiche Nutzung erfuhr und in einigen anderen Ländern zumindest vereinzelt vorkam, bevor es während der Revolution in Frankreich ebenfalls eine größere Verbreitung erlangte.

Die im 18. Jahrhundert in Europa vorherrschende künstlerische Wiedergabe der personifizierten Freiheit mit ihrem Attribut auf einer Stange oder Ähnlichem entfaltete in der staatlichen Selbstdarstellung der Vereinigten Staaten bis zum Ende des 19. Jahrhunderts Wirkung, als der 1890 entstandene Staat Idaho sein Siegel (Abb. 13) damit zierte; bereits zuvor waren in den Jahren 1831 und 1836 das neue Siegel des US-Senats und das Siegel des von einem Territorium zu einem Staat erhobenen Arkansas mit diesem Motiv versehen worden (Abb. 14, 15). Gleichzeitig wurde im 19. Jahrhundert in drei weiteren Siegeln auf die in Amerika bis-

\footnotetext{
»Respublica liberata« kam es erst in der 1621 in Padua erschienenen Ausgabe mit dem Titel »Andrea Alciati Emblemata cum commentariis« (S. 641); auf die Fehlerhaftigkeit der Darstellung in allen früheren Editionen wird in dieser Ausgabe ausdrücklich hingewiesen (S. 642).

${ }^{32}$ So Czarski/Jaworski, Respublica liberata (Fn. 30), S. 263.

${ }^{33}$ Appian, Bürgerkriege 2:119. Bereits früher, im Jahr 100 v. Chr., soll Lucius Appuleius Saturninus einen pileus in der Art eines Feldzeichens verwendet haben, um Sklaven zu den Waffen zu rufen (vgl. die Schilderung bei Valerius Maximus, Facta et Dicta Memorabilia, 8.6,2).

${ }^{34}$ Vgl. zu Paradins Emblem als möglicher Quelle niederländischer Bilder Carol Louise Janson, The Birth of Dutch Liberty. Origins of the Pictorial Image, Diss. phil. University of Minnesota 1982 (Mikrofilm), S. 111. Zur frühesten Nutzung einer aufgesteckten Kopfbedeckung als Zeichen der Freiheit kam es 1574 bei der Gestaltung von Notgeld der Stadt Leiden; hier war das Sinnbild - wie bei Paradin - auf eine (von einem steigenden Löwen gehaltene) Lanze gesetzt (ebd.). Daneben wurde in niederländischen Bildern - wie in den Alciato-Ausgaben von 1549/50 - bisweilen auf andere Waffen als Träger des Freiheitssymbols zurückgegriffen; frühe Beispiele hierfür sind zwei Graphiken von 1597 und ca. 1600-1605, in denen die Nederlandse Maagd einen Dolch bzw. ein Löwe ein kurzes Schwert mit einem Hut hält (RMA, ONr. RP-P-OB-80.447; RMA, ONr. RP-P-OB-80.650). Der aufgesteckte Freiheitshut blieb in den Niederlanden bis in die zweite Hälfte des 19. Jahrhunderts präsent, so auf Medaillen (Bspe.: MR, INr. 57722; MR, INr. 57710; MR, INr. 58795), in politischen Bildsatiren (Bsp. von 1866: RMA, ONr. RP-P-OB-89.630) oder in Graphiken, die historischer Ereignisse gedachten (Bsp. von 1872: RMA, ONr. RP-P-OB-89.230).
} 
lang weithin übliche Repräsentation der Freiheit durch eine allegorische Figur verzichtet: In den Siegeln der 1847 bzw. 1864 in die Union aufgenommenen Staaten Iowa und West Virginia sowie in dem 1880 abermals erneuerten Siegel des Senats wurde der nationale Grundwert allein von einer Freiheitsmütze verkörpert (Abb. 16-18). Dies war indes kein gänzlich neues Phänomen; schon in den 1770er Jahren waren auf der Flagge des 2nd South Carolina Regiment $^{35}$ und im Siegel des damals geschaffenen Board of War and Ordnance (Abb. 19) - des Vorläufers des heutigen Department of the Army, dessen Siegel im Grundsatz noch immer die damalige Gestalt aufweist - jeweils zentral positioniert und damit zum bedeutendsten Bildelement erhoben eine Mütze als Sinnbild der Freiheit eingesetzt worden. ${ }^{36}$ In beiden Fällen war die Kopfbedeckung aufgesteckt, was auch in damaligen englischen Bildern mit von der Libertas losgelöst dargestellten Freiheitsmützen ein geläufiges Motiv war; nicht geläufig war dort allerdings eine beflaggte Fahnenstange bzw. ein senkrecht stehender Pfahl oder Ähnliches als Träger. ${ }^{37}$ Bei dieser in den Abbildungen 16 und 19 zu sehenden Darstellungsweise mag ein originär amerikanisches Freiheitssymbol, der liberty pole, Pate gestanden haben. Hierbei handelte es sich um ein fahnenmastähnliches Gebilde, das von einer Freiheitsmütze gekrönt sein konnte. ${ }^{38}$ Auch eine Verzierung mit Flaggen kam vor, ${ }^{39}$ was möglicherweise eine Inspirationsquelle für die Gestaltung des Siegels von Iowa war.

Die genannte Darstellungsform fand in Nordamerika während und kurz nach dem Unabhängigkeitskrieg teilweise auch bei der Verzierung eines anderen potentiellen Trägers offizieller politischer Botschaften, den amtlichen Zahlungsmitteln, Anwendung, etwa auf einigen certificates des Staates Georgia aus den Jahren 1776/77 und auf der 1-Dollar-Note des Staates New

\footnotetext{
${ }^{35}$ Abb. in: David Hacket Fischer, Liberty and Freedom. A Visual Study of American Founding Ideas, Oxford 2005, S. 73.

${ }^{36}$ Die Zentralität der Freiheit wird im Fall der Regimentsflagge zusätzlich durch die Umschrift »Vita potior libertas « unterstrichen.

${ }^{37}$ Eine Ausnahme bildet die Radierung »The Difference« von 1758 (BM, RNr. 1868,0808.4109), die sich aus Großbritannien »deportiert« nunmehr auf einem fest im preußischen Boden verankerten Pfahl befindet. In der Graphik »An historical \& emblematic print, representing the late Earl of Chatham [...]« von $1782(\mathrm{BM}, \mathrm{RNr}$. 1899,0713.112) tanzen Menschen um eine Stange mit Freiheitsmütze; bei diesem Motiv dürfte es sich um einen »Import» aus Nordamerika handeln. Gleichermaßen »importiert«, in diesem Fall aus Frankreich, sind die in Drucken der 1790er Jahre gelegentlich zu sehenden mützenbekrönten Freiheitsbäume (zum Freiheitsbaum als einem »ausländischen« Freiheitssymbol in englischen Graphiken: Zeiler, Visuelle Repräsentation [Fn. 5]). »Freischwebende« senkrechte Stangen oder Stäbe mit Freiheitsmützen kommen in englischen Darstellungen bisweilen ebenfalls vor (z.B. auf dem Schild eines römischen Legionärs, der ein Portrait des Duke of Cumberland begleitet [BM, RNr. 1919,1111.33] oder auf einem von Wedgwood produzierten Teller (National Museums Scotland, Museum reference A.1873.21.16).

${ }^{38}$ Alfred F. Young, Liberty Tree. Made in America, Lost in America, in: ders., Liberty Tree. Ordinary People and the American Revolution, New York (N.Y.)/London 2006, S. 362.

${ }^{39}$ Ebd., S. 349.
} 
York aus dem Jahr $1781{ }^{40}$ Normalerweise wurde damals aber, wenn es galt, den Grundwert der Freiheit auf Geld graphisch zu repräsentieren, auf die Figur der Libertas zurückgegriffen. Dies geschah meist in der überkommenen neuzeitlichen Form einer Frau mit einer von der Freiheitsmütze gekrönten Stange in der Hand. In den 1780er Jahren wurde dieses Motiv auf Papiergeld aus New Jersey und New York durch die Wiedergabe der mit Libertas-Darstellungen versehenen Siegel dieser Staaten umgesetzt. ${ }^{41}$ Ein anderes Design aus dieser Zeit geht auf englische bzw. britische Münzen zurück, die in Anlehnung an römische Geldstücke ${ }^{42}$ eine sitzende Britannia mit einem Zweig in der Hand zeigen. ${ }^{43}$ Auf amerikanischen Münzen wurde die Personifikation wie in der oben erwähnten Cipriani-Bartolozzi-Graphik, der mutmaßlich die gleiche Genealogie eigen ist, ${ }^{44}$ bisweilen mit einer aufgesteckten Freiheitsmütze versehen und so graphisch zur Libertas gemacht, namentlich 1785/87 in Connecticut und 1787 in New York (Abb. 20a, b). ${ }^{45}$

Ähnlich wie im Fall der Staatssiegel zeitigte die mit Stange und Mütze versehene Personifikation der Freiheit bei der Schaffung von Münzgeld bis ins 19. Jahrhundert hinein Wirkung, und zwar in dem sog. Seated Liberty Dollar (Abb. 21), ${ }^{46}$ der von den $1830 \mathrm{er}$ bis in die 1870er Jahre in Gebrauch war. Im Allgemeinen wurden seit der Prägung der ersten US-Münzen Anfang der 1790er Jahre bei der Gestaltung der Libertas aber neue Wege beschritten: Die allegorische Figur erschien im 19. Jahrhundert gemeinhin nicht mehr als Ganzfigur, sondern als Büste, die eine (in ihrer Bedeutung teilweise unklare) ${ }^{47}$ Kopfbedeckung trägt, oder mit einer Art Diadem mit der Aufschrift »Liberty« geschmückt ist. Die Wiedergabe der Libertas als

${ }^{40}$ Eric P. Newman, The Early Paper Money of America, 5. Aufl., Iola (Wis.) 2008, S. 145, 148, 149 (Abb. S. 144) und S. 292. Auf einem bill of credit von South Carolina aus dem Jahr 1776 findet sich das Motiv des aufgesteckten Freiheitssymbols in einer abgewandelten Form als Kopfbedeckung auf einem Stab, der aus einem Buch auf einem Altar hervorragt (Abb. ebd., S. 55).

${ }^{41}$ Newman, ebd., S. 264 f., 292 f. (jeweils mit Abb.).

${ }^{42}$ Bsp.: BM, RNr. R.13619 (Sesterz aus der Regierungszeit von Antoninus Pius [140-144]).

${ }^{43}$ Bsp.: BM, RNr. C.5071 (Farthing von 1774). Die Britannia war seit der Regierungszeit von Kaiser Hadrian auf römischen Münzen in Gebrauch (Bsp.: BM, RNr. 1959,1019.4); auf englischen Geldstücken erschien sie erstmals in der Regierungszeit Karls II. (vgl. zur Figur der Britannia und zu ihrer Verwendung auf englischem/ britischem Münzgeld Katharine Eustace, Britannia: Some High Points in the History of the Iconography on British Coinage, in: British Numismatic Journal, Bd. 76 [2006], S. 323 ff.).

${ }^{44}$ Vgl. zu den Quellen dieses Bildes Frank H. Sommer, The Metamorphoses of Britannia, in: Charles F. Montgomery/Patricia E. Kane (Hrsg.), American Art 1750-1800. Towards Independence, Boston (Mass.) 1976, S. 41.

${ }^{45}$ Auf einer nicht in Umlauf gesetzten Münze von Massachusetts hält die Libertas ihr Attribut ausnahmsweise wie in römischer Zeit in der Hand (ebd., S. 43 f. [mit Abb.]). Ein direkter Rückgriff auf antike Darstellungen liegt hier allerdings nicht vor; vielmehr basiert dieser Münzentwurf ebenfalls auf dem Britannia-Modell und damit auf einer Bildkomposition englischen Ursprungs.

${ }^{46}$ Im Entstehungsprozess dieser Münze dienten britische Geldstücke und Medaillen als Vorlage (vgl. zur Geschichte R. W. Julian, Chapter 7: Gobrecht Dollars 1836-1839, Historical Background, in: Q. David Bowers, Silver Dollars \& Trade Dollars of the United States, Bd. 1, Wolfeboro [N.H.] 1993).

${ }^{47}$ Vgl. unten S. 21. 
Büste war in Großbritannien ebenso wenig üblich wie die Verwendung beschrifteter Diademe oder Ähnlichem als Ausweis ihrer Identität, so dass sich hier in der politischen Ikonographie der ehemaligen Kolonien eine Abkehr von der ikonographischen Tradition des Mutterlandes abzuzeichnen begann.

Eine solche Abwendung zeigt sich gleichermaßen in der »amerikanische Werte und Ziele ${ }^{48}$ zum Ausdruck bringenden Dekoration des Kapitols in Washington. Sinnbilder der Freiheit waren in der künstlerischen Ausstattung der Versammlungsstätten des US-Kongresses bereits frühzeitig präsent, eventuell schon im ersten Versammlungsort nach der Ratifizierung der Bundesverfassung, in der sog. Federal Hall in New York. Dort bestand einem Zeitungsartikel aus dem Jahr 1789 zufolge der Plan, hinter dem Stuhl des Präsidenten des Repräsentantenhauses eine Statue der Freiheit zu platzieren. ${ }^{49} \mathrm{Ob}$ es in der kurzen Zeit, in der der Kongress seinen Sitz in New York hatte, tatsächlich zur Errichtung eines solchen Denkmales kam, ist unbekannt. ${ }^{50}$ Sicher ist, dass im Jahr 1792 in der Congress Hall in Philadelphia hinter dem Speaker's Chair eine sich heute im Besitz der Library Company of Philadelphia befindliche Büste der Minerva als Patronin der amerikanischen Freiheit aufgestellt wurde, ${ }^{51}$ deren Brustschild mit einer sich auf einem senkrechten Stab befindlichen Mütze versehen ist. Geschaffen wurde die Skulptur von dem italienischen Künstler Giuseppe Ceracchi, der sich mit ihr vielleicht für die höhere Aufgabe der Gestaltung eines von ihm vorgeschlagenen »Monument designed to perpetuate the Memory of American Liberty« für die sich in Planung befindliche Hauptstadt Washington empfehlen wollte. ${ }^{52}$ Dieses Denkmal sollte wahrscheinlich unterhalb des Capitol Hill vor der Westfront des zukünftigen Kapitols seinen Platz finden, ${ }^{53}$ wurde aber nie realisiert. Verwirklicht wurde hingegen eine Statue der Freiheit für den Sitzungssaal des Repräsentantenhauses. Ihre Schaffung ging auf den 1796 aus England eingewanderten Benjamin Latrobe zurück. Der mit der Aufsicht über die Bauarbeiten an dem 1800 bezogenen,

\footnotetext{
${ }^{48}$ Donald R. Kennon, Preface, in: ders. (Hrsg.), United States Capitol (Fn. 7), S. vii.

49 »It is intended to place a statue of Liberty over the Speaker's chair [...]« (The Massachusetts Magazine, Juni 1789, abgedruckt in: Charlene Bangs Bickford u. a. [Hrsg.], Documentary History of the First Federal Congress of the United States of America, Bd. 15, Baltimore [Md.]/London 2004, S. 34).

${ }^{50}$ Richard Chenoweth, The Very First Miss Liberty: Latrobe, Franzoni, and the First Statue of Liberty, $1807-$ 1814, in: The Capitol Dome, Bd. 53 (2016), Nr. 1, S. 4.

${ }^{51}$ Ebd. S. 6; Abb. der Büste nebst einem Versuch, deren Standort in der Congress Hall zu rekonstruieren, ebd., S. 9.

${ }^{52}$ Siehe zu Ceracchi und seinem Denkmalplan ebd., S. 5 f., und Pamela Potter-Hennesey, The Italian Influence on American Political Iconography. The United States Capitol as Lure and Disseminator, in: Donald R. Kennon/ Thomas P. Somma (Hrsg.), American Pantheon. Sculptural and Artistic Decoration of the United States Capitol, Athens (Oh.) 2004, S. 25 ff. (S. 30 f. zum Denkmal).

${ }^{53}$ Chenoweth, Miss Liberty (Fn. 50), S. 5.
} 
aber noch unvollendeten Kapitol in Washington betraute Architekt veranlasste Anfang des 19. Jahrhunderts die Herstellung einer Libertas, die nach einem von ihm stammenden Entwurf dem neuzeitlichen Herkommen entsprechend eine Stange mit einer Freiheitsmütze auf der Spitze in der Hand halten sollte. ${ }^{54}$ Dies sollte nach der Vorstellung des seit 1851 für das Kapitol verantwortlichen Architekten Thomas U. Walter auch für die Freiheitsstatue auf der Kuppel gelten, wie einer Skizze Walters aus dem Jahr $1855 \mathrm{zu}$ entnehmen ist. ${ }^{55}$ Am Ende wurde aber keines der beiden Monumente in dieser Form verwirklicht; vielmehr gestaltete der von Latrobe beauftragte italienische Bildhauer Giuseppe Franzoni ein Gipsmodell, bei dem sich die Mütze wie in der Antike in der Hand der Libertas befand, ${ }^{56}$ und die von Thomas Crawford geschaffene Statue, die bis heute die Kuppel des Kapitols ziert, entbehrt des traditionellen Attributes gänzlich. ${ }^{57}$ Der Grund liegt darin, dass der damals die Oberaufsicht über die bauliche Erweiterung des Kapitols ausübende US-Kriegsminister Jefferson Davis (später wurde er Präsident der Konföderierten Staaten) sich wie bereits bei der ebenfalls Crawford übertragenen Gestaltung einer Figurengruppe über der Tür im Senatsflügel des Kapitols gegen die Verwendung des Symbols aussprach und mit seiner ablehnenden Haltung in beiden Fällen beim Künstler durchdrang. ${ }^{58}$ Das hinderte Crawford allerdings nicht, sich der Freiheitsmütze an anderer Stelle dennoch zu bedienen, zum einen in seiner Figurengruppe »Progress of Civilization«, wo sie sich auf dem Kopf der zentral positionierten Personifikation Amerikas befin$\operatorname{det},{ }^{59}$ und zum anderen in einem der von ihm in den 1850er Jahren entworfenen Reliefs der Bronzetüren im Flügel des Repräsentantenhauses, wo sie als Attribut der Libertas fungiert und dabei auf einer von dieser gehaltenen Stange steckt. ${ }^{60}$ Diese Art der Darstellung, die zwar, wie gesehen, bisweilen in Kunstwerken vorgesehen war, dann aber jeweils nicht umgesetzt wurde, ist für das Kapitol ungewöhnlich. Soweit die Freiheitsmütze hier als Attribut eingesetzt ist

\footnotetext{
${ }^{54}$ Vgl. zur Geschichte der Statue ebd., S. 10 ff. (mit Abb. des Latrobe-Entwurfs).

${ }^{55}$ Abb. in: Vivien Green Fryd, Art \& Empire. The Politics of Ethnicity in the United States Capitol, 1815-1860, New Haven (Conn.)/London, S. 191.

${ }^{56}$ Rekonstruktionen bei Chenoweth, Miss Liberty (Fn. 50), S. 2, 13, 14. Das Gipsmodell befand sich bis zu seiner Zerstörung während des britisch-amerikanischen Krieges (1814) in dem Versammlungsraum.

${ }^{57}$ Das hat sie mit der für gewöhnlich als Freiheit gedeuteten Skulptur von 1817-19 in der üblicherweise »Liberty and the Eagle « genannten Figurengruppe in der National Statuary Hall gemeinsam. Allerdings ist fraglich, ob es sich bei der eine Verfassungsurkunde haltenden Frau tatsächlich um eine Personifikation der Freiheit handelt oder ob hier nicht vielmehr eine Fehlinterpretation des zeitgenössisch als »Genius of the Constitution « bezeichneten Monuments vorliegt (vgl. zum Ganzen Fryd, Art \& Empire [Fn. 55], S. 187 f. [mit Abb.]).

${ }^{58}$ Siehe zum Ganzen Fryd, Art \& Empire (Fn. 55), S. 184, 188 ff. Die von Crawford ursprünglich geplante Figurengruppe »Liberty and Justice« wurde von ihm in eine allegorische Darstellung von Gerechtigkeit und Geschichte abgeändert (Abb. ebd., S. 183).

${ }^{59}$ Vgl. zu deren Entstehung Fryd, Art \& Empire (Fn. 55), S. 109 (Abb. der Figurengruppe S. 113, 114).

${ }^{60}$ Vgl. zu den Türen ebd., S. 125 (mit Abb. S. 127; die Libertas ist auf der linken Seite im dritten Feld von oben im Hintergrund).
} 
und nicht allein steht (wie etwa auf einer der ab 1856 verlegten Fußbodenfließen oder auf einer Kaminverkleidung von 1819) ${ }^{61}$ befindet sie sich regelmäßig auf dem Kopf der Personifikation, der sie zugewiesen ist. ${ }^{62}$ Dies gilt namentlich für die in den 1860er Jahren entstandenen Wandgemälde des 1852 aus Italien in die USA gekommenen Künstlers Constantino Brumidi. In den Werken dieses als »master of the classical tradition rooted in ancient Rome« charakterisierten Malers ${ }^{63}$ hat die Mütze beispielsweise Auftritte im Fries in der Rotunde, im Deckengemälde des President's Room und in der Hauptszene des »Apotheosis of Washington « betitelten Freskos in der Kuppel (Abb. 22) als Attribut der Freiheit sowie in einer Nebenszene - der Darstellung der Landwirtschaft als einem der den Vereinigten Staaten Wohlstand bringenden Tätigkeitsfelder - auf dem Kopf einer Verkörperung des jungen Amerika. ${ }^{64}$

\section{Freiheitssymbole im Dienste der Glorifizierung der »amerikanischen Freiheit« und ihrer Heroen}

Im Deckenfresko der Kuppel, in dem die Libertas einen engen Bezug zu dem in den Himmel erhobenen ersten Präsidenten der USA aufweist, verbindet sich die der staatlichen Selbstdarstellung dienende Verwendung von Freiheitssymbolen mit deren bereits im England des 18. Jahrhunderts geläufigen und in Nordamerika ebenfalls bekannten Gebrauch in personenbezogenen Kunstwerken mit einem preisenden Charakter. ${ }^{65}$ In dieser Funktion wurden Sinnbilder der Freiheit schon in den 1760er Jahren von Kolonisten unter enger Anlehnung an englische Vorlagen in einigen Druckgraphiken genutzt, ${ }^{66}$ und einschlägige amerikanische Werke aus den ersten Jahrzehnten der Unabhängigkeit ähneln englischen Schöpfungen ebenfalls in manchem, vor allem darin, dass in ihnen die Libertas, sofern sie als Bildelement vorkommt, ${ }^{67}$

\footnotetext{
${ }^{61}$ Auf der Fliese befindet sich die Mütze nach Auskunft von Eric Paff vom Office of the Curator at the Architect of the Capitol (E-Mail vom 9.8.2017) ohne Bezug zu einer Person auf einem Stab; am Kamin steckt sie auf einem Liktorenbündel (Abb. in: Glenn Brown's History of the United States Capitol, Washington [D.C.]) 2007, S. 163, 164). Die Freiheitsmütze wurde im Kapitol noch im frühen 20. Jahrhundert in den sog. Amateis Doors von 1908 als Motiv herangezogen; hier krönt sie eine Fahnenstange (vgl. die Beschreibung der Szene mit dem Titel »Naval Architecture and Commerce« in: Architect of the Capitol, The Amateis Doors. Bronze by Louis Amateis 1908, 2013, S. 4: »A sailor holds a flag surmounted by a liberty cap, significant of an open-door policy« [abrufbar unter: http://www.aoc.gov/sites/default/files/amateis_doors_2013.pdf]).

${ }^{62}$ Eine Ausnahme ist eine von Constantino Brumidi gemalte Figur im Senate Reception Room (Abb. in: Barbara A. Wolanin, Constantino Brumidi: Artist of the Capitol, Washington [D. C.] 1998, S. 116).

${ }^{63}$ Ebd., S. 3.

${ }^{64}$ Siehe zu Brumidis Wandgemälden allgemein Wolanin, ebd.; zum Fries vgl. S. 149 ff., zum President's Room S. 116 ff. und zum Fresko in der Kuppel S. 125 ff. (jeweils mit Abb.)..

${ }^{65}$ Hierzu Zeiler, Visuelle Repräsentation (Fn. 5).

${ }^{66}$ Zeiler, Visuelle Rechtsverteidigung (Fn. 3), S. 318 ff., 324 f.

${ }^{67}$ Bisweilen wird in verehrenden Graphiken die (aufgesteckte) Freiheitsmütze ohne die Libertas verwendet; vgl. als Beispiele die Abbildungen in: Joshua C. Taylor, America as Art, Washington (D.C.) 1976, S. 29, 30 (Mütze
} 
die Freiheitsmütze auf einer Stange hält. Dies ist etwa der Fall in einem 1786 geschaffenen Gemälde des Gründungsvaters Thomas Jefferson, ${ }^{68}$ auf der Rückseite einer aus Anlass seines Amtsantritts als Präsident (1801) geprägten Gedenkmedaille (Abb. 23), in einem verklärenden allegorischen Portrait von ihm aus der Zeit seiner Präsidentschaft (Abb. 24) oder in einer Verherrlichung George Washingtons als großer Heerführer, der die Vereinigten Staaten zu Friede und Freiheit geführt hat, ${ }^{69}$ und in Drucken, die nach dem Tod bekannter Persönlichkeiten entstanden. Derartige graphische Glorifizierungen jüngst Verstorbener mit der Abbildung einer Libertas waren wiederum in England schon länger bekannt - einschließlich der Darstellung eines fiktiven Grabmals, ${ }^{70}$ wie es in einem Stich von ca. 1804 zum Tod des Gründungsvaters Alexander Hamilton zu sehen ist (Abb. 25). Am häufigsten solchermaßen verehrt wurde George Washington, nach dessen Ableben im Jahr 1799 sich »fast ein Kult um den verstorbenen Helden« entwickelte. ${ }^{71}$ Eine frühe künstlerische Reaktion auf seinen Tod war ein Mezzotinto von ca. 1800, das ein von der Freiheit und anderen allegorischen Figuren eingerahmtes Portrait des Verstorbenen zeigt; ${ }^{72}$ in einem anderen Beispiel, einem populären Stich von 1802 (Abb. 26) ${ }^{73}$ wird der Verblichene in einer Auferstehungsszene von der Figur der Unsterblichkeit mit Unterstützung von Vater Zeit aus seinem Sarkophag gehoben und auf den Weg gen Himmel gebracht, während vor dem Sarkophag die personifizierte Freiheit nebst einer Personifikation Amerikas in der Pose der schlafenden Wächter vor dem Grab Christi kauert. ${ }^{74}$

\footnotetext{
auf einer Stange über dem Portrait von George Washington bzw. von einem Putto gehaltener Stab mit Mütze in einem gemalten Denkmal für Washington).

${ }^{68}$ National Portrait Gallery, Smithsonian Institution, ONr. NPG.99.66.

${ }^{69}$ Weatherwise's Massachusetts Almanac for the Year of our Lord 1791 (Abb. in: Barbara E. Lacey, From Sacred to Secular. Visual Images in Early American Publications, Newark [Del.] 2007, S. 101).

${ }^{70}$ Vgl. BM, RNr. 1868,0808.4444.

${ }^{71}$ So Taylor, America as Art (Fn. 67), S. 29.

${ }^{72}$ Abb. ebd., S. 34.

${ }^{73}$ Siehe zu diesem Bild Phoebe Lloyd Jacobs, John James Barralet and the Apotheosis of George Washington, in: Winterthur Portfolio, Bd. 12 (1977), S. 115 ff. Die Graphik wurde auch in Form von Verzierungen auf Krügen verbreitet (Abb. in: Christina H. Nelson, Transfer-Printed Creamware and Pearlware for the American Market, in: Winterthur Portfolio, Bd. 15 [1980], S. 103). Im Jahr 1865 wurde sie unter dem Titel »The Reward of the Just« erneut veröffentlicht, um den ermordeten Sklavenbefreier Lincoln, der Washingtons Stelle in dem Bild eingenommen hat, zu ehren (Abb. in: Harold Holzer, Columbia's Noblest Sons. Washington and Lincoln in Popular Prints, in: Journal of the Abraham Lincoln Association, Bd. 15 [1994], S. 45).

${ }^{74}$ So Jacobs, ebd., S. 125. Washington trat noch bis zur Mitte des 19. Jahrhunderts (nunmehr oft gemeinsam mit anderen Personen) in Graphiken auf, in denen sich eine in herkömmlicher Form gezeichnete Libertas befand. Allein mit einer solchen Freiheit verbunden ist er etwa in der Lithographie »Elements of national thrift and empire« von 1847 (LC, RNr. LC-USZ62-18134), zusammen mit anderen Personen ist er z. B. zu sehen in der (exzentrischen, weil versteckte Profilbildnisse enthaltenden) Lithographie »Portraits of the seven presidents of the U.S.« von 1834 (LC, RNr. LC-DIG-pga-04321), in dem Gedenkdruck »The Presidents of the United States. Liberty and Union« aus dem Jahr 1845 (LC, RNr. LC-DIG-pga-01202) und in einer Lithographie von 1839, in der an die Unabhängigkeitserklärung und die Revolution erinnert wird (LC, RNr. LC-DIG-pga-0222); hier bildet der gemeinsam mit Repräsentanten der 13 Gründungsstaaten der Union auftretende Washington, der zentral
} 
Neben Drucken, die in bekannter Manier Personen preisen, entstanden ab den späten 1770er Jahren verherrlichende Werke mit Sinnbildern der Freiheit, in denen die Union bzw. ihre Verfassung mit dem hohen Wert der Freiheit in Verbindung gebracht wurde. Dies konnte mithilfe der Figur der Libertas geschehen, wie in einer 1788 von John Trenchard geschaffenen Radierung, die das »nunmehr«, d.h. durch die neue Bundesverfassung, errichtete »Gebäude für die Freiheit« feiert. Umgesetzt wird dies in dem als Frontispiz für das von Trenchard mitgetragene Columbian Magazine dienenden Druck durch die Darstellung eines mit dreizehn die Unionsstaaten repräsentierenden Säulen versehenen Tempels, auf dessen Giebelspitze die personifizierte Freiheit als Verkörperung des neben der Gerechtigkeit und dem Frieden höchsten Wertes der Union thront (Abb. 27). ${ }^{75}$ Derartige Preisungen, die graphisch die Freiheit betonen und sich dazu des Motivs der Libertas bedienen, gab es bis in die 1830er Jahre, ${ }^{76}$ während in zwei frühen Drucken mit einer ähnlichen Thematik die Freiheit durch eine anderen Gestalten zugewiesene Stange mit Mütze verkörpert wird. In einem 1779 für das kurzlebige United States Magazine entworfenen Titelbild ist es die vor einem triumphalen Bogengang, der für die »großartige« Konföderation »mächtiger Staaten« stehen soll, nach Westen fliegende und dabei die »noblen« Namen all derer, welche »the fabric of the states« entworfen haben, verkündende Fama, ${ }^{77}$ die das Freiheitssymbol in der Hand hält (Abb. 28), und im Titelbild von Bickerstaff's Boston Almanack für das Jahr 1788 kommt diese Rolle Benjamin Franklin zu (Abb. 29). Er sitzt zusammen mit George Washington in einem »Federal Chariot«, der von dreizehn die »happy Union« repräsentierenden »Freemen« gezogen

positioniert eine Urkunde mit der Aufschrift »We declare ourselves free and independent« hält, ausweislich der Bildunterschrift den »Hauptgegenstand« der Graphik.

${ }^{75}$ Verbal wird die Dreiheit durch die Inschrift des Tempels »Sacred to Liberty, Justice and Peace« und durch eine Zeile des beigefügten Gedichts verdeutlicht: »[...] a Fabric now to Freedom rear'd [...]. Where Justice, too, and Peace, by us ador'd, Shall heal each wrong, and keep unsheath'd the sword «.

${ }^{76}$ Vgl. das patriotische Flugblatt mit dem Titel »The first great Western empire: or, the United States of America« von 1812 und den patriotischen Holzschnitt »Temple of Liberty« aus dem Jahr 1834 (LC, RNr. LC-USZ6240915; RNr., LC-DIG-ppmsca-17520). Im ersten Fall wird eine Verbindung von Freiheit und Verfassung hergestellt, indem in der Mitte des Flugblattes ein von der Libertas gekrönter »Tempel der Freiheit« gezeigt wird, in dessen Innerem die Worte »The Federal Constitution« stehen. Der Holzschnitt ist hingegen eine Aufforderung zur Wahrung der Union. Dies wird explizit auf einem Banner ausgedrückt, das von Justitia und Minerva gehalten wird (»The Union Must and Shall Be Preserved«). Zwischen den beiden weiblichen Gestalten und unter dem Banner ist der namensgebende Freiheitstempel zu sehen, in dem eine Libertas mit Stange und Mütze in der rechten und einer Schriftrolle mit den Worten »Bill of Rights« in der linken Hand aus den Flammen eines Altars emporsteigt. Die Aufschrift auf diesem Altar - »Preserved by Concord « - verkündet die Botschaft, dass Freiheit nur existieren kann, wenn Eintracht im Land herrscht.

${ }^{77}$ Vgl. aus dem beigefügten Gedicht $»$ A Bold triumphal Arch you see, Such as by antiquity [...]. The Pillars which support the weight, Are each of them a mighty State [...] new states shall added be, To the great Confederacy. [...] Fame before the vista flies, Rising to the western skies [...] where new states shall yet have place [...]. O! heavenly-winged cherub, Fame, Bear aloft each noble name Of those whose comprehensive mind, The fabric of the states design'd " (zitiert nach Donald H. Cresswell, The American Revolution in Drawings and Prints. A Checklist of 1765-1790 Graphics in the Library of Congress, Washington [D.C.] 1975, S. 316 f.). 
wird, wie die Erläuterung auf der dem Frontispiz folgenden Seite ausführt. ${ }^{78}$ Washington hält dabei die neue Bundesverfassung - »the grand Fabrick of American Independence « -, die, sobald sie ratifiziert sein wird, die amerikanische Freiheit sichern wird, wie die von Franklin gehaltene Stange mit Mütze ausdrücken soll.

\section{Freiheitspersonifikationen als Verkörperungen des freien Amerikas}

Wie Großbritannien im 18. Jahrhundert bisweilen mittels der Libertas oder der mit einer Freiheitsmütze versehenen Britannia (vgl. Abb. 2) bildlich als Land der Freiheit ausgewiesen wurde, wurden in den Kolonien mit dem Beginn der militärischen Auseinandersetzungen mitunter Freiheitspersonifikationen mit Amerika in Verbindung gebracht. Von Europäern wurde Amerika (etwa auf Landkarten) in der Regel durch Ureinwohner personifiziert, eine Art der Darstellung, die in englischen Drucken teilweise mit einer Freiheitsmütze auf einer Stange kombiniert wurde. ${ }^{79}$ In der ersten Zeit nach der Unabhängigkeitserklärung nutzten Kolonisten diese Form teilweise ebenfalls. Ein Beispiel findet sich auf der im September 1775 geschaffenen Standarte der Ende 1774 ins Leben gerufenen Miliztruppe Philadelphia Light Horse ${ }^{80}$ mit einer Fama und einem Ureinwohner, ${ }^{81}$ der eine Stange mit einer Mütze in der Hand hält. Ein weiterer Ureinwohner mit Stange und Mütze ist auf einem von Paul Revere entworfenen bill of credit der Colony of the Massachusetts Bay vom Juli 1775 abgebildet, ${ }^{82}$ während Revere 1781 für die Vignette im Titel der Zeitung Massachusetts Spy, in der sich bis dahin eine sitzende Libertas in einer Britannia-Darstellungen ähnelnden Haltung befand, ${ }^{83}$ eine Ureinwohnerin mit Stange und Mütze versah und sie mit einem Speer gegen ein Untier als Verkörperung der Tyrannei kämpfen ließ.$^{84}$ Derartige Personifikationen waren aber eher selten, weil die Bewohner der nach Unabhängigkeit strebenden Gemeinwesen deren visuellen Repräsenta-

\footnotetext{
${ }^{78}$ Bickerstaff's Boston Almanack for the Year 1788, Boston (Mass.) 1787.

${ }^{79}$ Hierzu Zeiler, Visuelle Repräsentation (Fn. 5).

${ }^{80}$ Abb. in: Fischer, Liberty and Freedom (Fn. 35), S. 136.

${ }^{81}$ Bei dem es sich nach einer bei George H. Preble, Origin and History of the American Flag, Bd. 1, Philadelphia (Pa.) 1917, S. 254, wiedergegebenen Beschreibung - wohl in Anspielung auf die von verkleideten Sons of Liberty durchgeführte Boston Tea Party - allerdings um einen »continental masquerading as an American Indian« handeln soll.

${ }^{82}$ Clarence S. Brigham, Paul Revere's Engravings, New York (N.Y.) 1969, pl. 73.

${ }^{83}$ Dieses Bild (LC, RNr. LC-USZ62-7984) stammt ebenfalls von Revere, wobei die Bildkomposition allerdings starke Ähnlichkeit mit dem Titelkopf des in den Jahren 1769/70 erscheinenden englischen Oppositionsblattes The Freeholder's Magazine aufweist. Bereits im Jahr 1770 hatte Revere die sich seit Mitte der 1750er Jahre in dem vom Independent Advertiser übernommenen Titelkopf der Boston Gazette befindliche sitzende (mutmaßlich Britannia darstellende) Frau, die einen Vogel freilässt, in die Figur der freiheitsmützenbewehrten BritanniaLibertas verwandelt (Brigham, Rever's Engravings [Fn. 82], S. 199 mit pl. 67; Abb. des Titelkopfes des Independent Advertiser: LC, RNr. LC-USZ62-42755).

${ }^{84}$ Brigham, Rever's Engravings (Fn. 82), pl. 70.
} 
tion durch Ureinwohner skeptisch gegenüberstanden. ${ }^{85}$ Stattdessen favorisierten sie die Libertas als »nationale Gottheit « ${ }^{86}$ Eine solche zeigt sich in hergebrachter Form auf einem Frontispiz für das Massachusetts Magazine (Abb. 30) von 1790, wo sie das der Tyrannei enthobene und damit freie Amerika kennzeichnet, ${ }^{87}$ oder - in vom Üblichen abweichender Gestalt - in Edward Savages populärem und oft kopierten Bild »Liberty. In the form of the goddess of youth« von 1796 (Abb. 31). ${ }^{88}$ Hier befindet sich die Freiheitsmütze auf einem Mast mit der amerikanischen Flagge, der über der jugendlichen, den amerikanischen Adler aus einem Kelch nährenden Freiheit schwebt.

In anderen Bildern wird die Libertas - zumindest mittelbar - in eine Personifikation Amerikas verwandelt. So deutet im Frontispiz für das 1775 in New York erschienene Buch »A concise natural history of East and West Florida« die von der antiken Formel »SPQR « abgeleitete Aufschrift »SPQA« auf dem Schild einer sitzenden Frau mit einer Mütze auf einer Stange auf eine Personifikation Amerikas hin (Abb. 32), während im Titelbild des Columbian Magazine von 1789 und im Frontispiz zum Ladies Magazine and Repository of Entertaining Knowledge von 1792, der ersten US-Ausgabe von Mary Wollstonecrafts »A Vindication of the Rights of Woman«, dasselbe durch die mit dem US-Wappen bzw. mit Sternen verzierten Schilde an der Seite von sitzenden (wiederum an Abbildungen der Britannia gemahnenden) Frauen mit Mützen auf Stangen suggeriert wird (Abb. 33, 34).

Derartige Verschmelzungen der Libertas und der Personifikation des neuen Staates traten seit dem frühen 19. Jahrhundert bisweilen unter der Bezeichnung »Columbia« auf. Diese Kunstgestalt entstand wohl als Gegenstück zu der aus der Antike stammenden Personifikation Britannia $^{89}$ und hat viele Erscheinungsformen, von denen diejenige mit einer Freiheitsmütze nur eine ist ${ }^{90}$. Vielleicht erstmals mit dem Namen »Columbia« in Verbindung gebracht erschien eine solche allegorische Gestalt auf einer von dem Engländer Thomas Wyon entworfenen Münze aus dem Jahr 1785. Diese zeigt zu der Umschrift »Immune Columbia« eine weibliche Figur in einer von entsprechenden Britannia-Darstellungen bekannten sitzenden Pose

\footnotetext{
${ }^{85}$ John Higham, Indian Princess and Roman Goddess. The First Female Symbols of America, in: American Antiquarian Society, Proceedings, Bd. 100 (1991), S. 55, mit Ausführungen zu möglichen Gründen S. 55 f.

${ }^{86}$ Ebd., S. 58 ff. (Zitat S. 59).

${ }^{87}$ Vgl. aus der Erklärung des Titelbildes: »America, as having received the prime illuminations of Freedom, glows with an intense purity of light $[\ldots]$.. Visuell wird die Befreiung durch am Boden liegende Ketten und die im Hintergrund »with precipitate dread« den Rückzug antretende Personifikation der Tyrannei ausgedrückt (Zitate in: Massachusetts Magazine, or, Monthly Museum of Knowledge \& Rational Entertainment, Bd. 2 [1790], Ausgabe 1).

${ }^{88}$ Siehe hierzu etwa Fischer, Liberty and Freedom (Fn. 35), S. 236 f. (mit Abb.).

${ }^{89}$ Higham, Indian Princess (Fn. 85), S. 63.

${ }^{90}$ Siehe hierzu Ray B. Browne u. a. (Hrsg.), Frontiers of American Culture, West Lafayette (Ind.) 1968, S. 15 ff.
} 
mit einer Mütze auf einem Stab, an dem eine Flagge hängt (Abb. 35). Ausdrücklich als »Columbia« bezeichnet wird eine derartige Personifikation etwa in der ca. 1813 anlässlich des amerikanisch-britischen Krieges gestochenen Bildsatire »Columbia teaching John Bull his new lesson« (Abb. 36), ebenso wie in einem Ölbild von ca. 1855 mit dem Titel »Miss Columbia ${ }^{91}$ und in dem »Columbia Welcoming the South Back into the Union« benannten Brumidi-Fresko von 1876 im US-Kapitol ${ }^{92}$. Die Identifikation der Frau mit Freiheitsmütze als Nationalpersonifikation erfolgte im 19. Jahrhundert regelmäßig durch die Einbeziehung des Designs der US-Flagge, sei es durch die beigegebene Fahne selbst, durch ein entsprechend bemaltes Wappenschild, eine mit Sternen und Streifen versehene Mütze oder durch einen flaggenartigen Umhang wie in dem angeführten Ölgemälde. Da die amerikanische Freiheit ebenfalls in der beschriebenen Weise identifiziert wurde, sind sie und die Figur der Columbia mit Freiheitsmütze aber austauschbar, und mitunter lässt sich kaum entscheiden, welche Personifikation jeweils gemeint ist.

\section{Von der »britischen« zur »amerikanischen« Freiheit}

Als im Jahr 1730 die (mutmaßlich) erste künstlerische Wiedergabe einer Libertas in Nordamerika auf dem Siegel der Kolonie North Carolina erschien, war diese rein britischer Herkunft; ${ }^{93}$ ebenso bewegte sich die erste umfassendere Nutzung von Sinnbildern der Freiheit durch die Kolonisten in den 1760er Jahren vollständig im Rahmen der britischen Politik und Kultur. ${ }^{94}$ Dies brachte es mit sich, dass Freiheitssymbole bis zur Unabhängigkeitserklärung in jeder Beziehung wie im Mutterland herangezogen wurden, d. h. sowohl als Mittel der Preisung von »Vorkämpfern der Freiheit« wie auch als Mittel der Kritik am politischen Gegner, während sie danach in Abkehr von der englischen Tradition zunächst nur noch in einem positiven Sinn Verwendung fanden. Dies änderte sich in einer substantiellen Form wieder in der dritten Dekade des 19. Jahrhunderts, als mit der die öffentliche Meinung tief spaltenden Präsidentschaft von Andrew Jackson (1829-1837) polemische Drucke allgemein und solche mit einer Libertas/Columbia oder mit Darstellungen einer von Personifikationen unabhängigen

\footnotetext{
${ }^{91}$ Abb. in: Taylor, America as Art (Fn. 67), S. 14.

${ }^{92}$ Abb. in: Wolanin, Brumidi (Fn. 62), S. 162.

${ }^{93}$ Das Siegel entstand anlässlich der Umwandlung der Eigentümerkolonie North Carolina in eine Kronkolonie und wies mit der Darstellung des von der personifizierten Freiheit begleiteten Königs Georg II. eine Bildkomposition auf, die auf einen Vorschlag der Lords of Trade in London zurückging (vgl. Zeiler, Visuelle Rechtsverteidigung [Fn. 3], S. 323).

94 Ebd., S. 323 ff.
} 
Freiheitsmütze im Besonderen zahlreicher zu werden begannen. ${ }^{95}$ Damals wurde in der Bildpropaganda beider Seiten auf diese Motive zurückgegriffen, ${ }^{96}$ und sie traten dabei nicht mehr notwendigerweise in glorifizierender Absicht auf, sondern konnten auch Teil der Kritik am politischen Gegner sein. ${ }^{97}$ Von nun an dienten Freiheitssymbole in Bildsatiren und Karikaturen öfter als Mittel der innenpolitischen Kritik, ${ }^{98}$ so dass sich in dieser Beziehung gleichsam eine Rückkehr zu den (britischen) Wurzeln vollzog - mit dem Unterschied freilich, dass die Sinnbilder nun für die amerikanische Freiheit standen. Gleichzeitig bestand mit dem in Großbritannien nie Fuß fassenden Gebrauch der Libertas und der Freiheitsmütze im Bereich der staatlichen Selbstdarstellung eine in Nordamerika begründete Verwendungsweise fort, die im 19. Jahrhundert in der gelegentlichen Nutzung dieser Embleme in Wahlkampagnen ${ }^{99}$ und zur Zeit des Ersten Weltkrieges in Propagandaplakaten ${ }^{100}$ zwei im einstmaligen Mutterland ebenso unbekannte Ergänzungen fand.

Im Hinblick auf die Gestaltung der genannten Motive gab es in den ersten Jahrzehnten der Existenz des neuen Staatswesens wie gesehen eine weitgehende Orientierung an der englischen Tradition. Das ist insofern wenig verwunderlich, als es damals in künstlerischer Hinsicht noch verschiedentlich Verbindungen zum ehemaligen Mutterland gab. Diese bestanden etwa darin, dass in den 1780er Jahren mit der eingangs angeführten Radierung »America Triumphant and Britannia in Distress « (Abb. 1) und mit dem 1781 in Boston publizierten, auf

\footnotetext{
${ }^{95}$ Siehe zur Verwendung der Libertas in den politischen Auseinandersetzungen der zweiten Hälfte des 19. Jahrhunderts Higham, Indian Princess (Fn. 85), S. 67 ff. Eine (seltene) einschlägige frühere Graphik stammt mit dem Druck »See Porcupine in Colours just Potray'd « aus dem Jahr 1796 aus der Zeit des Prinzipienstreits zwischen den Federalists um Alexander Hamilton mit einer Libertas, die an einem Denkmal für die amerikanische Unabhängigkeit weint, während neben ihr ein melancholischer amerikanischer Adler ihren Stab mit Mütze hält (siehe zu dieser Karikatur Fischer, Liberty and Freedom [Fn. 35], S. 204 f. [mit Abb.]).

${ }^{96}$ Siehe zu den Auseinandersetzungen dieser Zeit und der sie begleitenden Bildpropaganda Fischer, Liberty and Freedom (Fn. 35), S. 208 ff.

${ }^{97}$ Ein Beispiel für eine damalige Bildsatire ist »The Grand National Caravan Moving East« (LC, RNr. LCUSZ62-9646), wo mehrere Aspekte der Präsidentschaft Jacksons aufs Korn genommen werden: Hier befindet sich eine clownesk wirkende Mütze auf einem Mast, an dem eine Fahne mit der Aufschrift »Rights of Man« hängt; der Mast ist an einem von einem Pferd gezogenen Käfig befestigt, in dem mehrere Ureinwohner eingesperrt sind. Dies ist wohl eine Bezugnahme auf Jacksons umstrittenes Umsiedlungsprogramm, so dass die Freiheitsmütze in diesem Fall in einer ironisierenden Weise verwendet wird. Weitere Beispiele von Graphiken mit Freiheitsmützen für und gegen Jackson sind LC, RNr. LC-USZ62-9646 und LC, RNr. LC-USZ62-1578.

${ }^{98}$ Bspe.: LC, RNr. LC-USZ62-17296; LC, RNr. LC-USZ62-1424; LC, RNr. LC-USZ62-63685.

${ }^{99}$ Sie erschienen vorzugsweise auf Wahlplakaten und election tickets; Bspe.: LC, RNr. LC-USZ62-3985; LC, RNr. LC-DIG-ppmsca-19254; LC, RNr. LC-DIG-ppmsca-17562; LC, RNr. LC-USZ61-1460; LC, Call Number: Portfolio 69, Folder 34.

${ }^{100}$ Vgl. etwa die Poster der National War Garden Commission mit den Slogans »Sow the Seeds of Victory! Plant \& Raise Your Own Vegetables« und »The Fruits of Victory« (LC, RNr. LC-USZC4-10234; LC, RNr. LCUSZC4-5561) oder Werbeplakate für Kriegsanleihen (Bspe.: LC, RNr. LC-USZC4-9462; LC, RNr. LC-USZC49874); auch der unten Fn. 122 genannte Blashfield schuf in dieser Zeit einschlägige Propagandaposter (Bsp.: LC, RNr. LC-DIG-ppmsca-40020).
} 
einem Ölbild des Londoner Malers Robert Edge Pine von 1778 basierenden Stich »America« (Abb. 37) ebenso wie im Frontispiz zum Boston Magazine vom Dezember 1783 (Abb. 38a), einer modifizierten Kopie eines Londoner Titelbildes (Abb. 38b), und 1830 bei der Gestaltung des Seated Liberty Dollar (Abb. 21) weiterhin einschlägige Vorlagen aus England adaptiert wurden. ${ }^{101}$ Daneben gab es in den Vereinigten Staaten mit der personifizierten Freiheit versehene (Alltags-)Gegenstände, die in Großbritannien in Auftrag gegeben worden waren (z. B. von der New Yorker Firma Talbot, Allum \& Lee in England bestellte Token [Abb. 39]) ${ }^{102}$ oder dort aus Eigeninitiative für den amerikanischen Markt produziert wurden (z. B. bedruckte Stoffe u. a. mit dem »Apotheosis of Franklin and Washington«-Motiv [Abb. 40]), ${ }^{103}$ und auch manch einer der Urheber entsprechender Werke hatte Beziehungen zu England. So war John Trenchard, der Schöpfer des Titelbildes zum Columbian Magazine von 1788 (Abb. 27), bei dem ungefähr 1768 nach Philadelphia eingewanderten englischen Graphiker James Smither in die Lehre gegangen, ${ }^{104}$ während der Maler des erwähnten Jefferson-Gemäldes von 1786, Mather Brown, ein zwar in Boston geborener, aber in London (wo auch das Portrait entstand) tätiger Künstler war; ${ }^{105}$ Gleiches gilt für den aus Philadelphia stammenden, aber die meiste Zeit seines Lebens in England verbringenden Samuel Jennings, der vor allem wegen seines (wiederum in London gefertigten) Gemäldes »Liberty Displaying the Arts and Sciences, or The Genius of America Encouraging the Emancipation of the Blacks « bekannt ist, ${ }^{106}$ und die Apotheose Washingtons (Abb. 26) sowie die Bildsatire »Columbia teaching John Bull

\footnotetext{
${ }^{101}$ Im Entstehungsprozess der Münze dienten britische Geldstücke und Medaillen als Muster (vgl. zur Geschichte R. W. Julian, Chapter 7: Gobrecht Dollars 1836-1839, Historical Background, in: Q. David Bowers, Silver Dollars \& Trade Dollars of the United States, Bd. 1, Wolfeboro [N.H.] 1993).

${ }^{102}$ Vgl. Sylvester S. Crosby, The Early Coins of America, Boston (Mass.) 1879, S. 335.

${ }^{103} \mathrm{Vgl}$. hierzu und zu weiteren Beispielen bedruckter Textilien Edith A. Standen, English Washing Furnitures, in: The Metropolitan Museum of Art Bulletin, N. F., Bd. 23 (1964), S. 121 f. Ein anderes Beispiel von für den amerikanischen Markt produzierten Erzeugnissen sind mit Bildern verzierte Töpferwaren wie der in Fn. 73 genannte Krug.

${ }^{104}$ David McNeely Stauffer, American Engravers Upon Copper And Steel, Bd. 1, New York (N.Y.) 1907, S. 254 (zu Smither), 276 (zu Trenchard).

${ }^{105}$ Vgl. zu dem Portrait Alfred L. Bush, The Life Portraits of Thomas Jefferson, in: William Howard Adams (Hrsg.), Jefferson and the Arts: an Extended View, Washington (D.C.) 1976, S. 21 f. (mit Abb.).

${ }^{106}$ Dies ist die mutmaßlich erste Verwendung der Libertas in einem von einem US-Amerikaner geschaffenen Bild, das gegen die Sklaverei gerichtet ist (Robert C. Smith, Liberty Displaying the Arts and Sciences. A Philadelphia Allegory by Samuel Jennings, in: Winterthur Portfolio, Bd. 2 [1965], S. 85). Hier dient die Libertas (wohl erstmals) nicht als Symbol für politische Freiheit, sondern als Verweis auf eine mögliche Emanzipation der Sklaven (Fryd, Art \& Empire [Fn. 55], S. 189). Als Beispiel für eine spätere Nutzung der Libertas durch die Abolitionisten sei auf eine bei Fischer, Liberty and Freedom (Fn. 35), S. 247, abgebildete proabolitionistische Lithographie aus den 1860er Jahren verwiesen; daneben kamen Freiheitssymbole in einschlägigen Bildsatiren zum Einsatz (Bspe.: LC, RNr. LC-DIG-ppmsca-34495; LC, RNr. LC-USZ62-19673). Während des Bürgerkriegs bedienten sich bisweilen die Nordstaaten in Propagandabildern der Symbole (Bspe.: LC, RNr. LC-DIG-pga01777; LC, RNr. LC-DIG-pga-02893; LC, RNr. LC-USZ62-91851), danach wurde mitunter die Abschaffung der Sklaverei mit ihrer Hilfe gefeiert (Bspe.: LC, RNr. LC-DIG-pga-01805; LC, Call Number: Emancipation broadside 33$)$.
} 
his new lesson« (Abb. 36) rühren mit dem irischen Maler John James Barralet und dem Schotten William Charles ${ }^{107}$ von britischen Künstlern her, die vor ihrer Auswanderung in die USA in London wirkten.

Weitverbreitete Änderungen in der Darstellungsweise der Libertas/Columbia begannen erst ab der Mitte des 19. Jahrhunderts Platz zu greifen. Nunmehr wurde Personifikationen das Attribut vermehrt auf den Kopf gesetzt oder - wie teilweise im Washingtoner Kapitol und anderen öffentlichen Bauwerken $-{ }^{108}$ ganz darauf verzichtet. ${ }^{109}$ Ersteres war eine Art der Darstellung, die ursprünglich weder in der Antike noch in der Neuzeit gebräuchlich war. In England, wo Freiheitspersonifikationen bis zum Ausbruch der Französischen Revolution neben den Niederlanden am häufigsten eingesetzt wurden, galt dies für die zahlreichen Auftritte der Libertas in Druckgraphiken ebenso wie für ihr weniger zahlreiches Erscheinen in Monumenten, auf Gemälden und Medaillen oder Ähnlichem. ${ }^{110}$ Und auch in Frankreich, wo allegorische Gestalten mit Freiheitsmützen 1789 ebenfalls verstärkt in Mode kamen, hatten diese die Kopfbedeckung zunächst nicht aufgesetzt, sondern hielten sie der modernen Tradition entsprechend auf einem Gegenstand. ${ }^{111}$ Als Anfang der 1790er Jahre die Freiheitsmütze in der Gestalt des insbesondere von Sansculotten und Jakobinern tatsächlich auf dem Kopf getragenen, eine phrygische Form aufweisenden »bonnet rouge« in größerem Umfang Popularität erlangte, ${ }^{112}$ entstanden dort aber abweichend vom Hergebrachten zusätzlich Bilder mit Perso-

\footnotetext{
107 Siehe zu ihm Lorraine Welling Lanmon, American Caricature in the English Tradition. The Personal and Political Satires of William Charles, in: Winterthur Portfolio, Bd. 11 (1976), S. $1 \mathrm{ff}$.

${ }^{108}$ So etwa auf den Kuppeln des Texas State Capitol und des Allen County Courthouse in Fort Wayne (Ind.). Die bekannteste Verkörperung der Freiheit ohne Mütze ist die Freiheitsstatue in New York.

${ }^{109}$ Ein Grund, warum ab der Mitte des 19. Jahrhunderts verschiedentlich Freiheitspersonifikationen ohne das traditionelle Attribut entstanden, ist das Missfallen, mit dem die Freiheitsmütze in manchen Kreisen betrachtet wurde, weil sie angeblich als Zeichen von befreiten Sklaven nicht als Symbol für die konstitutionelle Freiheit taugte oder weil sie als durch die Französische Revolution diskreditiert angesehen wurde oder weil sie eine abolitionistische Konnotation erhalten hatte (vgl. hierzu Jean Fagan Yellin, Caps and Chains: Hiram Powers' Statue of »Liberty«, in: American Quarterly, Bd. 38 [1986], S. 804 ff.; Vivien Green Fryd, Hiram Powers's »America«. »Triumphant as Liberty and in Unity«, in: American Art Journal, Bd. 18 [1986], S. 66 f.).

${ }^{110}$ Im Bereich der Druckgraphik ist eine auf dem Kopf getragene (jeweils seltsam geformte) Freiheitsmütze ausnahmsweise zu sehen in den beiden Bildsatiren »The Merry go Round « aus dem Jahr 1762 (Abb. in: Robin Eagle, Francophilia in English Society, 1748-1815, Basingstoke/London 2000) und $»$ Review of the York regiment« (BM, RNr. 1868, 0808.3788) von ca. 1778 (hier ist es jeweils die Britannia, die dergestalt bekleidet ist) sowie in George Richardson, Iconology, London 1779, pl. LXXIV, fig. 285 (in der Erläuterung heißt es ausdrücklich »Liberty is allegorically expressed by the figure of a woman [...] with a cap on her head « [ebd., S. 56]). In den Niederlanden gab es ganz zu Beginn der Nutzung des Freiheitshutes auf einem Jeton von 1573 eine Darstellung, in der die Kopfbedeckung aufgesetzt war (siehe hierzu Janson, Dutch Liberty [Fn. 34], S. 110). ${ }^{111}$ Bspe. für frühe Medaillen aus dieser Zeit: Michel Hennin, Histoire Numismatique de la Révolution Française, Paris 1826, Abb. Nr. 39, 41, 74; Bspe. für frühe Druckgraphiken aus dieser Zeit: BnF, ID/Cote: btv1b84107475; BnF, ID/Cote: btv1b6943287h.

${ }^{112}$ Siehe zur Freiheitsmütze in Frankreich zur Zeit der Revolution Jennifer Harris, The Red Cap of Liberty. A Study of Dress Worn by French Revolutionary Partisans 1789-94, in: Eighteenth-Century Studies, Bd. 14
} 
nifikationen, die mit der Mütze bekleidet sind. ${ }^{113}$ Mit dieser Neuerung einher ging die gelegentliche Ersetzung der bisher in der Neuzeit normalerweise verwendeten Ganzfigur der Libertas $^{114}$ durch Brust- oder Kopfbilder. ${ }^{115}$

In den USA fanden Libertas-Bildnisse in Form von Kopfbildern mit aufgesetzten Mützen gleichfalls ab den 1790er Jahren Verwendung. Sie erschienen erstmals Mitte des Jahrzehnts und dann in veränderter Gestalt ab 1807 auf US-Münzen (Abb. 41a, b). Indes ist zweifelhaft, ob der Kopfschmuck ursprünglich als Freiheitsmütze gedacht war. Nach den Erkenntnissen von Samuel Moore, der sich während seiner Amtszeit als Direktor der amerikanischen Münzanstalt (1824-1835) um Informationen zur korrekten Gestaltung der Freiheit auf Münzen bemühte, ${ }^{116}$ war dies nicht der Fall. ${ }^{117}$ Allerdings wurden die Kopfbedeckungen weithin so interpretiert. ${ }^{118} \mathrm{Zu}$ einer Veränderung bei der Verwendung des Attributs der Libertas/Columbia kam es außerhalb des Münzwesens zunächst aber nicht. Erst in den 1850/60er Jahren erschienen, wie dargelegt, in der künstlerischen Ausstattung des Kapitols sowohl mützenlose Verkörperungen der Freiheit als auch Personifikationen, welche die Freiheitsmütze auf dem Kopf tragen, und auch Werke der US-amerikanischen Bildpublizistik begannen in dieser Zeit allmählich von allegorischen Gestalten mit aufgesetzten Freiheitsmützen bevölkert zu werden, z. B. in einer Lobpreisung des ungarischen Freiheitskämpfers Lajos Kossuth, der einer nie-

(1981), S. 283 ff.; Richard Wrigley, Transformations of a Revolutionary Emblem. The Liberty Cap in the French Revolution, in: French History, Bd. 11 (1997), S. $131 \mathrm{ff}$.

113 Bspe. für Druckgraphiken von 1791/92: BnF, ID/Cote: btv1b6948032d; BnF, ID/Cote: btv1b6948037g.

114 Eine (berühmte) Ausnahme hiervon ist die von dem französischen Medailleur Auguste Dupré entworfene Vorderseite zu der von Benjamin Franklin ersonnenen Libertas-Americana-Medaille.

${ }^{115}$ Vgl. als frühes Beispiel die Radierung »La Liberté: patrone des répub.ns français indivisible et invincible« (BnF, ID/Cote: btv1b6950328b). Im Jahr 1795 fand der mit einer phrygischen Mütze bekleidete Kopf einer Frau durch Dupré Eingang in das französische Münzwesen (Abb.: BnF, ID/Cote: btv1b7700402s).

${ }^{116}$ Vgl. seinen Brief an Thomas Jefferson vom 14.2.1825, in: Founders Online, National Archives, 2017, http:// founders.archives.gov/documents/Jefferson/98-01-02-4960, in dem er diesbezügliche Fragen stellt.

${ }^{117}$ Schreiben vom 9.7.1834, abgedruckt in: Niles' Weekly Register, Bd. XLVI (1834), S. 448: »[...] the cap on our coins was not designed as the liberty cap. It was not introduced on the silver coins until about the year 1806, and was then copied from what was considered a handsome specimen of the female head dress of that day. On the gold coins a cap had been introduced from the first, which has certainly some resemblance to the usual form of the cap of liberty. I am, however, satisfied, from several considerations, and have indeed the direct assurance of Mr. Eckfeldt, the chief coiner, who has been familiar with the whole subject form the first, that it was not so intended. « Jefferson äußerte in seinem Antwortschreiben an Moore, dass die Libertas nicht mit dem pileus verbunden werden dürfe, weil die Amerikaner keine freigelassenen Sklaven seien (Brief vom 3.3.1825, in: Founders Online, National Archives, 2017, http://founders.archives.gov/documents/Jefferson/98-01-02-5013). Moore deutete diese Aussage in besagtem Schreiben vom 9.7.1834 dahingehend, dass Jefferson die der Tradition zuwiderlaufende Platzierung der Mütze auf dem Kopf für untunlich hielt.

${ }^{118}$ Ebd.: »The cap has by many been regarded as intended for the classic cap of liberty, and under this idea has received favor [...]. « In der Literatur wird in der Regel ebenfalls davon ausgegangen, dass es sich bei den Kopfbedeckungen um Freiheitsmützen handelt (siehe z. B. Cornelius Vermeulen, Numismatic Art in America, Cambridge [Mass.] 1971, S. 33, 35; James O. Sweeny, The Liberty Cap. Numismatic Symbol Sans Pareil, in: The Numismatist, Juli 1984, S. 1366, mit der apodiktischen Aussage, die Kopfbedeckung »[was] undoubtedly [...] intended to be a freedom cap «. 
dergeworfenen Libertas mit phrygischer Mütze auf dem Kopf zu Hilfe kommt (Abb. 42). Dies entsprach einer europäischen Entwicklung, die im Verlauf der ersten Hälfte des 19. Jahrhunderts in Frankreich zur zunehmenden Durchsetzung mützentragender Freiheits- und Republikpersonifikationen führte ${ }^{119}$ und ab den 1840er Jahren auch in anderen Ländern deren Gebrauch bewirkte ${ }^{120}$, um schließlich zu einer weitverbreiteten Darstellungsform zu werden ${ }^{121}$. In den Vereinigten Staaten setzte sich die auf dem Kopf getragene Freiheitsmütze im Verlauf der zweite Hälfte des 19. Jahrhunderts ebenfalls immer mehr durch und wurde, soweit ersichtlich, im frühen 20. Jahrhundert zur alleinigen Verwendungsweise des Attributs bei Personifikationen. ${ }^{122}$ Gleichzeitig nahm die Kopfbedeckung immer öfter die phrygische Form an, ${ }^{123}$ die erstmals im Frankreich der Großen Revolution mit der Freiheitsmütze in Verbindung gebracht worden war. ${ }^{124}$ Dies bedeutete zusammen mit der oben beschriebenen »Amerikanisierung« der personifizierten Freiheit durch ihre Verzierung mit dem Design der US-Flagge das Ende der aus dem 18. Jahrhundert stammenden »englischen« Libertas in den USA.

119 Diese Darstellungsweise hatte sich in Frankreich im Bereich der Druckgraphik bis zur Revolution von 1848/49 fast vollständig durchgesetzt (Bsp. für eine Ausnahme aus dieser Zeit: Germanisches Nationalmuseum [Hrsg.], 1848: Das Europa der Bilder, Bd. 1, Nürnberg 1998, S. 203); auf Medaillen kam die Mütze auf einer Stange noch etwas öfter vor (Bspe. in: Jean-Pierre Collignon, Médailles politiques et satiriques, décorations et insignes de la $2^{\mathrm{e}}$ République française, 1848-1852, Paris u. a. 1984, Abb. 1848-7 ff., 1848-16 f.).

${ }^{120}$ Etwa in Italien; vgl. die Beispiele in: Germanisches Nationalmuseum, 1848 (Fn. 119), S. 82, 158, sowie in: Giovanni Spadolini, L'Italia repubblica, Rom 1988, S. 169, 175.

${ }^{121}$ So wurde in Großbritannien die dort geradezu ikonische Repräsentation der Freiheit mit einer mützenbewehrten Stange in der zweiten Hälfte des 19. Jahrhunderts in Cartoons des Punch oder in der sozialistischen Kunst von Walter Crane vollständig von mützentragenden allegorischen Figuren verdrängt (hierzu Zeiler, Visuelle Repräsentation [Fn. 5]), und auch in der deutschen Arbeiterkunst wurde die aus der Französischen Revolution übernommene rote phrygische Mütze als Kennzeichen der Sozialdemokratie/des Sozialismus von Personifikationen stets auf dem Kopf getragen (hierzu in Bezug auf Bildsatiren Frank Zeiler, Der »bonnet rouge« im Wahren $J a c o b$. Erscheinungsformen und Verwendungsweisen eines revolutionären Freiheitssymbols in einem sozialdemokratischen Satiremagazin zur Zeit des Kaiserreichs und der Weimarer Republik, 2016, http://www.freidok. uni-freiburg.de/data/ 11161).

${ }^{122}$ Beispiele aus dem Bereich der Staatsrepräsentation sind ein Mosaik von Kenyon Cox im Wisconsin State Capitol in Madison) sowie Wandgemälde von Edwin Blashfield in der Kuppel ebenda und in den Gerichtsgebäuden von Youngstown (Oh.) und Baltimore (Md.) (vgl. hierzu Anne E. Samuel, Vision Conceptualized in the American Renaissance Murals of Edwin Howland Blashfield, Diss. phil. Univ. of Delaware 2007, mit Abbildungen auf den S. 215, 228, 394, 537). Für weitere Beispiele vgl. die in Fn. 100 angeführten Bilder.

${ }_{123}$ Dies bildet wiederum eine Parallele zu europäischen Ländern, in denen die Freiheitsmütze in der zweiten Hälfte des 19. und im frühen 20. Jahrhundert ebenfalls meist in phrygischer Gestalt erschien (vgl. für Großbritannien und Deutschland Fn. 121; für Frankreich siehe z. B. die Abbildungen in: Marie-Louise von Plessen [Hrsg.], Marianne und Germania 1789-1889, Berlin o. J. [1996]) . In den Niederlanden trat im 19. Jahrhundert dagegen weiterhin der dort traditionell verwendete Freiheitshut auf (für Beispiele siehe Fn. 34).

${ }^{124}$ In der Literatur wird die Freiheitsmütze oft generell als phrygische Mütze bezeichnet. Dieser Sprachgebrauch ist unpräzise; die phrygische Mütze ist eine Kopfbedeckung, die durch eine umgeklappte Spitze charakterisiert ist. Diese Form weist die Freiheitsmütze weder in niederländischen noch in englischen oder amerikanischen Druckgraphiken aus der Zeit vor der Französischen Revolution auf. In Frankreich kamen Mützen mit gebogener Spitze in der revolutionären Bildpublizistik (zunächst vereinzelt) ab den Jahren 1789/90 vor, z. B. in der Graphik »Projet de l'étendart de la liberté, à l'imitation de celui des Romains« (BnF, ID/Cote: btv1b69429065) und auf einigen Medaillen (Bspe.: Hennin, Histoire Numismatique [Fn. 111], Nr. 60, 74, 126). Als Beispiel für eine einschlägige Münze siehe Abb. 8. 
Anmerkung: Dieser Beitrag fand in seiner Entstehungsphase als Typoskript in Teilen Verwendung bei der Abfassung von Thomas Würtenberger, Symbole der Freiheit. $\mathrm{Zu}$ den Wurzeln westlicher politischer Kultur, Wien/Köln/Weimar 2017. 


\section{Abbildungen}

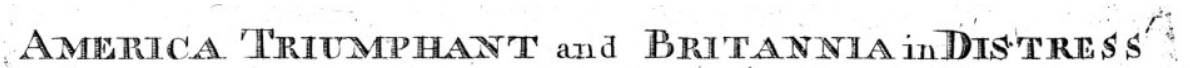

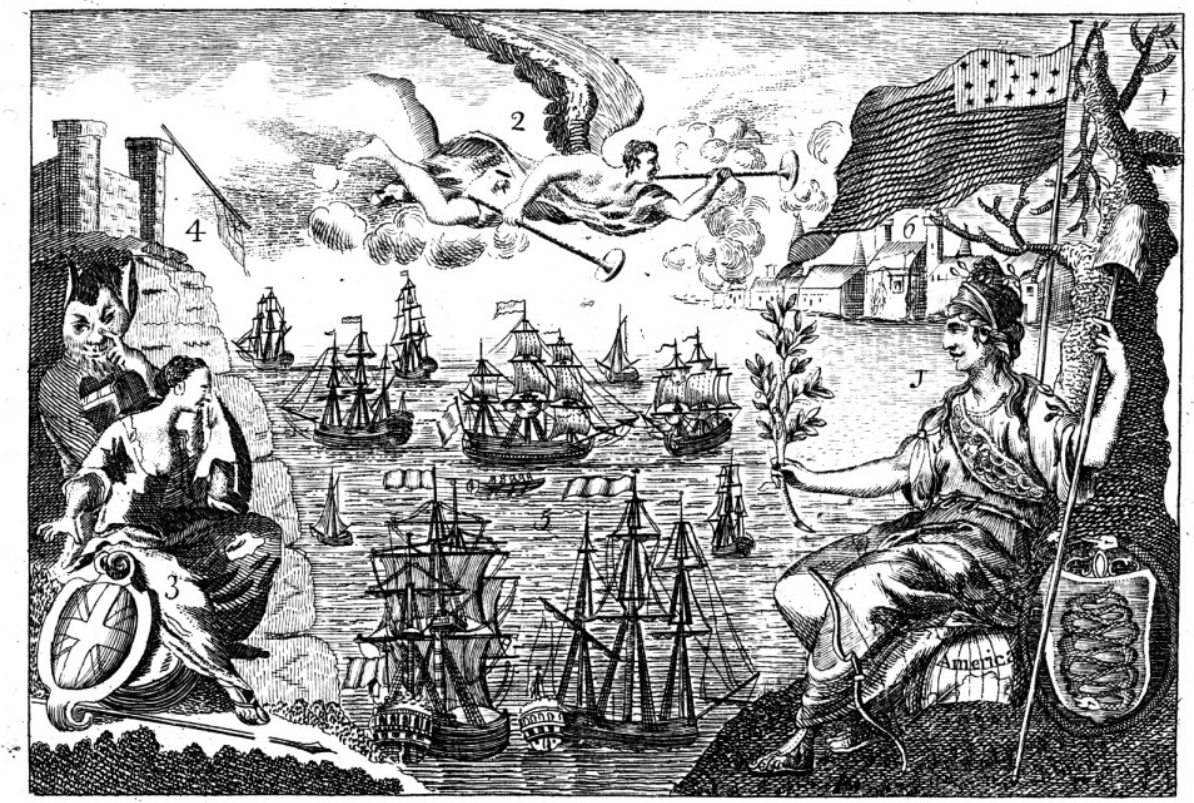

EXPI, $\mathbb{N} \mathbb{N} T I O \mathbb{N}$.

I America fitting on that quirter of the globe with thePlag III Britnnia weeping, at the lofs of the trade, of America, atten: of the United States difplayed over her head; holding in ided with an evil oenius.

one hand the Olive branch,inviting the fhips of all nations IV The Britim flag. ftruck, on lyer frong- Fortrefses.

to partake of her commerce; and in the other hand Pup $\quad V$ French, $S_{\text {panilh, Duth, ronlipping in the harbours of America. . }}$

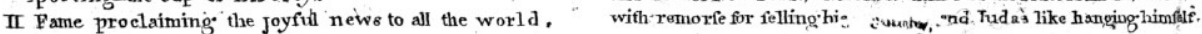

Abb. 1: America Triumphant and Britannia in Distress (1782), Library of Congress

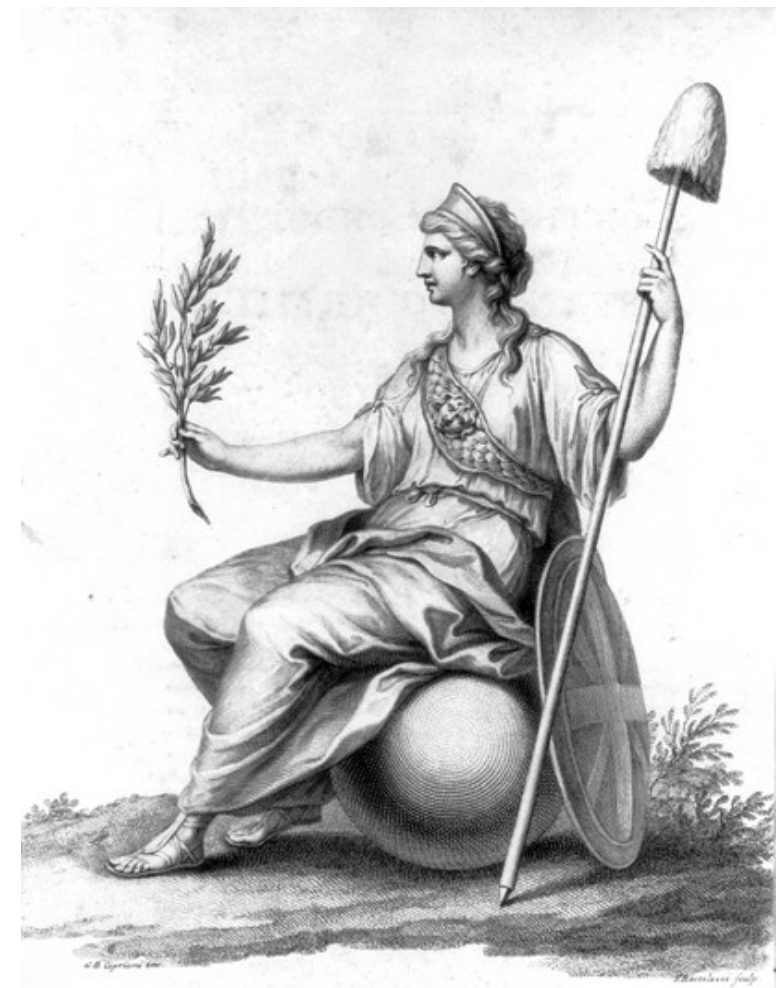

Abb. 2: G. B. Cipriani (inv.)/F. Bartolozzi (sculp.), Liberty or Britannia (1775), Library of Congress 


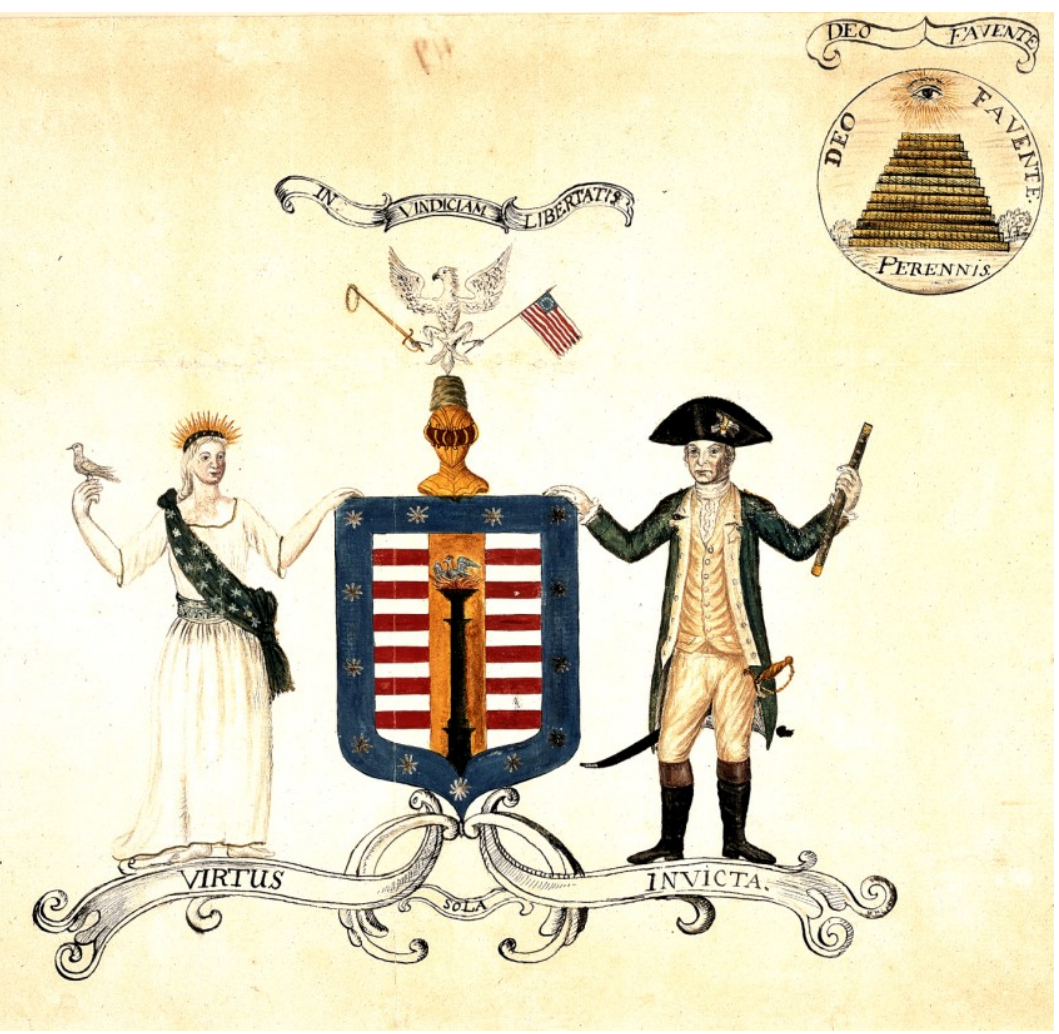

Abb. 3: Entwurf für die Vorderseite des Siegels der Union von 1782, National Archives and Records Administration

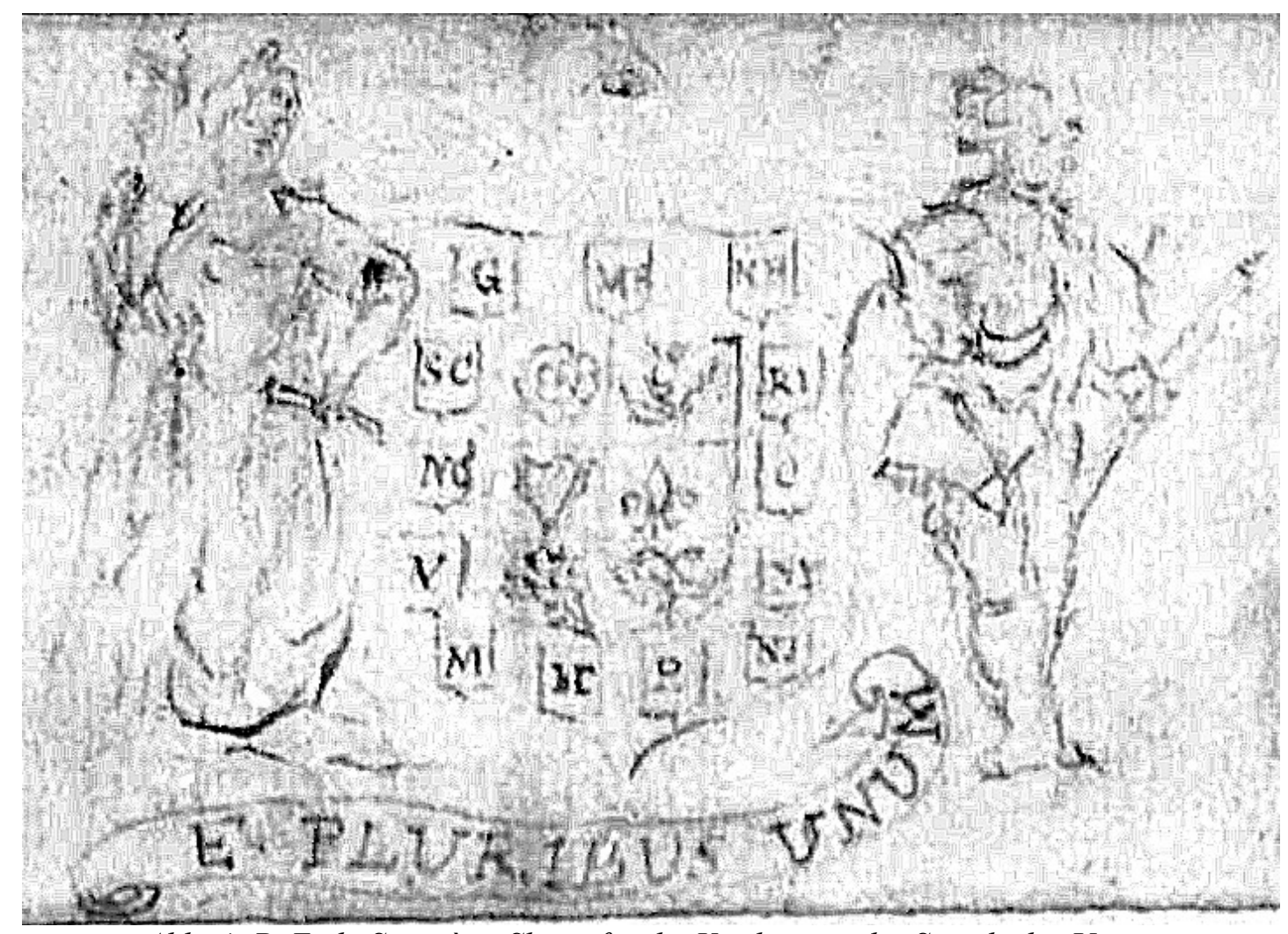

Abb. 4: P. E. du Simitière, Skizze für die Vorderseite des Siegels der Union von 1776, Library of Congress 

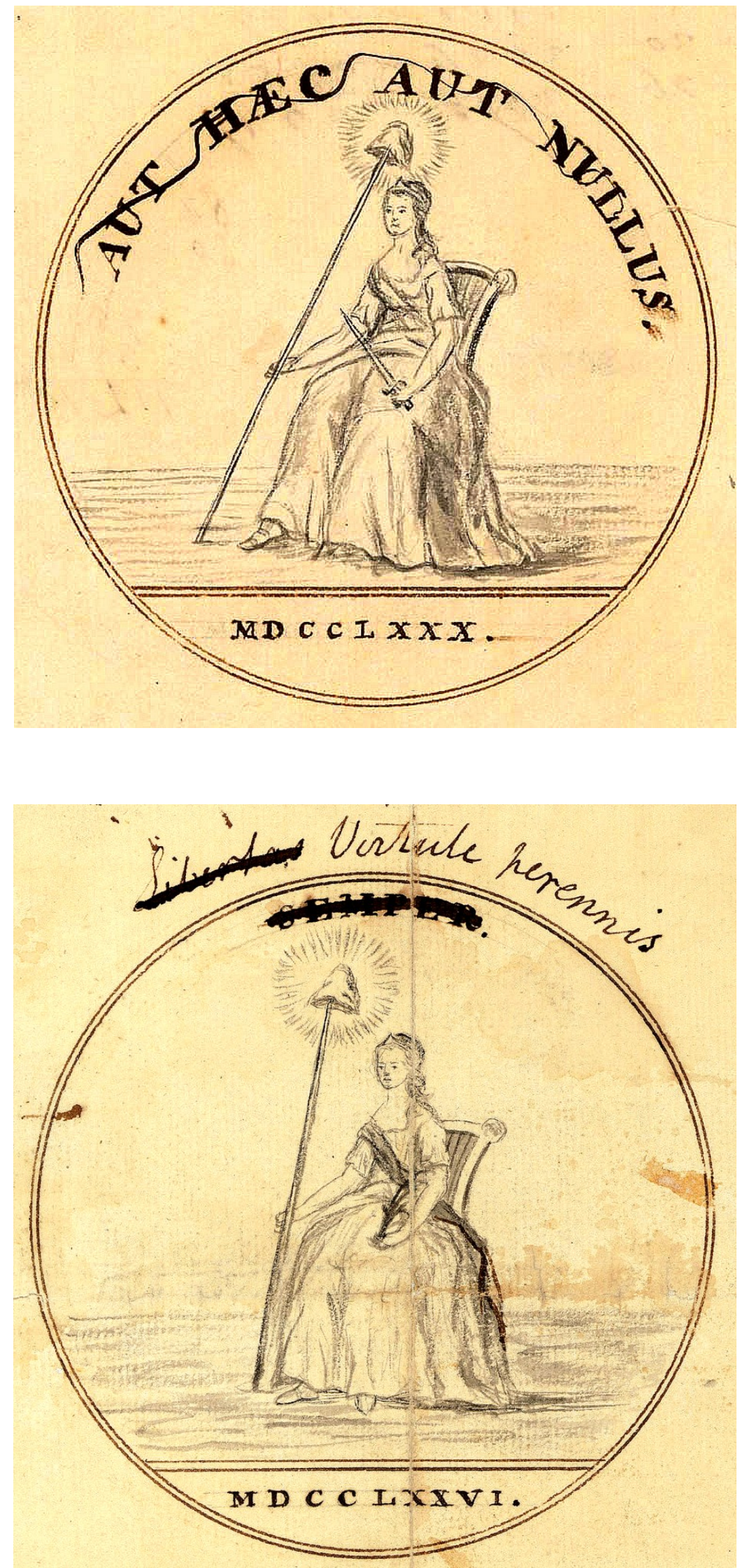

Abb. 5a, b: Erster und zweiter Entwurf für die Rückseite des Siegels der Union von 1780, National Archives and Records Administration 


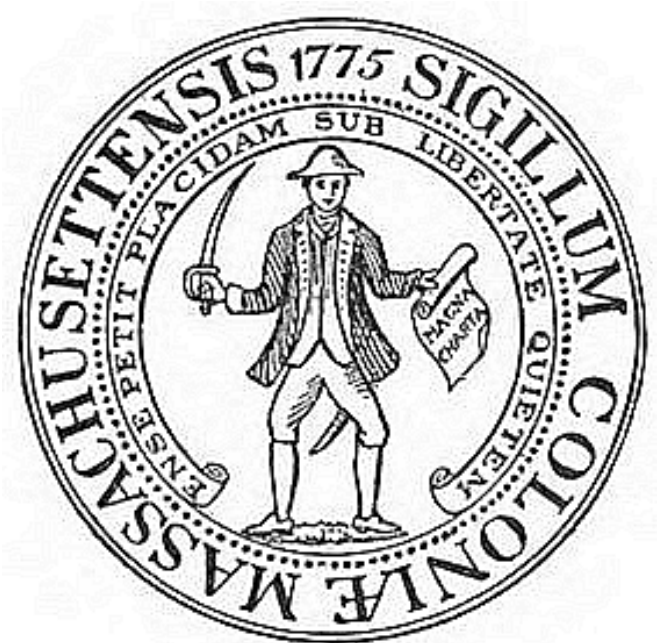

Abb. 6: Siegel von Massachusetts (1775), reproduziert aus: Eugene Zieber, Heraldry in America, Philadelphia (Pa.) 1895, S. 143

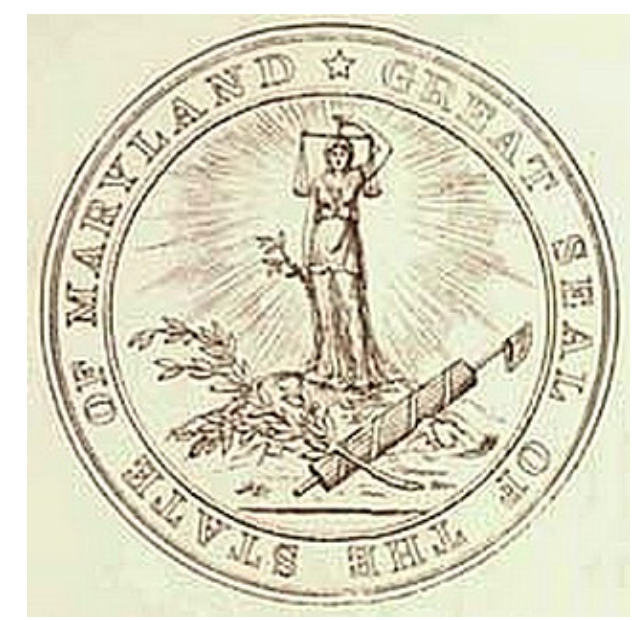

Abb. 7: Vorderseite des Siegels von Maryland (1794), Maryland State Archives

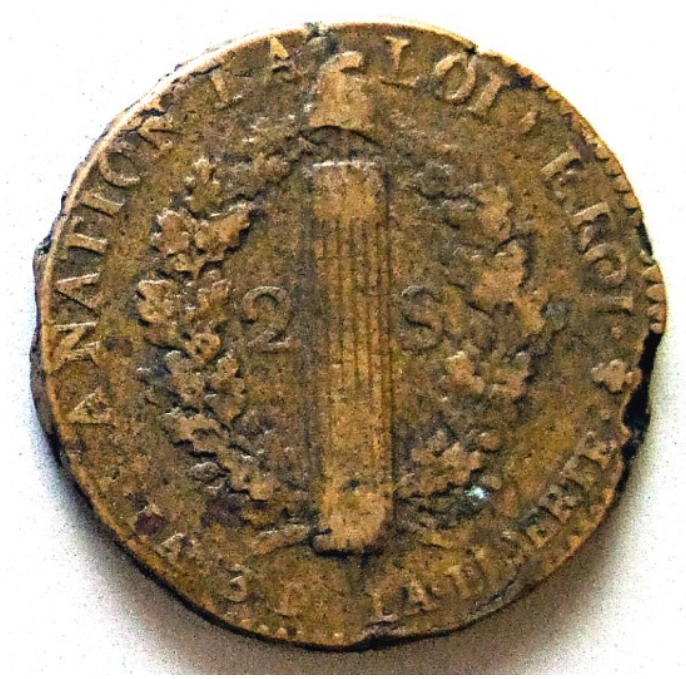

Abb. 8: 2-Sol-Münze (1793), Yale University Art Gallery 


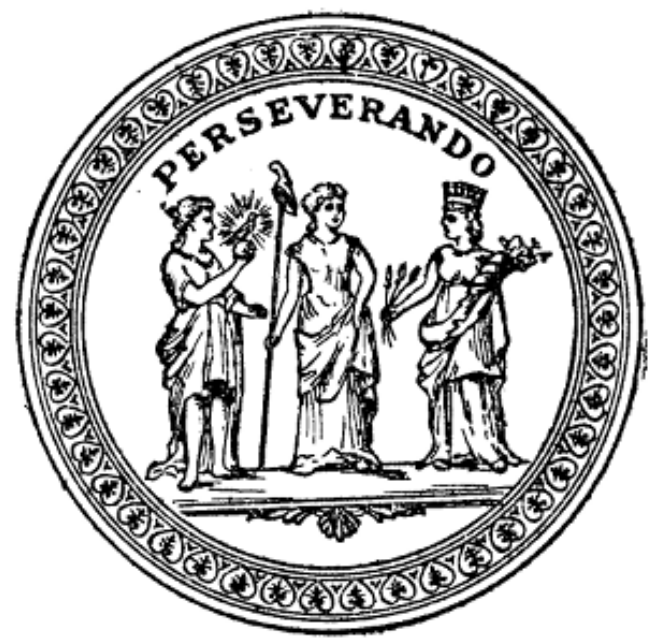

Abb. 9a: Rückseite des Siegels von Virginia (1776), reproduziert aus: Lyon G. Tyler, The Seal of Virginia, in: The William and Mary Quarterly, Bd. 3 (1894), S. 94

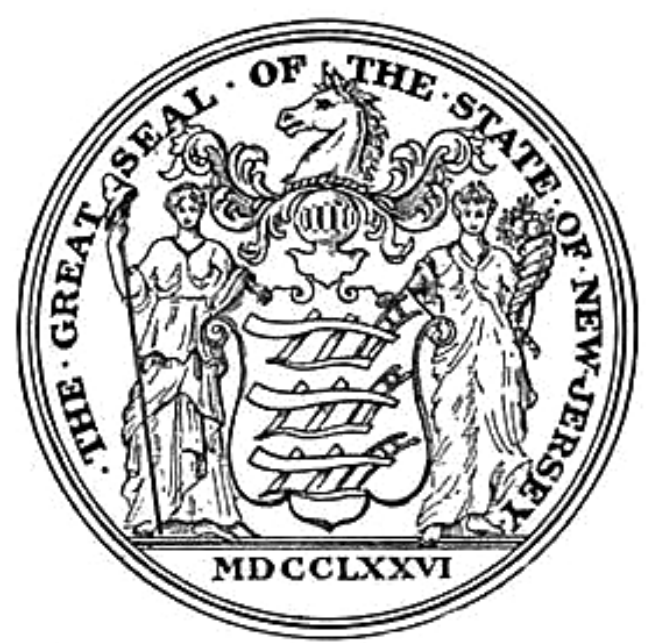

Abb. 9b: Siegel von New Jersey (1777)

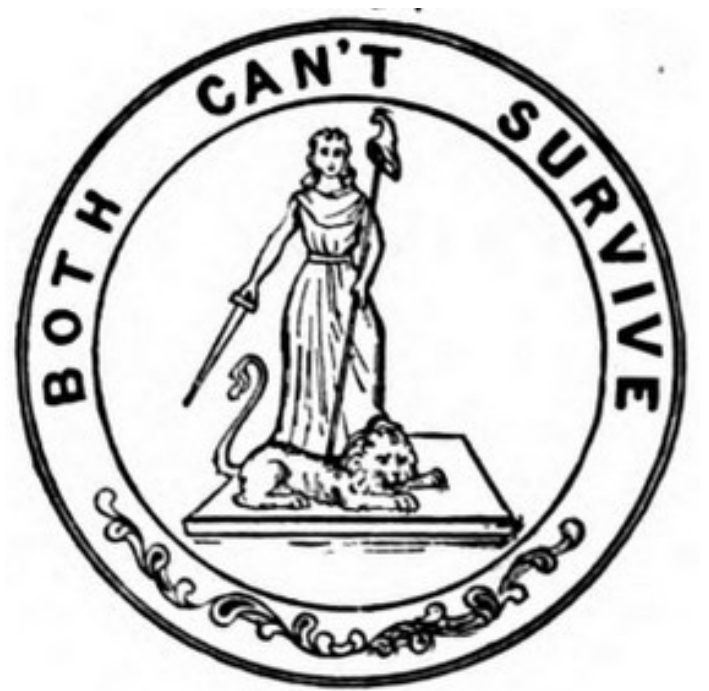

Abb. 9c: Rückseite des Siegels von Pennsylvania (1777) 


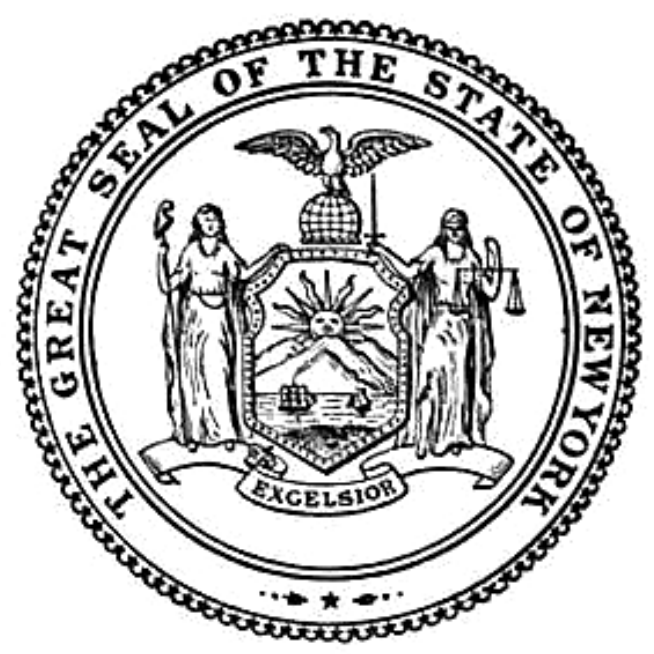

Abb. 9d: Siegel von New York (1778)

Abb. 9b-d reproduziert aus: Eugene Zieber, Heraldry in America, Philadelphia (Pa.) 1895, S. 159, 176, 166, 167

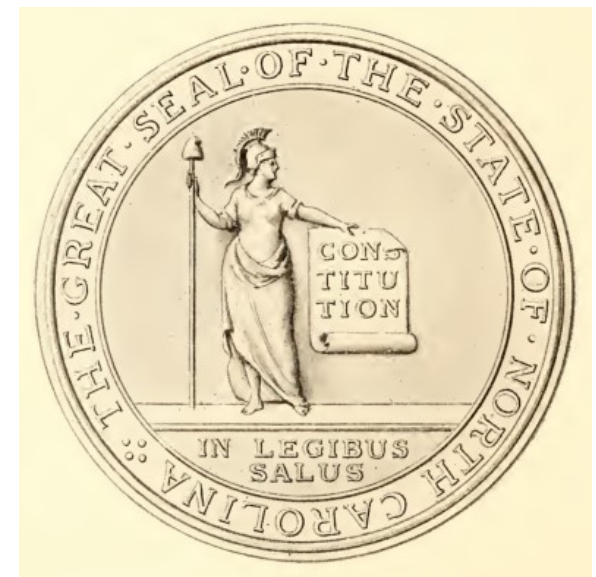

Abb. 9e: Siegel von North Carolina (1778), reproduziert aus: J. Bryan Grimes, The Great Seal of the State of North Carolina 1666-1909, Raleigh (N.C.) 1909, nach S. 8

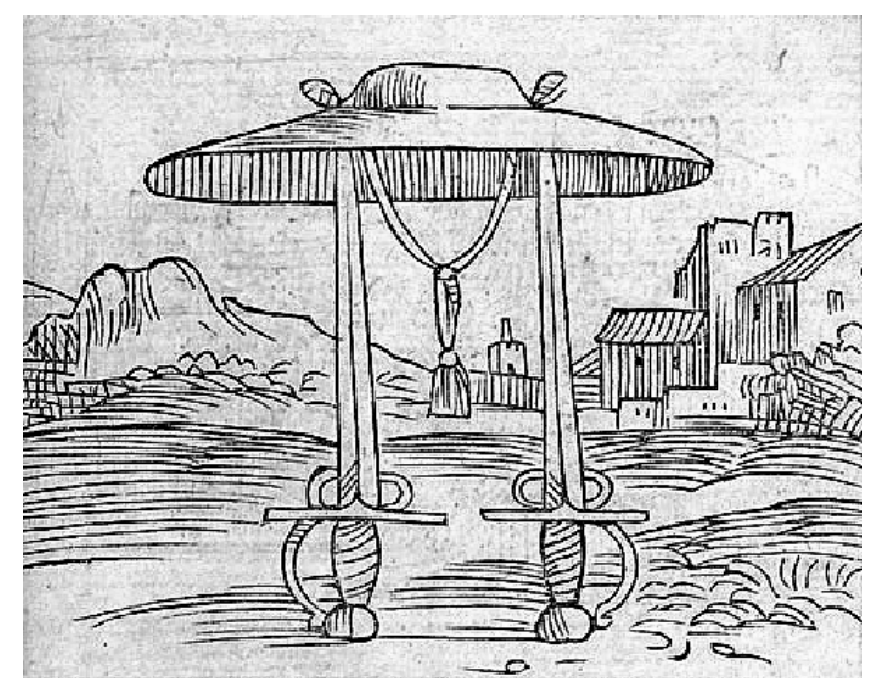

Abb. 10: A. Alciato, Emblematum libellus, Venedig 1546, S. 26 


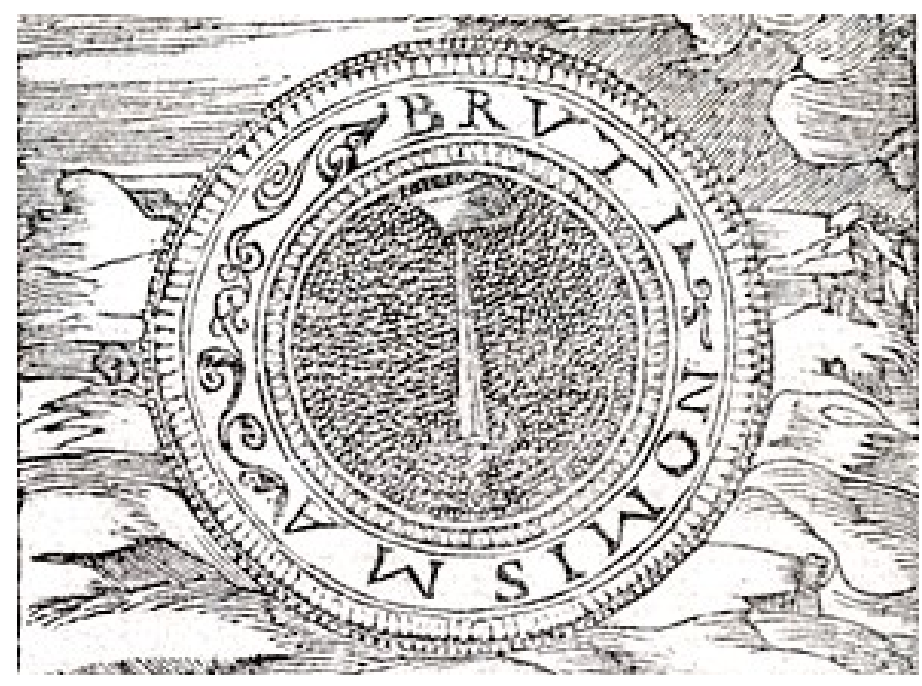

Abb. 11: Los emblemas de Alciato, Lyon 1549, S. 202
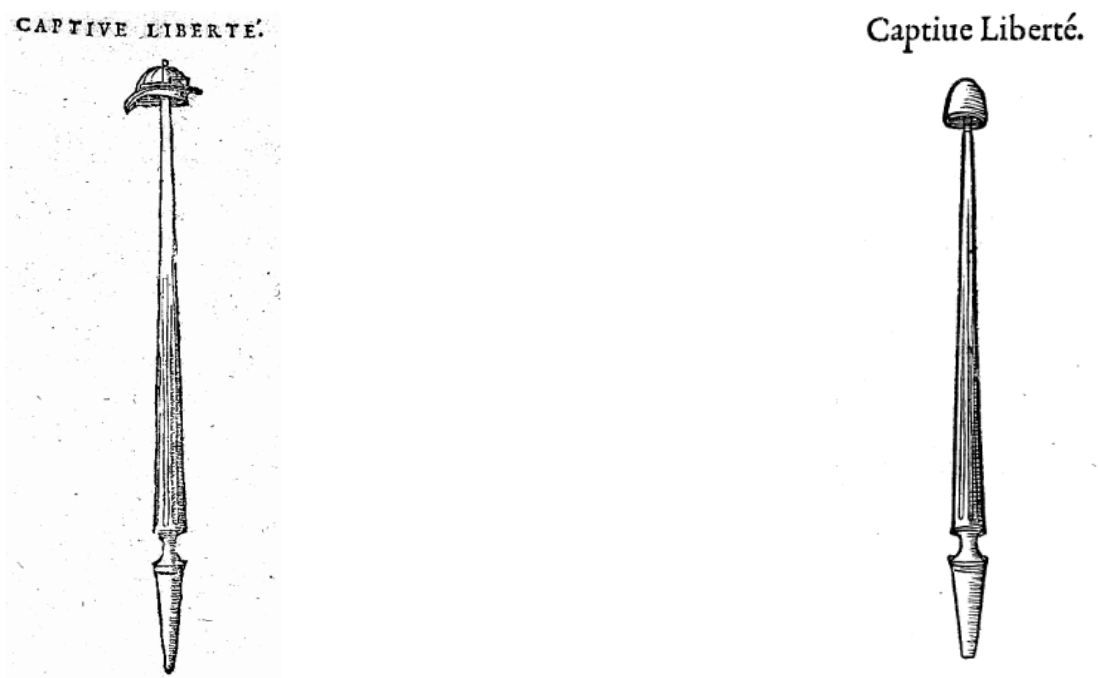

Abb. 12a: C. Paradin, Devises heroïques, Lyon 1551, S. 115
Abb. 12b: C. Paradin, Devises heroïques, Lyon 1557, S. 176

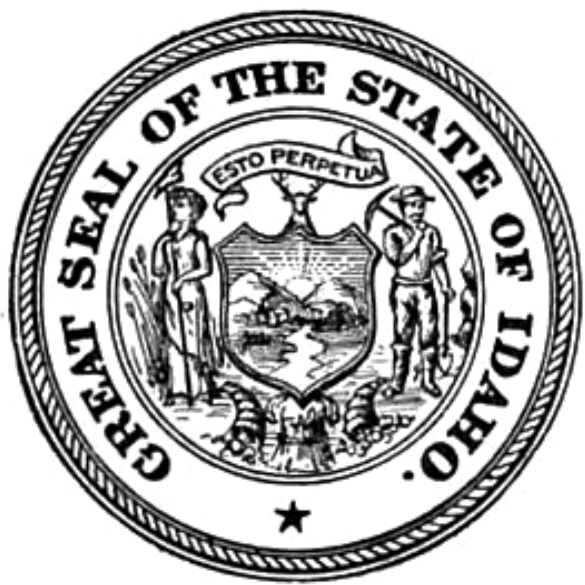

Abb. 13: Siegel von Idaho (1890), reproduziert aus: Eugene Zieber, Heraldry in America, Philadelphia (Pa.) 1895, S. 127 


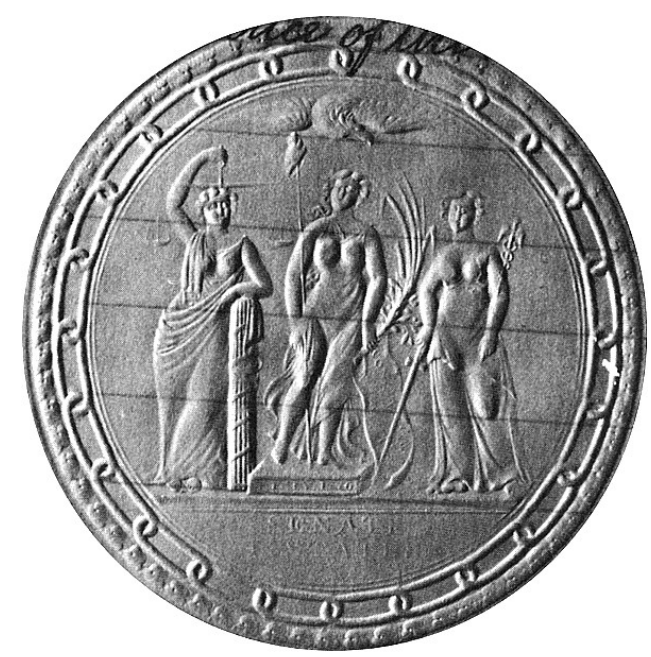

Abb. 14: Siegel des US-Senats (1831), Wikimedia Commons

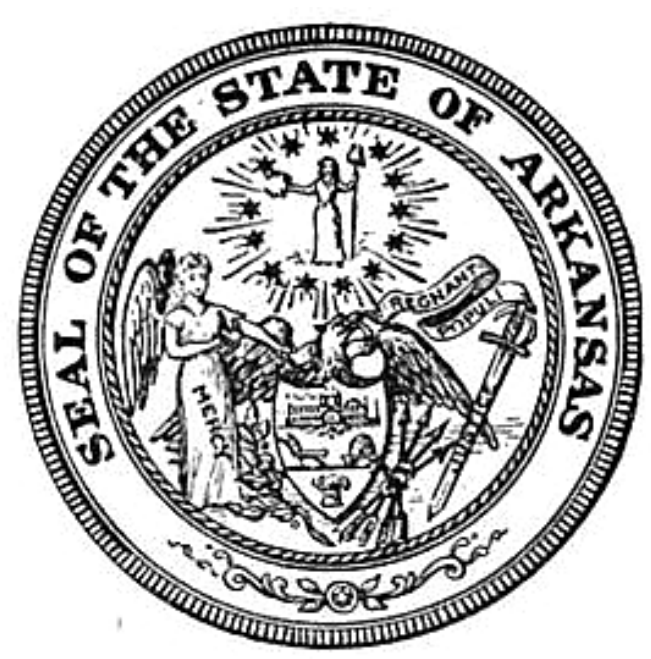

Abb. 15: Siegel von Arkansas (1832)

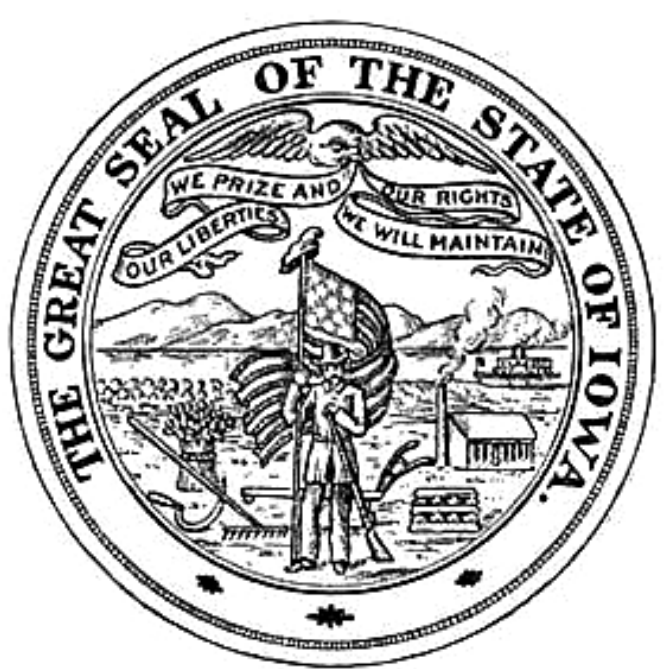

Abb. 16: Siegel von Iowa (1847) 


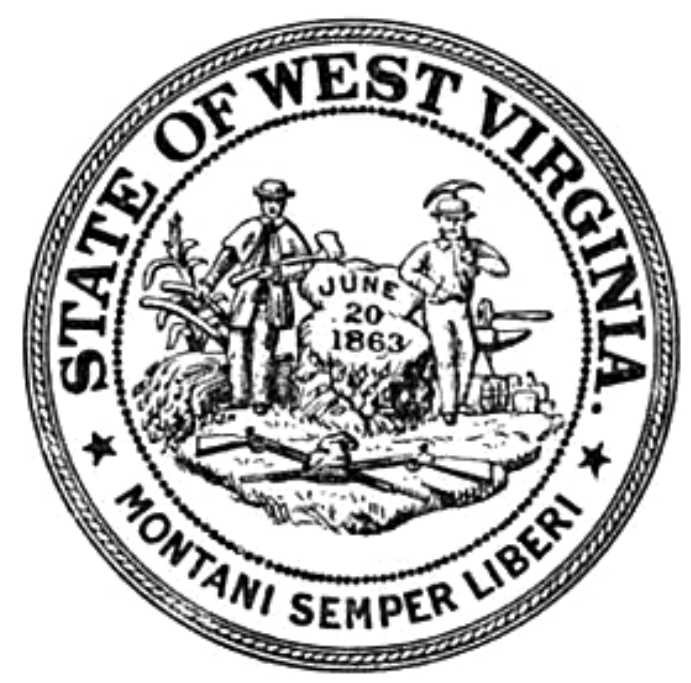

Abb. 17: Siegel von West Virginia (1863)

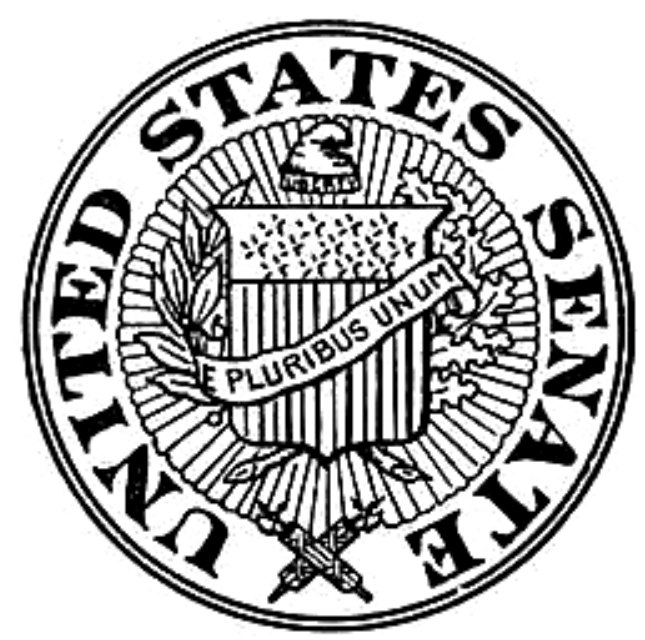

Abb. 18: Siegel des US-Senats (1880)

Abb. 15-18 reproduziert aus: Eugene Zieber, Heraldry in America, Philadelphia (Pa.) 1895, S. 113, 131, 193, 107

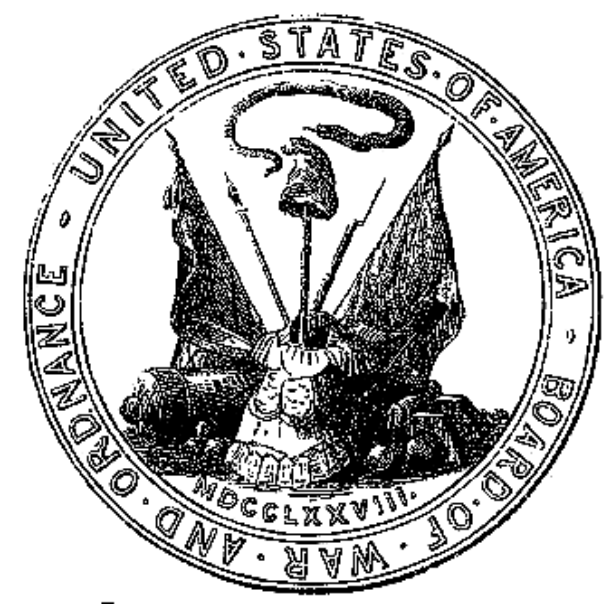

Abb. 19: Siegel des »Board of War and Ordnance« (1778), reproduziert aus: Benson J. Lossing, The Pictorial Field-Book of the Revolution, Bd. 2, New York (N.Y.) 1852, S. 868 

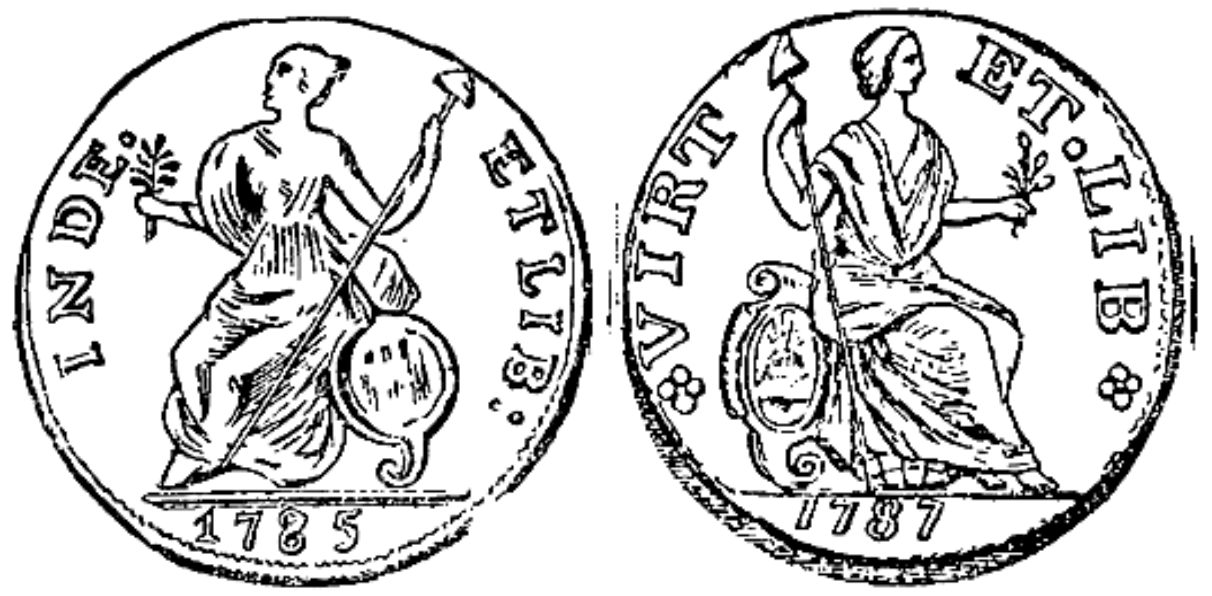

Abb. 20a, b: Münzen aus Connecticut (1785) und New York (1787), reproduziert aus:

J. W. Scott's standard coin catalogue no. 2, New York (N.Y.) 1913, S. 20, 23

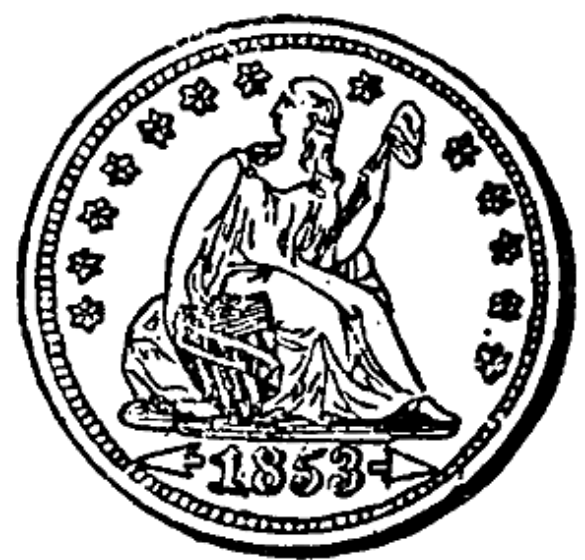

Abb. 21: Quarter Dollar (1853), reproduziert aus: J. W. Scott's standard coin catalogue no. 1, New York (N.Y.) 1906, S. 22

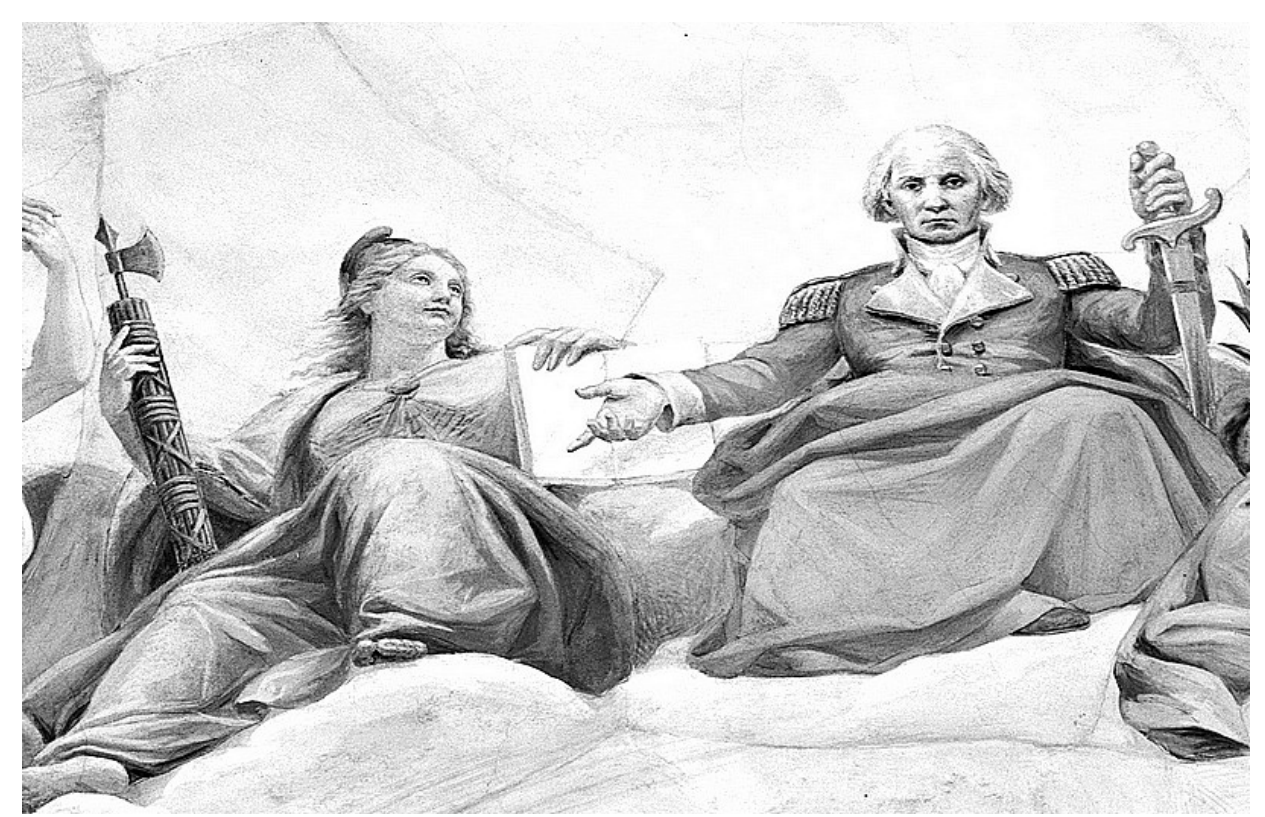

Abb. 22: C. Brumidi, The Apotheosis of Washington (1865), Library of Congress (Ausschnitt) 

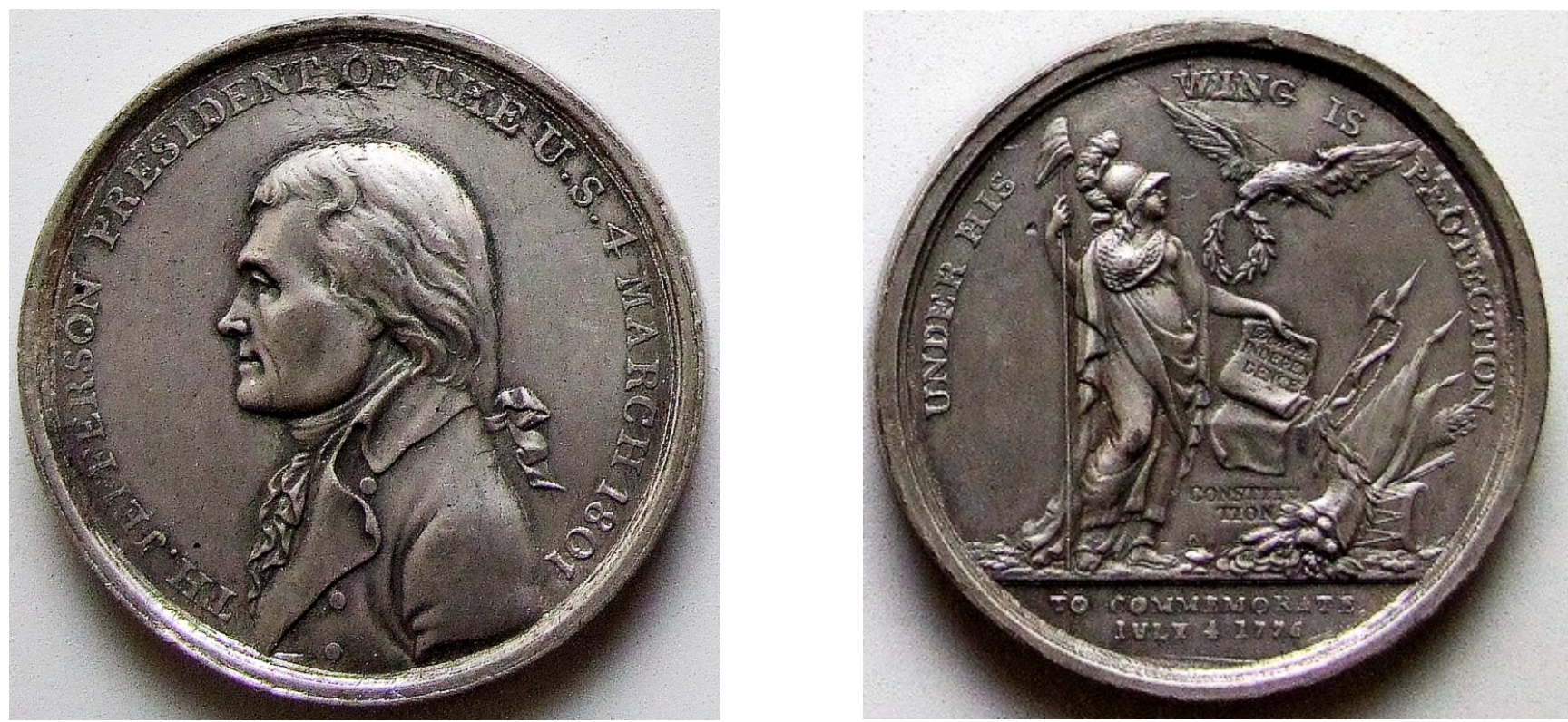

Abb. 23: J. Reich, Gedenkmedaille zur Amtseinführung von Thomas Jefferson (1801), Yale University Art Gallery

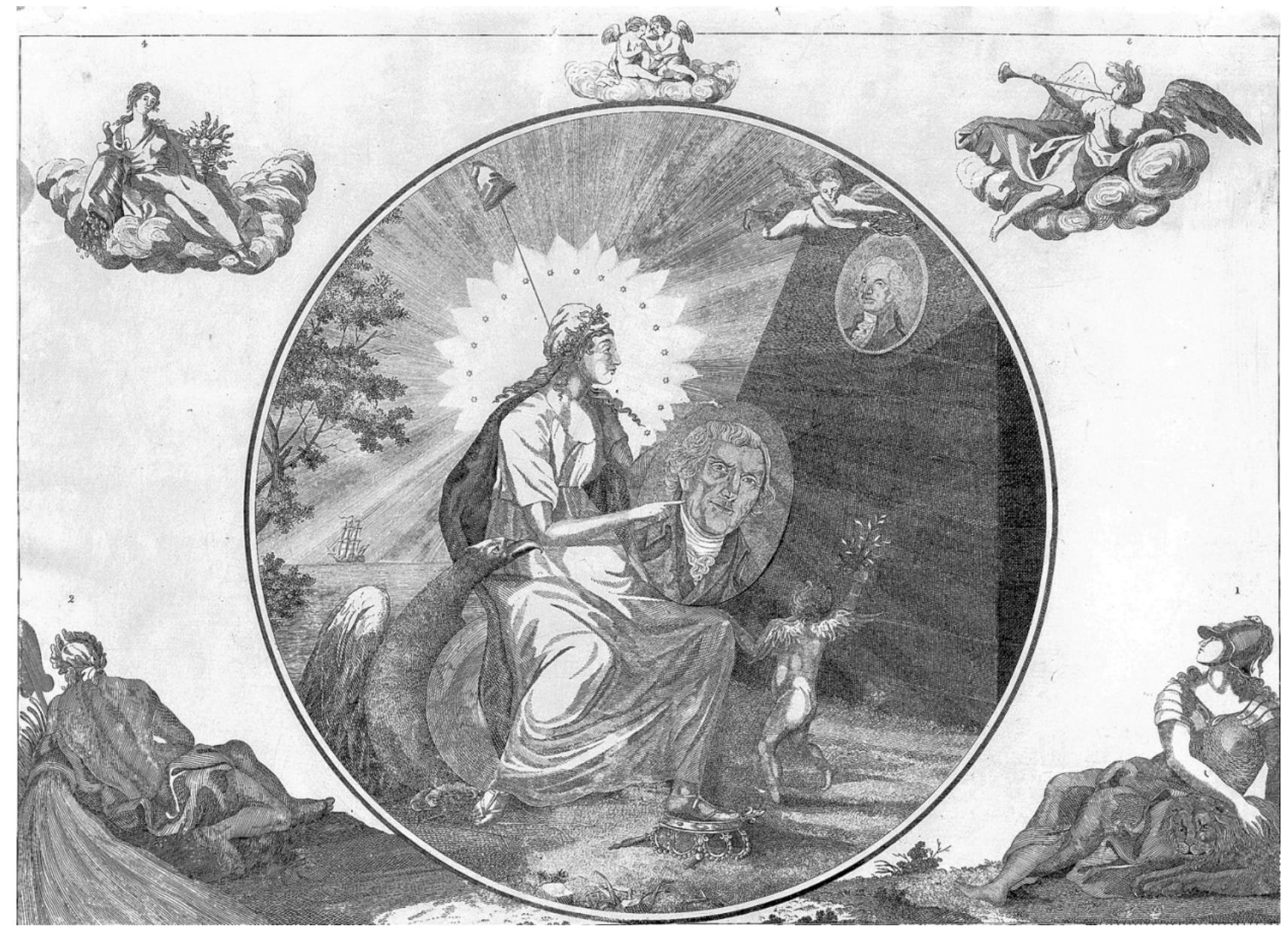

Abb. 24: H. Dean, Allegorisches Portrait von Thomas Jefferson (1807), Yale University Art Gallery 


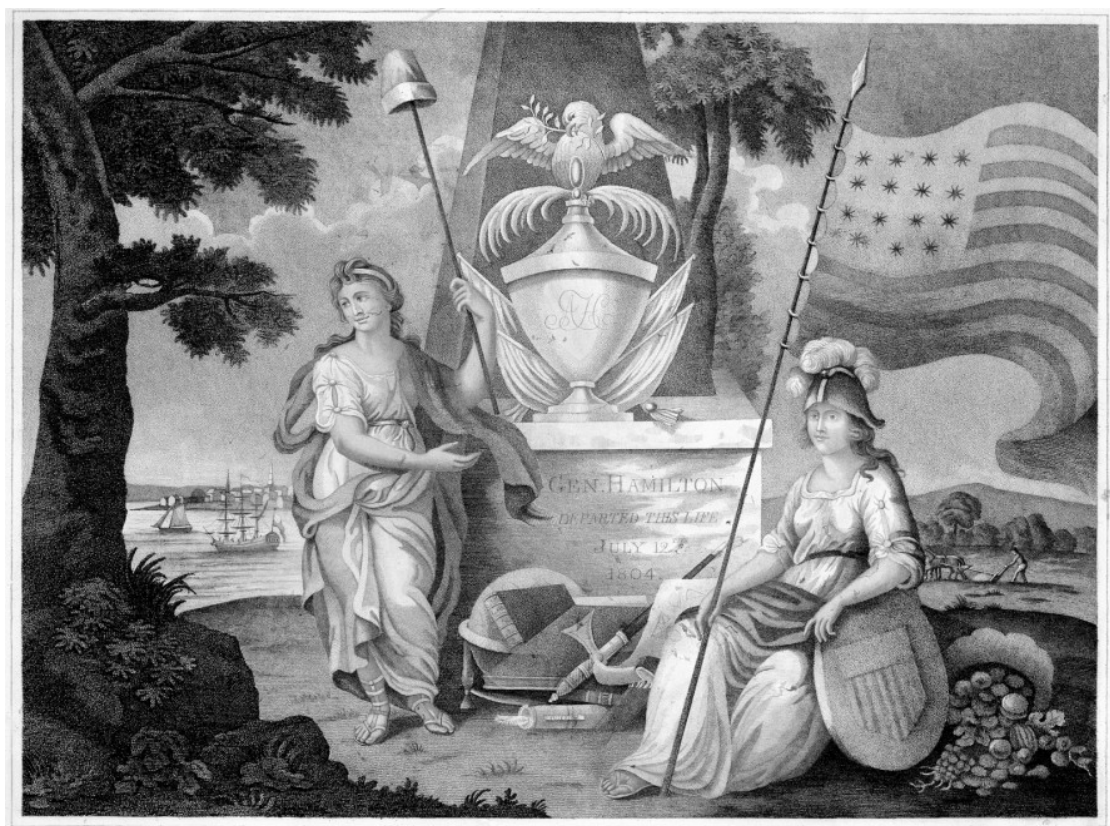

CONSECRITED wh MEMORY GEY.ATEATNDER IIAMILTON

Abb. 25: J. Scoles (sculp.), Consecrated to the Memory of Gen. Alexander Hamilton (ca. 1804), Library of Congress

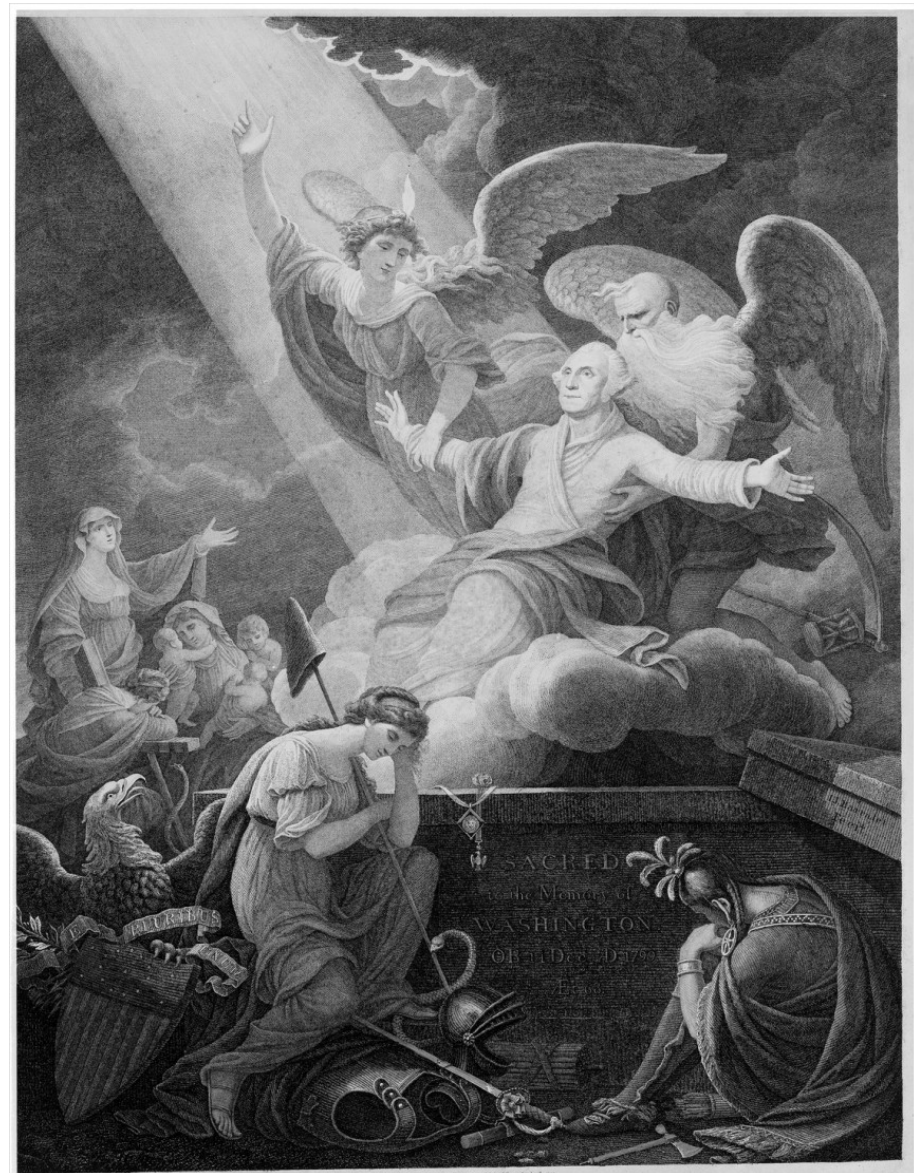

Abb. 26: J. J. Barralet, Apotheosis of Washington (1802), The Metropolitan Museum of Art 


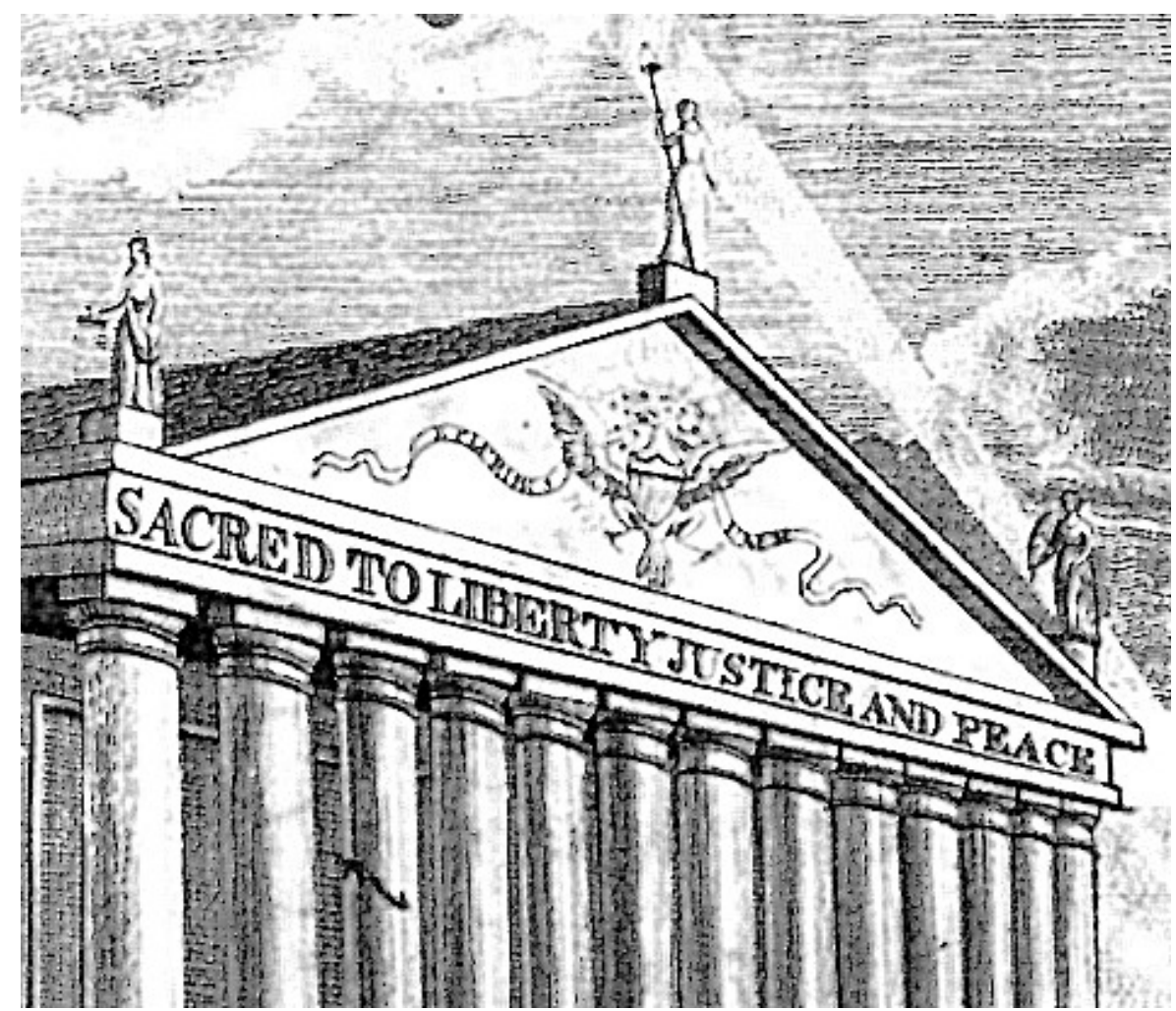

Abb. 27: J. Trenchard, Frontispiz zu »Columbian Magazine« (1788), Library of Congress (Ausschnitt)

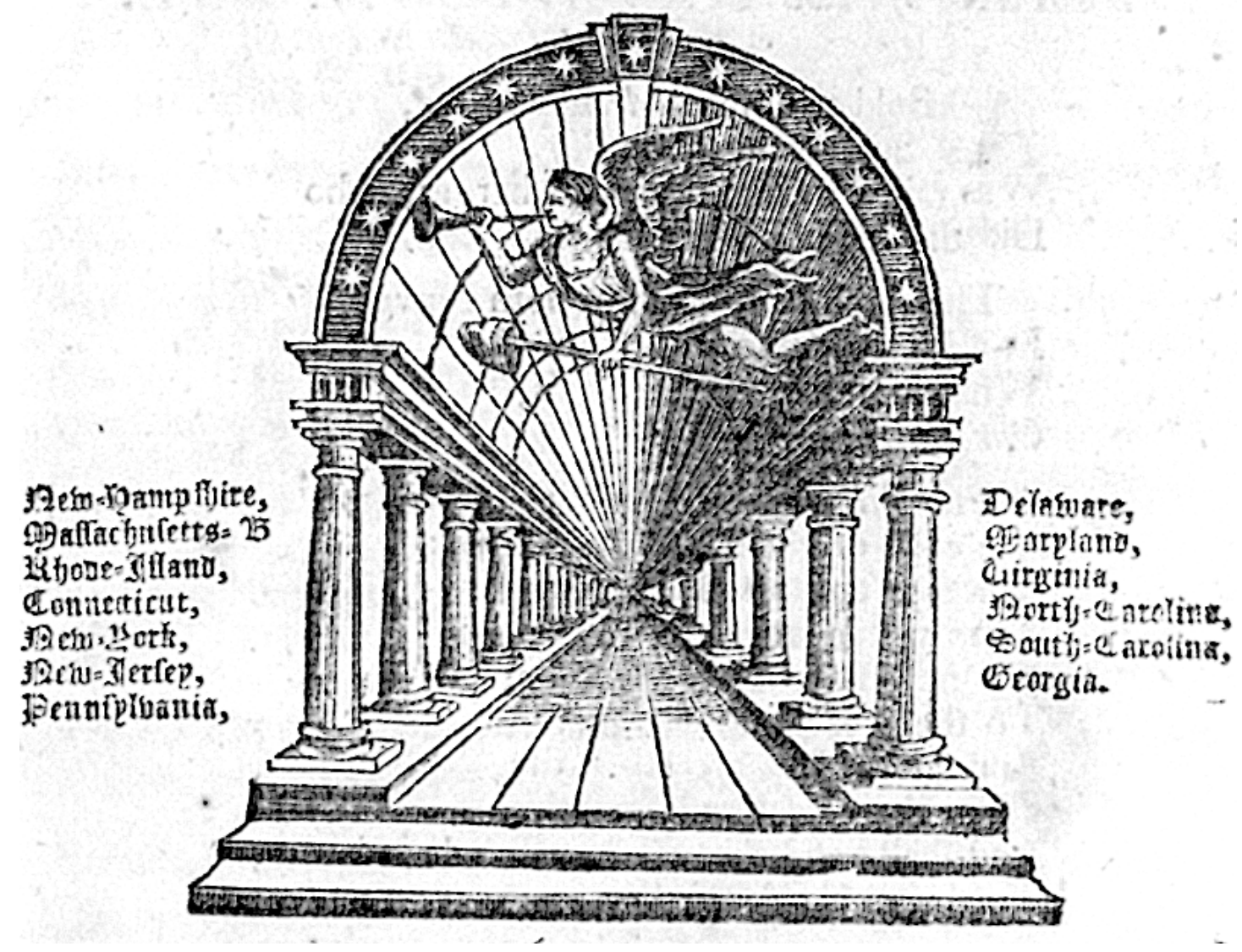

Abb. 28: Frontispiz zu »The United States Magazine« (1779), Library of Congress 


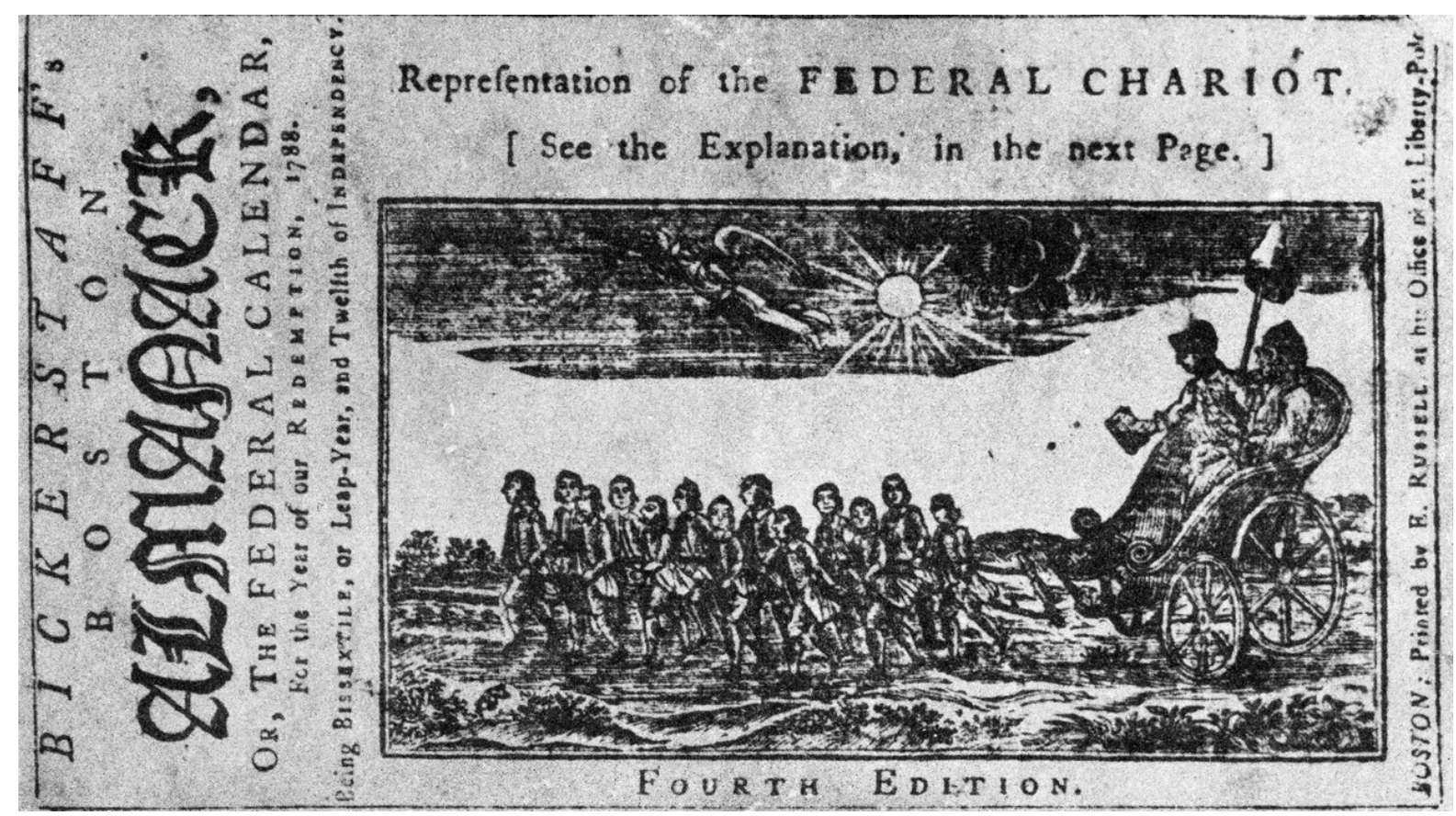

Abb. 29: Frontispiz zu »Bickerstaff's Boston Almanack« (1787), reproduziert aus:

William Murrell, A History of American Graphic Humor, Bd. 1, New York (N.Y.) 1933, S. 35

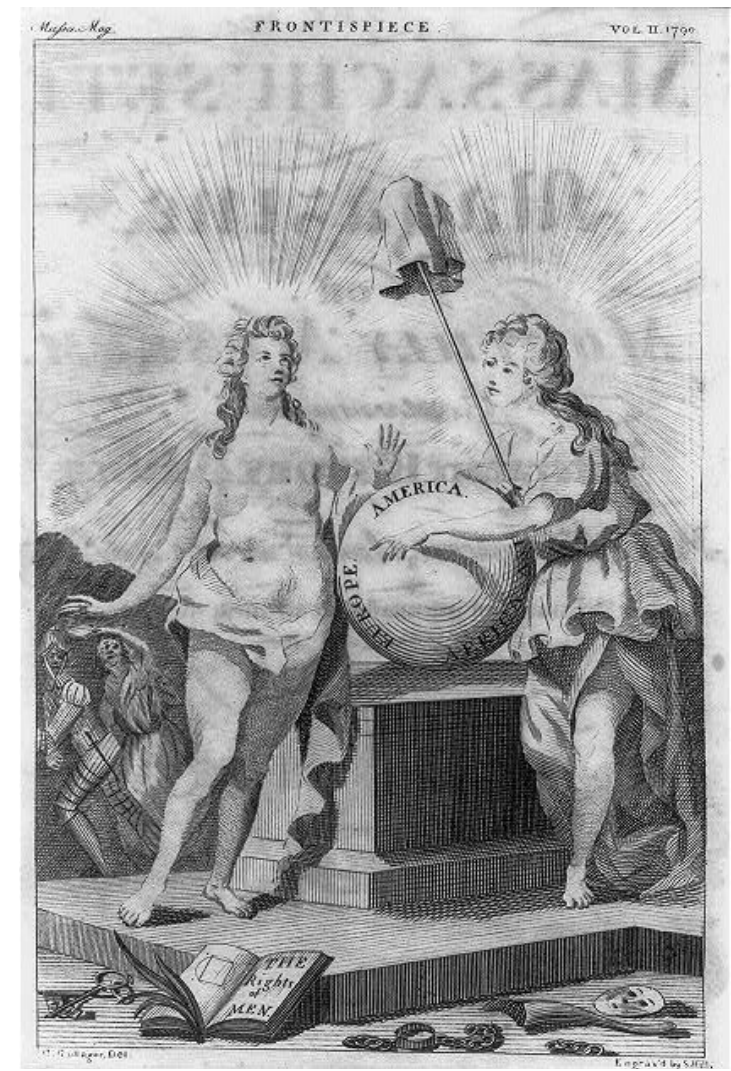

Abb. 30: Frontispiz zu »Massachusetts magazine» (1790), Library of Congress 


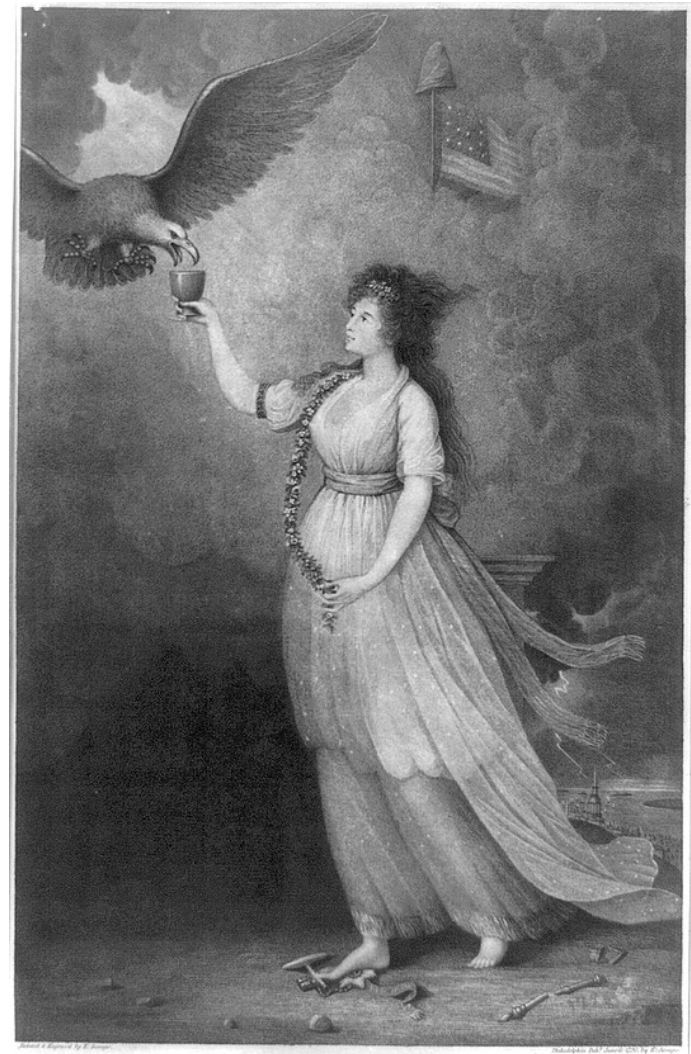

Abb. 31: E. Savage, Liberty (1796), Library of Congress

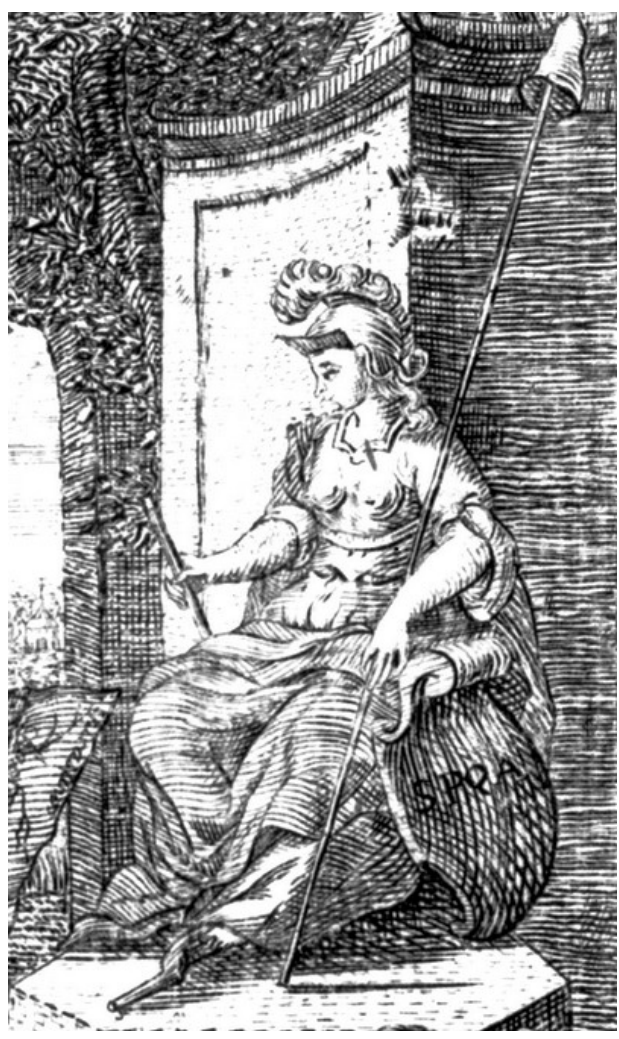

Abb. 32: Frontispiz zu B. Romans, A concise natural history of East and West Florida (1775), Library of Congress (Ausschnitt) 


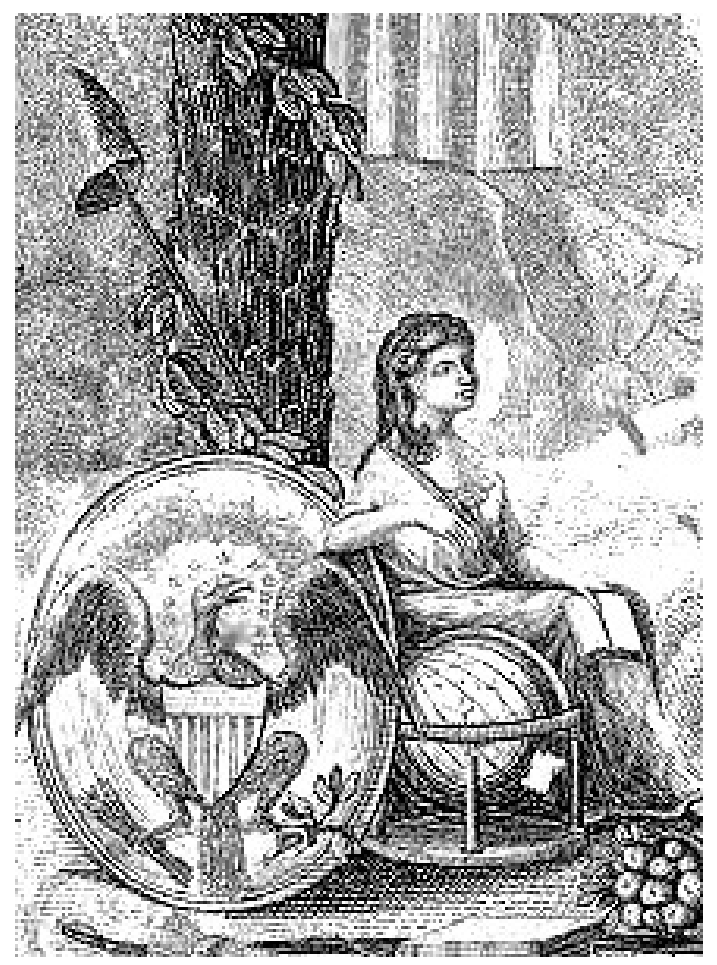

Abb. 33: Frontispiz zu »Columbian magazine» (1789), Library of Congress (Ausschnitt)

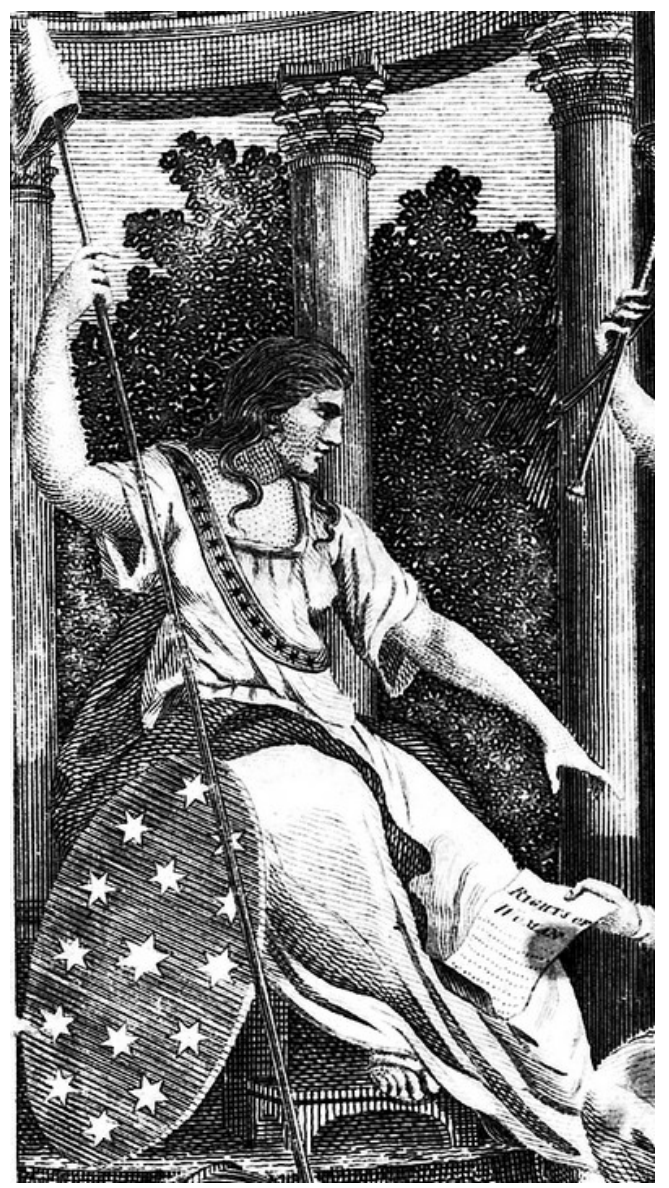

Abb. 34: Frontispiz zu »Ladies Magazine and Repository of Entertaining Knowledge« (1792), Library of Congress (Ausschnitt) 


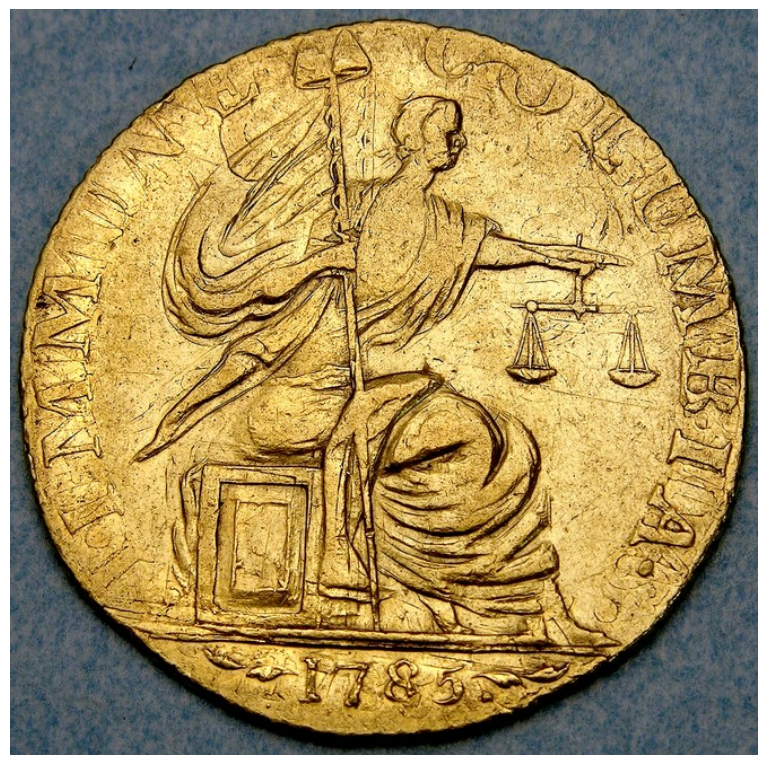

Abb. 35: »Immune Columbia«-Münze (1785), National Numismatic Collection, National Museum of American History ${ }^{125}$

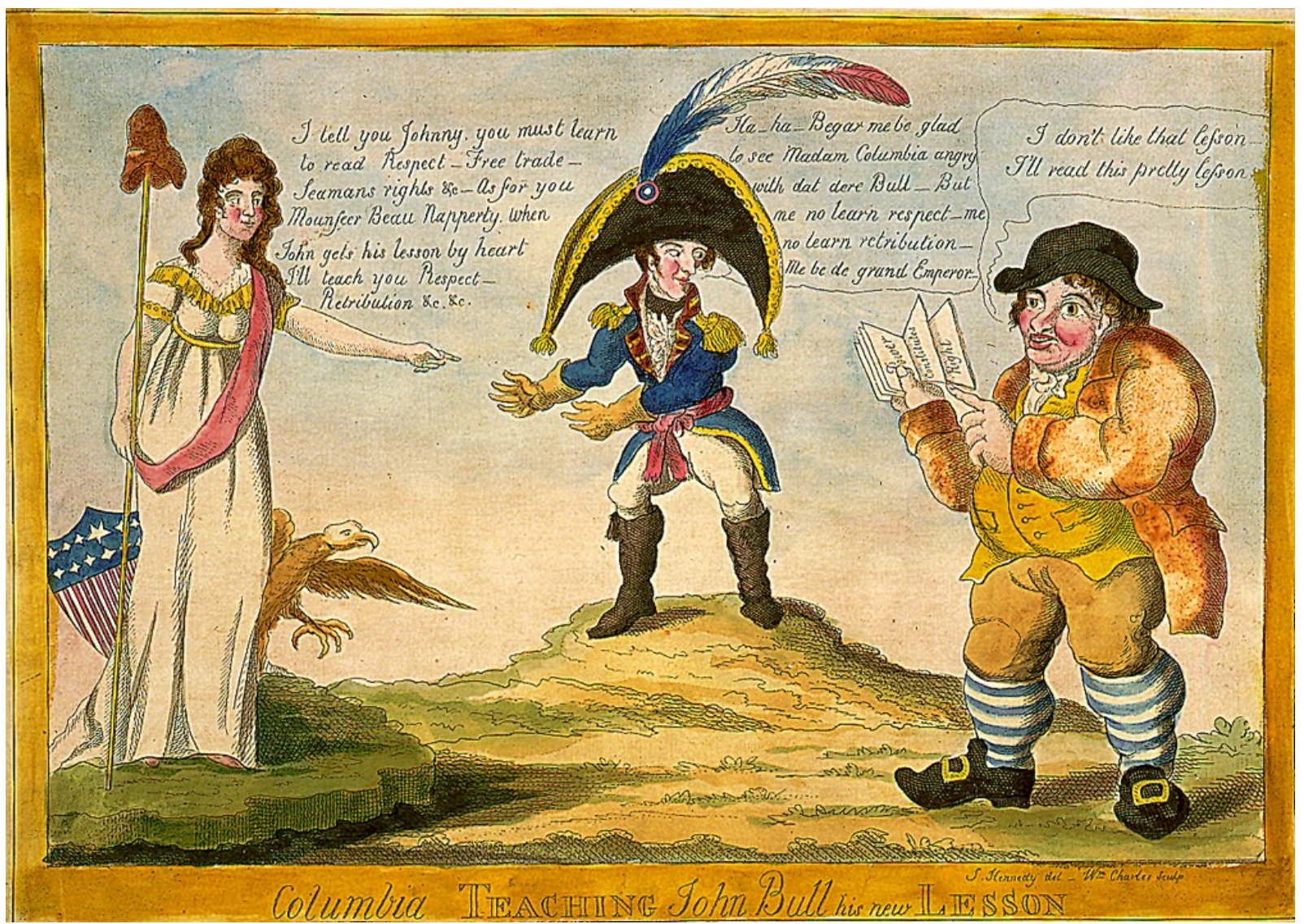

Abb. 36: S. Kennedy (del.)/W. Charles (sculp.),Columbia Teaching John Bull his new Lesson (ca. 1813), Library of Congress

${ }^{125} \mathrm{Http} / / /$ americanhistory.si.edu/collections/search/object/nmah_1094990. 


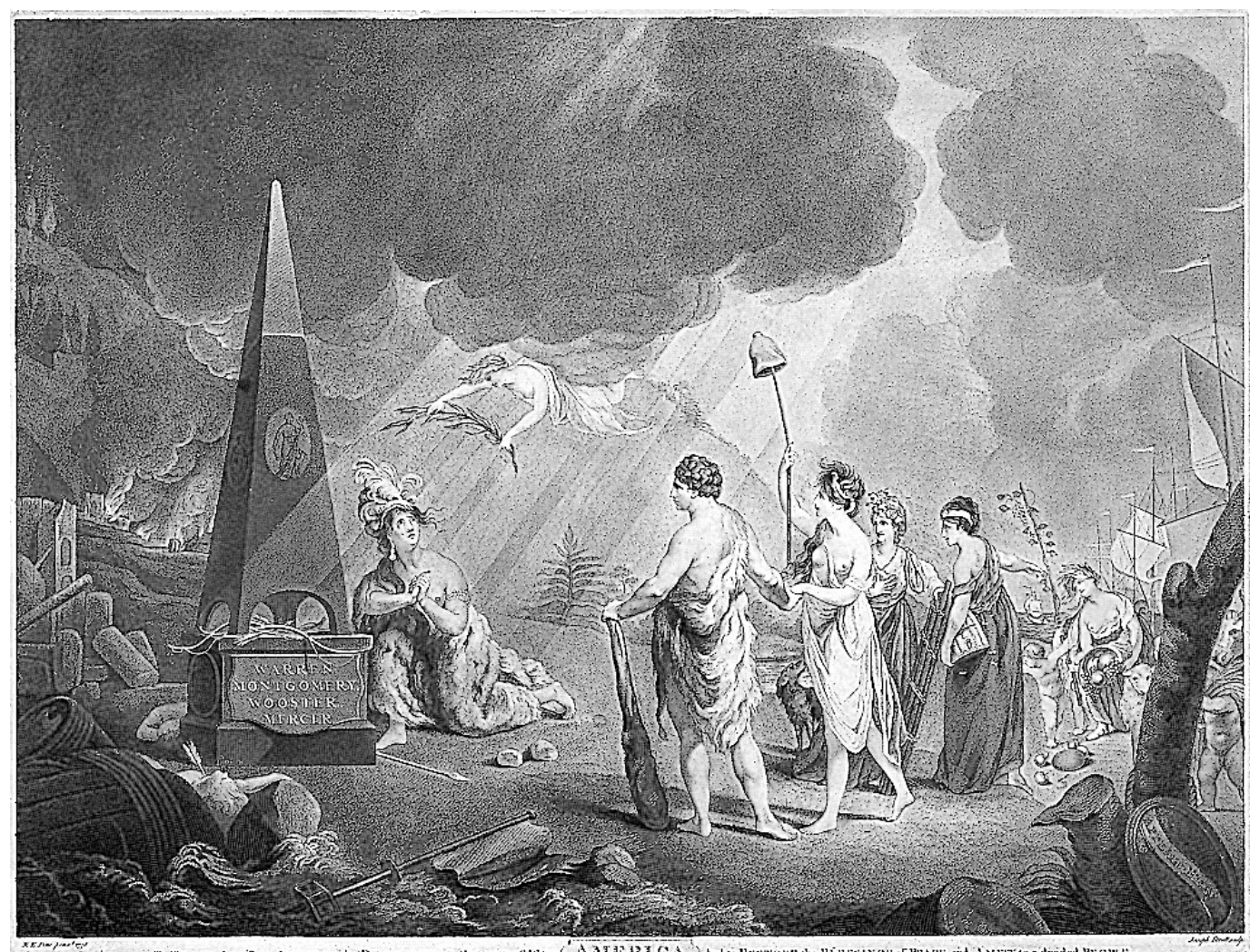

Abb. 37: R. E. Pine (pinxt.)/J. Strutt (sculp.), America (1781), Library of Congress

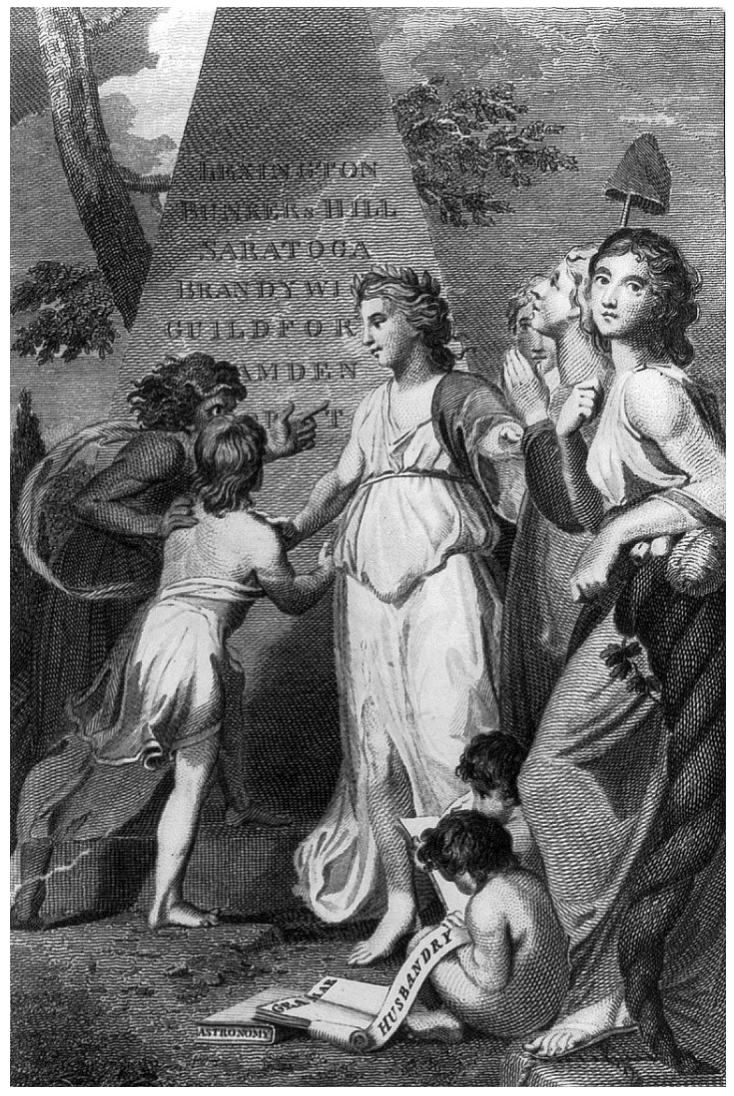

Abb.: 38a: Frontispiz zu »The Boston Magazine» (1783), Library of Congress

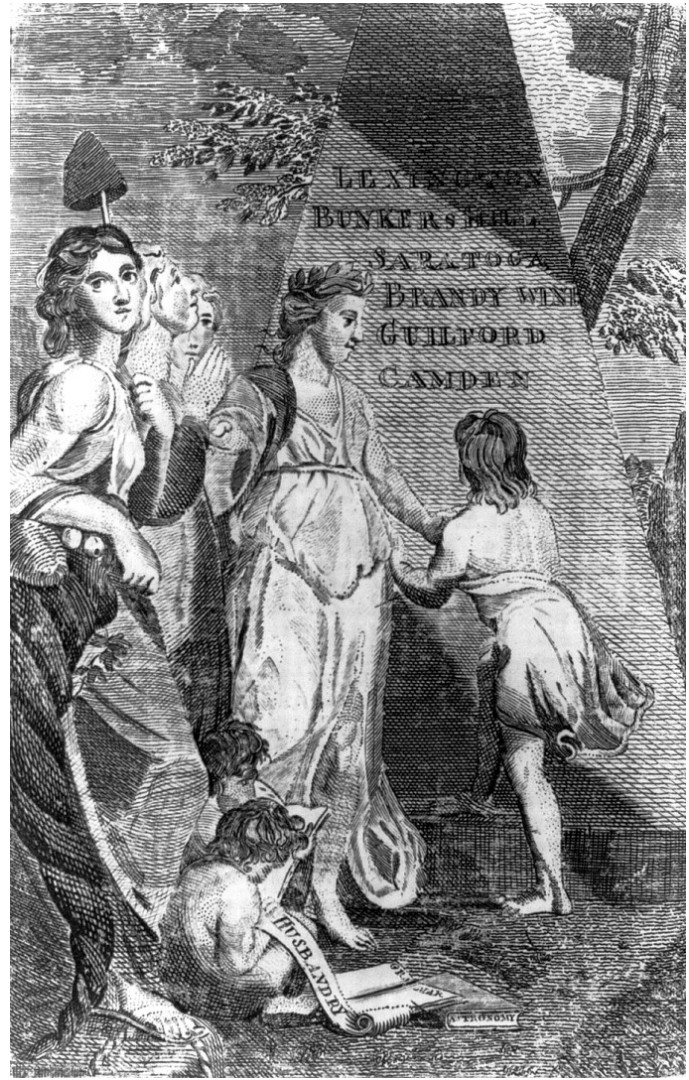

Abb. 38b: Frontispiz zu »The universal Magazine of knowledge" (1783), Library of Congress 


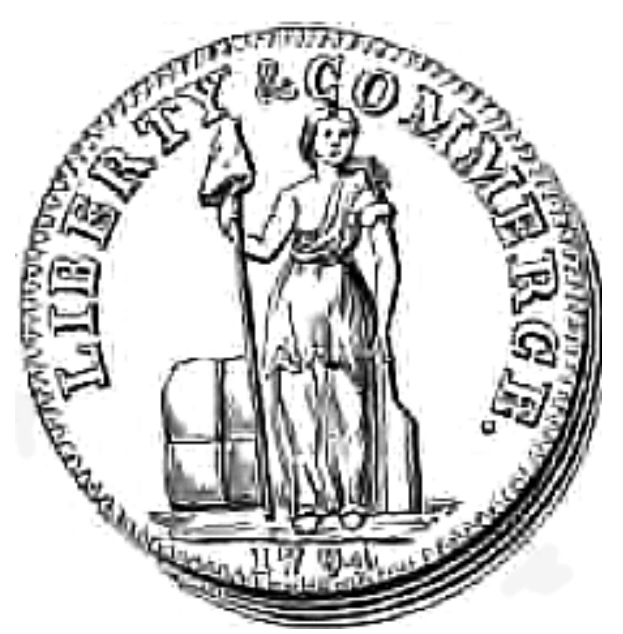

Abb. 39: Token der Firma Talbot, Allum \& Lee (1794), reproduziert aus: Sylvester S. Crosby, The Early Coins of America, Boston (Mass.) 1879, S. 335

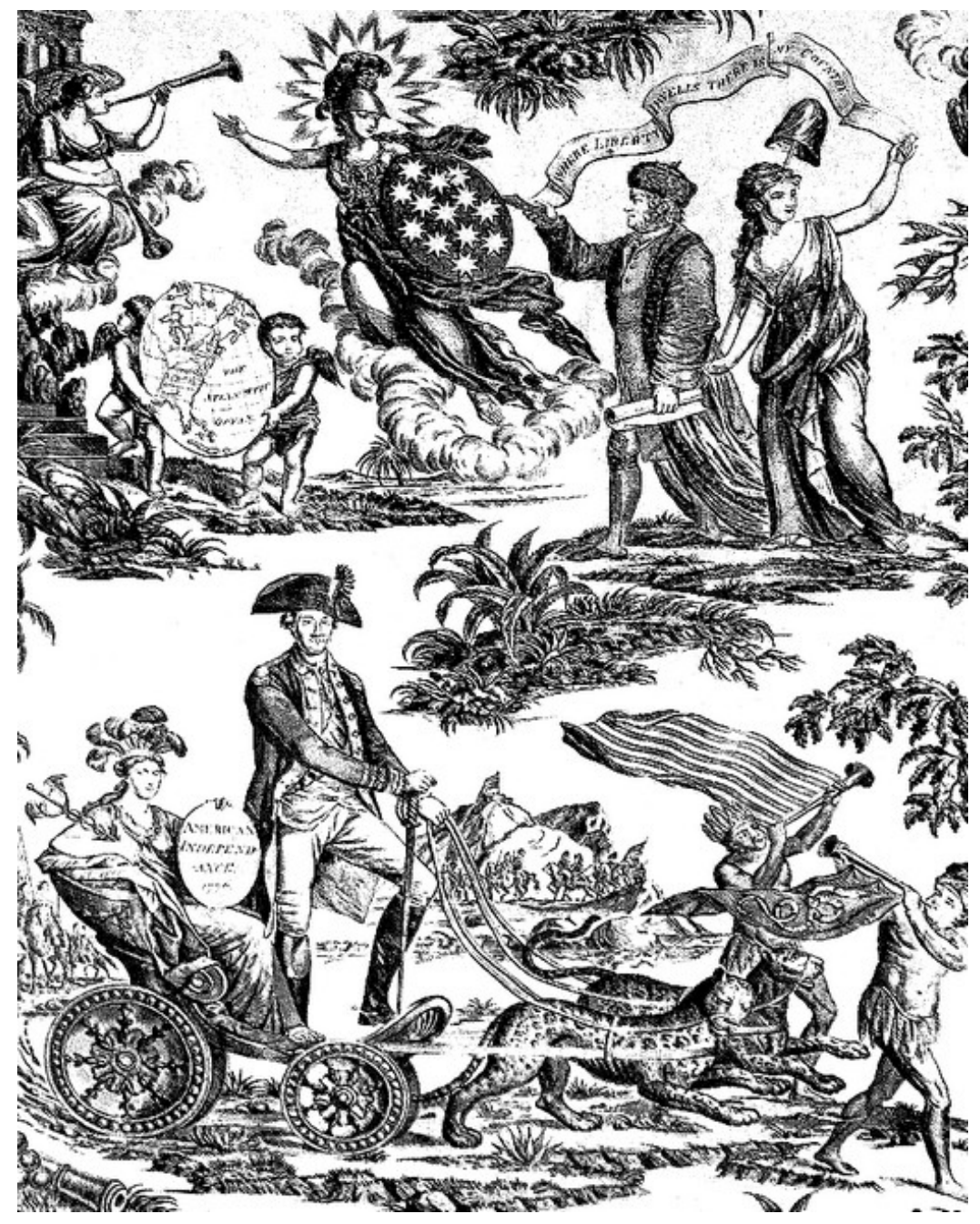

Abb. 40: Apotheosis of Franklin and Washington (1785), Courtesy of The New York Public Library (Ausschnitt) ${ }^{126}$

\footnotetext{
${ }^{126} \mathrm{Https}$ //digitalcollections.nypl.org/items/510d47e3-4a7f-a3d9-e040-e00a18064a99.
} 


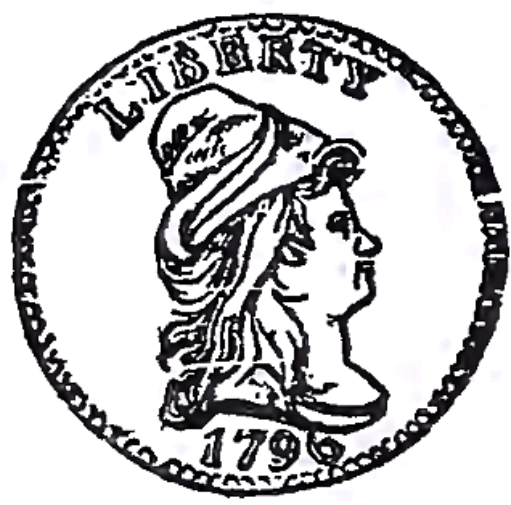

Abb. 41a: US-Münze, 1795-1807

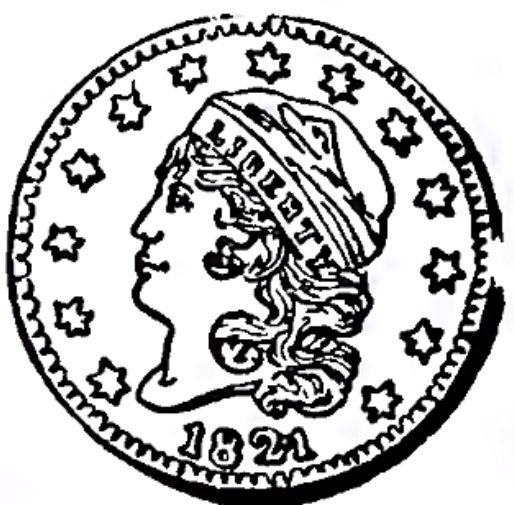

Abb. 41b: US-Münze, 1808-1834

Reproduziert aus: J. W. Scott's standard coin catalogue no. 1, New York (N.Y.) 1906, S. 2

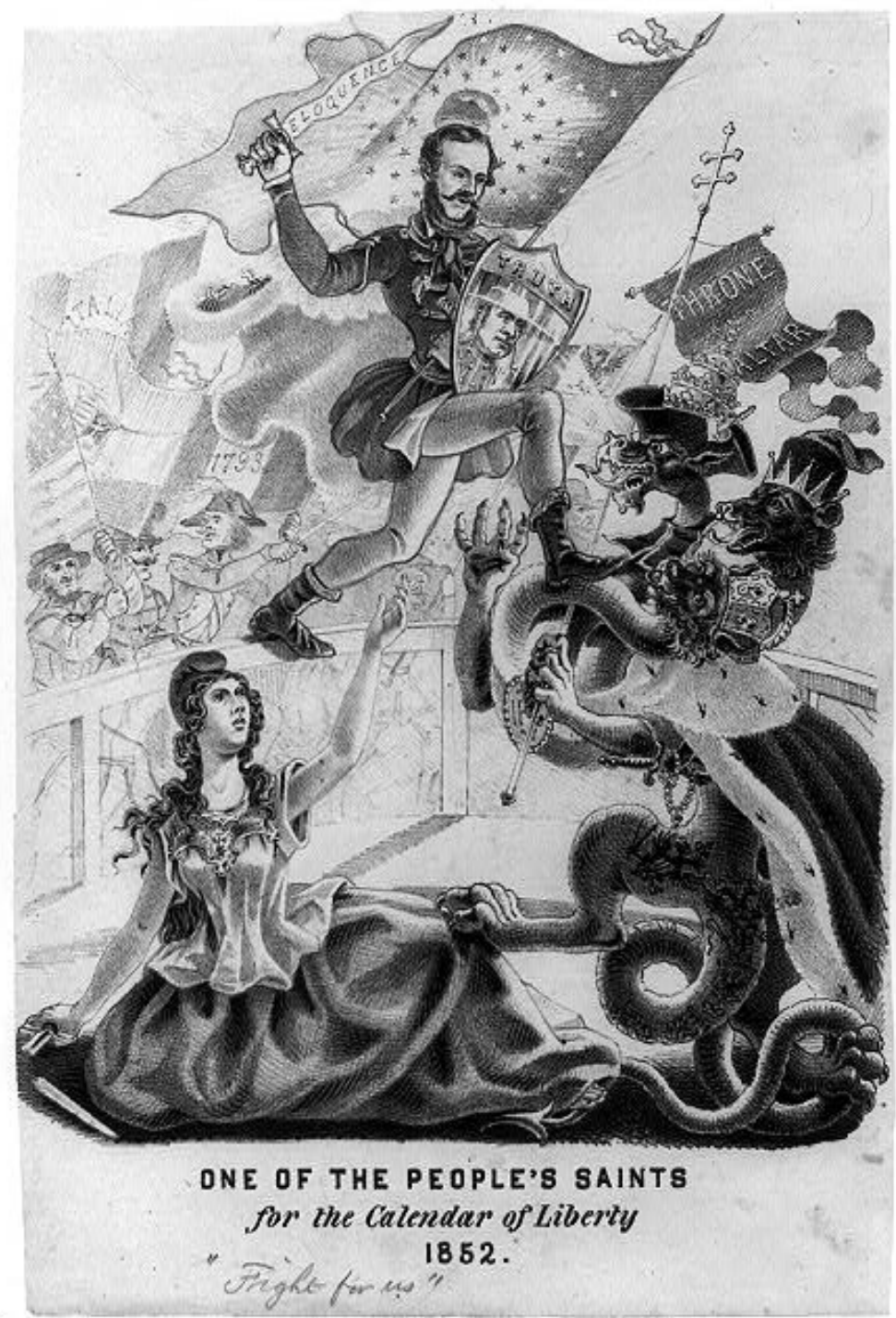

Abb. 42: One of the people's saints for the calendar of liberty 1852 (1851/52), Library of Congress 


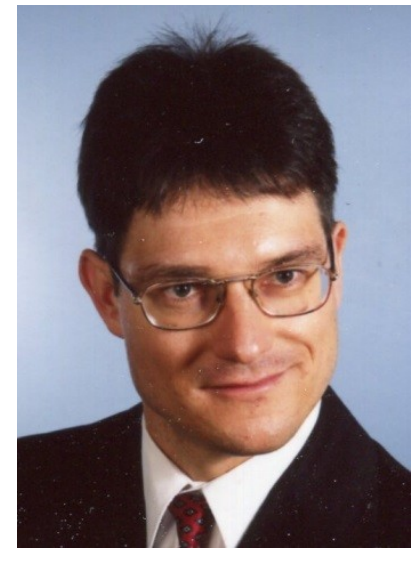

\section{Frank Zeiler}

Studium der Rechtswissenschaft an der Universität Freiburg; Promotion ebd. mit einer Arbeit zur Entwicklung der Freiburger juristischen Fakultät im universitären Expansionsprozess des Deutschen Kaiserreichs; Tätigkeit als wissenschaftlicher Mitarbeiter am Institut für öffentliches Recht der Universität Freiburg und bei Prof. em. Thomas Würtenberger; Mitwirkung an einem Projekt zur Geschichte von Symbolen der Freiheit; in diesem Rahmen Beschäftigung mit der Verwendung von Sinnbildern der Freiheit und der Verfassung in englischen und nordamerikanischen Druckgraphiken sowie in Bildbeiträgen deutscher Satiremagazine. Hieraus hervorgegangene Publikation:

- Visuelle Rechtsverteidigung im Nordamerikakonflikt. Ein Beitrag zur Rezeption der englischen Freiheits- und Verfassungssymbolik in nordamerikanischen Druckgraphiken der Jahre 1765-1783, in: Signa Ivris, Bd. 13 (2014), S. 315-346, 16 Abb. (verfügbar unter: http://www.freidok.uni-freiburg.de/data/11157)

- Verfassungsbildsatiren zwischen Republikfeindschaft, Vernunftrepublikanismus und Republiktreue. Eine Darstellung der Bildbeiträge zur Weimarer Verfassung in den Satiremagazinen Kladderadatsch, Simplicissimus, Der Wahre Jacob und Lachen Links, in: Jahrbuch der Juristischen Zeitgeschichte, Bd. 16 (2016), S. 395-439, 7 Abb. (verfügbar unter: https://freidok.uni-freiburg.de/data/15715)

- Der »bonnet rouge« im Wahren Jacob. Erscheinungsformen und Verwendungsweisen eines revolutionären Freiheitssymbols in einem sozialdemokratischen Satiremagazin zur Zeit des Kaiserreichs und der Weimarer Republik, 2016, 32 S. (verfügbar unter: https://www.freidok.uni-freiburg.de/data/11161)

- Die visuelle Repräsentation der Freiheit in englischen Druckgraphiken des 17. bis 19. Jahrhunderts. Eine Darstellung der Entstehung der englischen Freiheitssymbolik und ihrer Verwendungsweisen in politischen Drucken von der Zeit des Commonwealth bis zum Reform Act von 1832 (in Vorbereitung) 